\title{
Barriers, Facilitators, and Frequency of Evidence Based Practice Use in Athletic Training
}

Michael J. Boehke

Follow this and additional works at: https://researchrepository.wvu.edu/etd

\section{Recommended Citation}

Boehke, Michael J., "Barriers, Facilitators, and Frequency of Evidence Based Practice Use in Athletic Training" (2014). Graduate Theses, Dissertations, and Problem Reports. 5225.

https://researchrepository.wvu.edu/etd/5225

This Dissertation is protected by copyright and/or related rights. It has been brought to you by the The Research Repository @ WVU with permission from the rights-holder(s). You are free to use this Dissertation in any way that is permitted by the copyright and related rights legislation that applies to your use. For other uses you must obtain permission from the rights-holder(s) directly, unless additional rights are indicated by a Creative Commons license in the record and/ or on the work itself. This Dissertation has been accepted for inclusion in WVU Graduate Theses, Dissertations, and Problem Reports collection by an authorized administrator of The Research Repository @ WVU.

For more information, please contact researchrepository@mail.wvu.edu. 
Barriers, Facilitators, and Frequency of Evidence Based Practice Use in Athletic Training

\author{
Michael J. Boehke
}

Dissertation submitted to the College of Human Resources and Education at West Virginia University in partial fulfillment of the requirements

for the Degree of

Doctor of Education

in

Educational Leadership Studies, Higher Education Administration

Dr. Nathan Sorber, Chair

Dr. Ernest Goeres

Dr. Lauryl Lefebvre

Dr. George Mamboleo

Dr. Ericka Zimmerman

College of Education and Human Services

Morgantown, West Virginia

2014

Keywords: Evidence Based Practice, Athletic Training, Professionalization

Copyright 2014 Michael J. Boehke 


\section{ABSTRACT \\ Barriers, Facilitators, and Frequency of Evidence Based Practice Use in Athletic Training}

\section{Michael J. Boehke}

Many professions, including medicine, engineering, and design, have embraced the notion of using research to making informed decisions, thus increasing client satisfaction. Called evidence based practice (EBP) in Athletic Training; the concept is viewed as a means to promote the profession, not only through improved patient care, but also through increasing the reputation of athletic trainers as cost-effective health care providers. Over the past two decades, EBP has become a common term and subject of study. However, the extent of research regarding barriers and facilitators to the use of EBP within athletic training lags behind that of other health care professions. The objective of this study was to advance the knowledge of barriers and facilitators of EBP that practitioners face so that others can use this information to promote a change in educational proactices used to encourage research use among Athletic Trainers. The instrument consisted of the Barriers to Research Utilization Scale (BARRIERS Scale), a scale of facilitators, a series of questions regarding frequency of EBP and research utilization, and demographic questions. The survey was completed by 313 Athletic Trainers listed as Certified-Regular members of the National Athletic Trainers' Association (NATA).

The results indicated that the three greatest barriers to EBP in athletic training include a feeling of being overwhelmed by the amount of research information $(\mathrm{M}=3.18, \mathrm{SD}=1.23)$, a lack of time to read research $(\mathrm{M}=3.12, \mathrm{SD}=1.32)$, and facilities that are inadequate for implementation $(\mathrm{M}=3.12, \mathrm{SD}=1.20)$. The three greatest facilitators were found to be an increased budget for continuing education courses, workshops, or presentations $(\mathrm{M}=4.08, \mathrm{SD}=$ 1.11), the availability of research that is applicable to the clinician's needs $(\mathrm{M}=4.02, \mathrm{SD}=$ $0.92)$, and research that is clinically focused and relevant $(\mathrm{M}=3.86, \mathrm{SD}=1.01)$.

The study found a number of similarities to barriers and facilitators identified by studies previously conducted with other health care professions. However it also found a number of topics that differed from that of previous studies, such as the feeling of not having the authority to change patient care was found to be the least likely barrier to research utilization $(\mathrm{M}=2.38$, $\mathrm{SD}=1.30)$.

The study also found that athletic trainers need further knowledge and experience with the steps to evidence-based practice as the first and arguably most important step, formulating an answerable question, was found to be among the steps least frequently completed $(\mathrm{M}=3.13$, SD $=0.94$ ). Professionals may also benefit from a greater understanding of how to critically appraise the quality of research as this step was completed least frequently $(\mathrm{M}=2.78, \mathrm{SD}=$ 1.02).

This research may provide many contributions to the field of athletic training as it is the first to identify the barriers and facilitators to research utilization within the profession. The results of this study may also serve as a source of information for the development of future EBP technique workshops, presentations, and programs. The techniques used in this study as well as the information gained may be relatable to professions aspiring to move toward an evidenceinformed model. 
Barriers, Facilitators, and Frequency of EBP Use in Athletic Training iii

\section{Dedication}

To my wife, Brandy Boehke, who has supported me throughout this entire process with her constant love, moral support, and understanding. I do not think I could have completed this without her dedication and willingness to listen.

To my son, Simon Boehke, who was always willing to play quietly or wait patiently until I

finished a thought or paragraph. I hope this project shows him the importance of education and perseverance.

To my mother, Cindy Boehke, who has always supported me and kept me moving forward through her encouraging words and sage advice. 


\section{Acknowledgements}

“Not every mountain has a gondola.” I found this phrase to be a fitting commentary on my dissertation process as it has been a long, difficult climb to the summit. To climb a formidable mountain one often employs a guide or guide service. Those who climb Mount Everest will often utilize the knowledge and skills of the Sherpa people. So too, ascending the mountain of a doctorate requires the knowledge and skills of a dissertation chair. My climb afforded me the opportunity to work with three different chairs, Dr. Ernest Goeres, Dr. Daniel Hursh, and Dr. Nathan Sorber. I thank each of them for their dedication, especially Dr. Sorber who was willing to chair my project during a time of uncertainty. Next, a novice climber needs the advice of experienced mountaineers to help with management and problem solving throughout the climb. The individuals representing the experienced climbers on my journey include my dissertation committee, Dr. Lauryl Lefebvre, Dr. Ericka Zimmerman, and Dr. George Mamboleo, as well as Dr. Melissa Hartley who helped me with data analyses. Perhaps the most important portion of the climb is the base camp, this is a safe haven where climbers rest, refuel, and prepare for their attempt at the summit. My wife, son and family members represent my base camp. They have climbed beside me the entire time and I know that I would not have been able to make it if it were not for their love and support. I don't think they can comprehend how much I appreciate the love they showed and sacrifices they made in order for me to reach this summit. Finally, I would like to thank my fellow climbers, the doctoral students in my cohort; it is the time and conversations with these individuals that has been the most rewarding part of the journey. In particular, I would like to thank Dr. R. Craig Miller for being available and willing to exchange ideas every time I needed him. Thank you, everyone who helped me to achieve. 


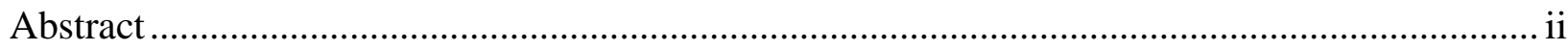

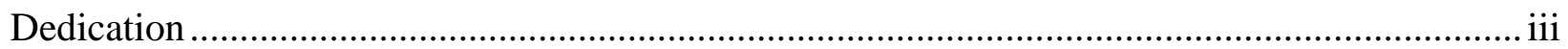

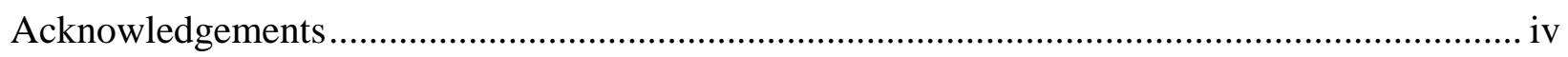

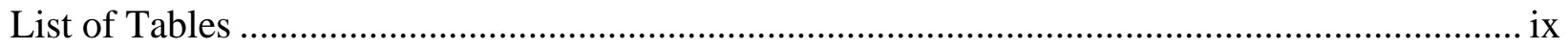

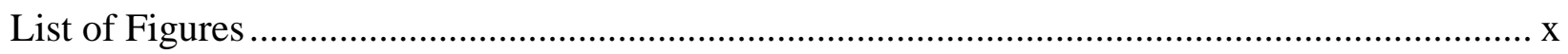

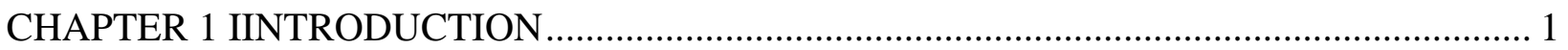

The Athletic Training Profession ........................................................................... 1

Statement of Problem and Purpose of Study................................................................ 5

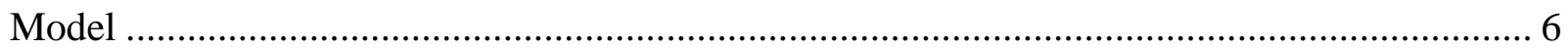

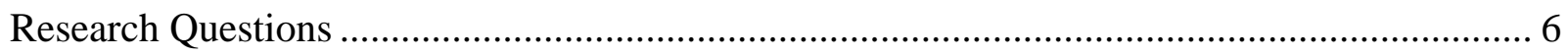

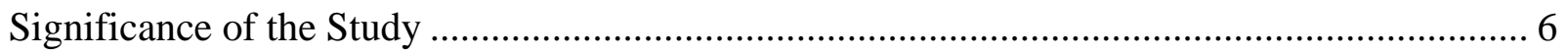

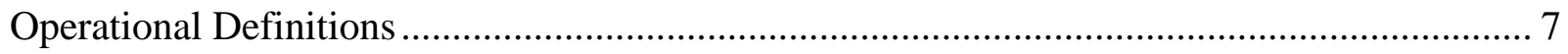

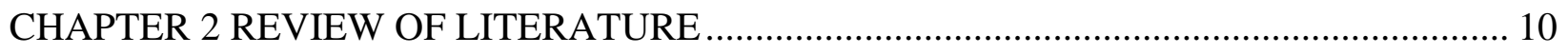

History of Athletic Training Education...................................................................... 10

Clinical Proficiencies ............................................................................................. 14

Recent Changes in Athletic Training ......................................................................... 15

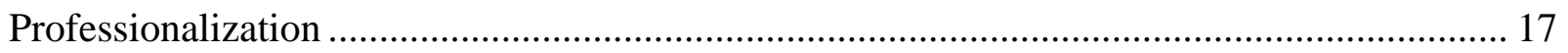

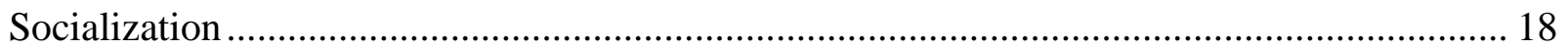

Definition and History of Evidence Based Practice........................................................ 20

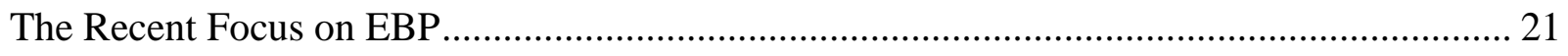

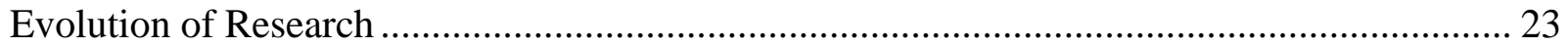




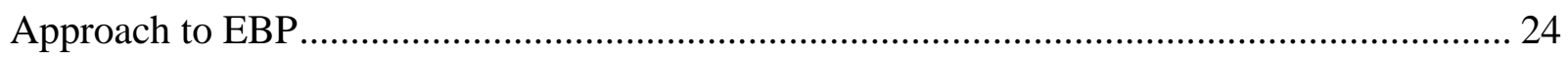

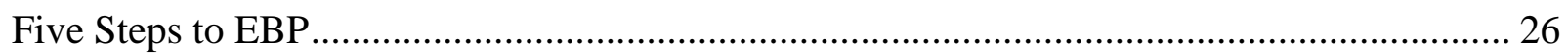

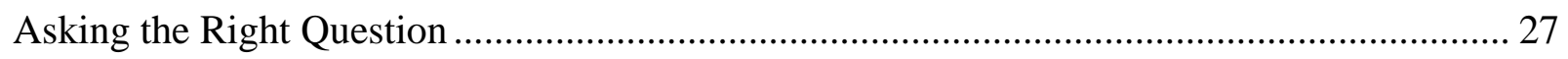

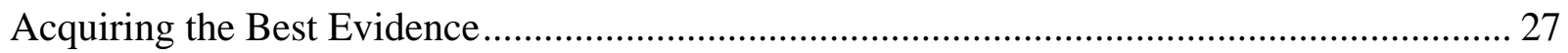

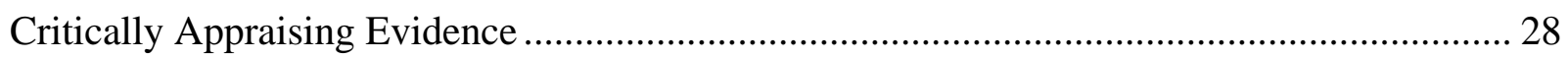

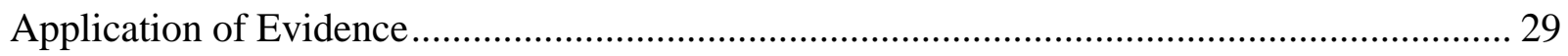

Evaluating the EBP Experience …………......................................................................... 30

Evidence Based Practice and Athletic Training ....................................................................... 30

Barriers to Evidence Based Practice ....................................................................................... 31

Perceived Complications with EBP …………………........................................................ 33

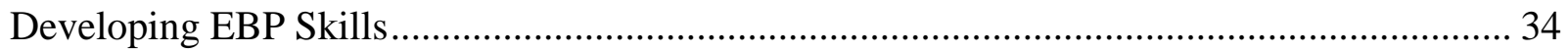

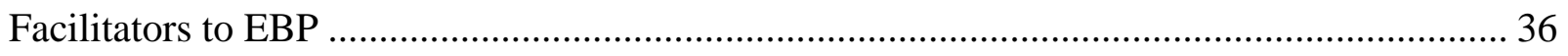

Implementation and the National Athletic Trainers Association ............................................... 39

Frequency of Research Use by Athletic Trainers.................................................................... 40

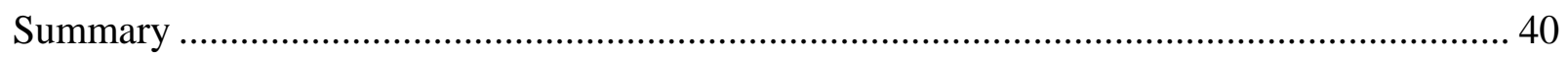

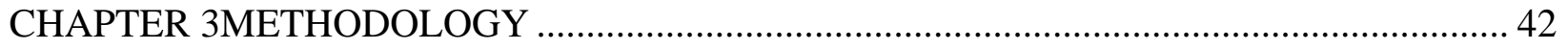

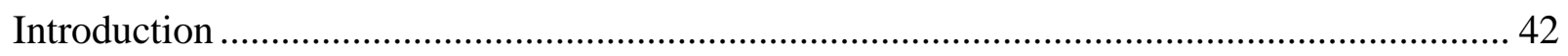

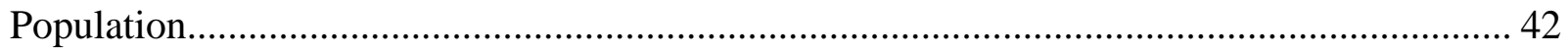

Sample

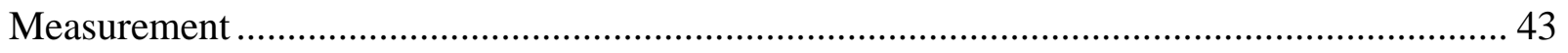

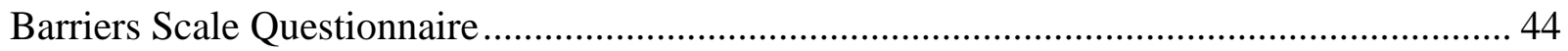

Factor 1 - Characteristics of the adopter.......................................................................... 44

Factor 2 - Characteristics of the organization........................................................................ 45 
Factor 3 - Characteristics of the research........................................................................... 45

Factor 4 - Characteristics of the communication ............................................................. 46

Hutchinson and Johnston Questionnaire ............................................................................... 48

Evidence Based Practice Questionnaire (EBPQ) ........................................................................ 49

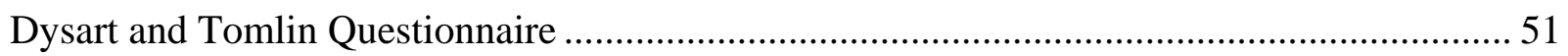

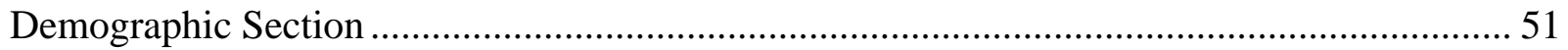

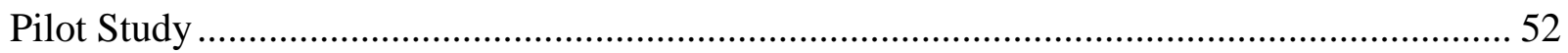

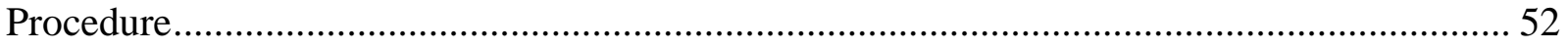

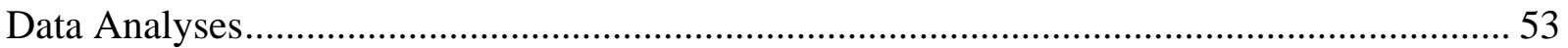

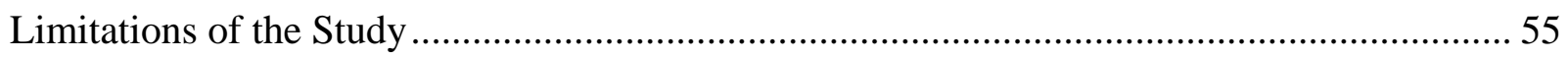

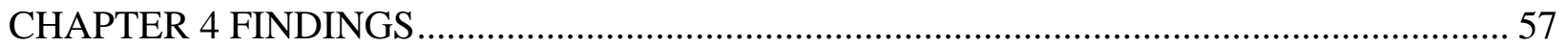

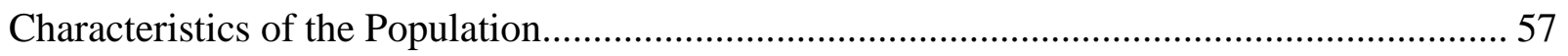

Question One: Frequency of Research.................................................................................. 58

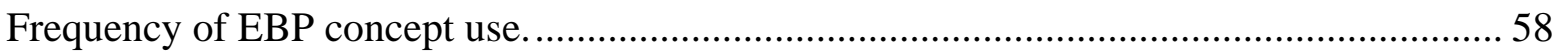

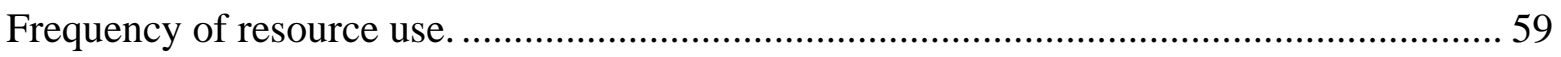

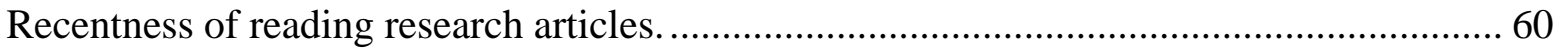

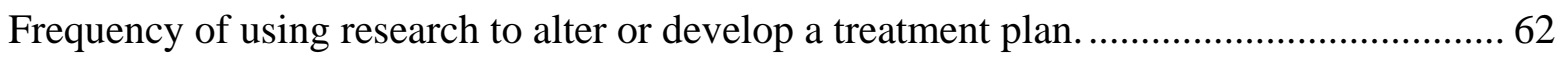

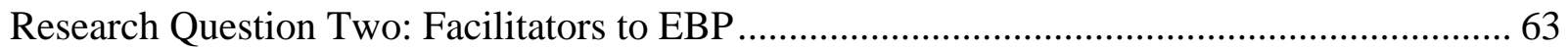

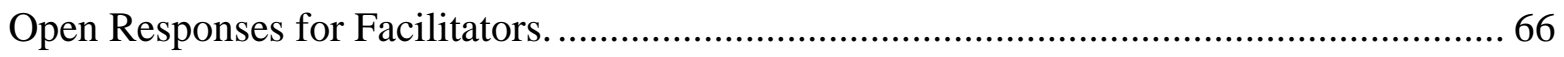

Research Question Three: Barriers to EBP ………………................................................... 68

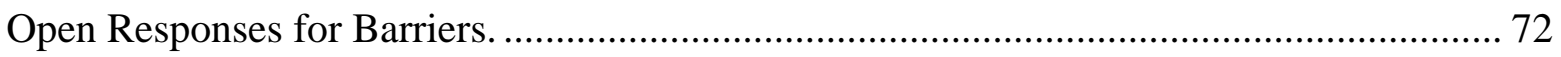

Research Question Four: Barriers and Career Setting …………….......................................... 73

Research Question Five: Barriers related to Characteristics ....................................................... 76 


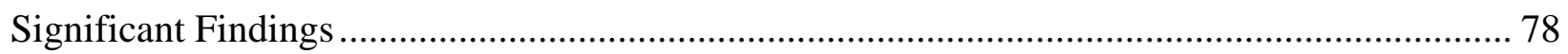

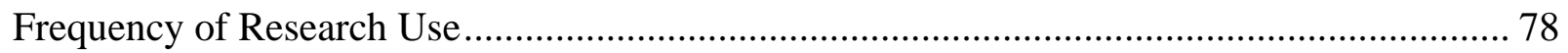

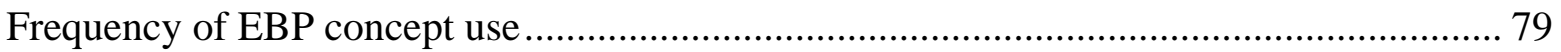

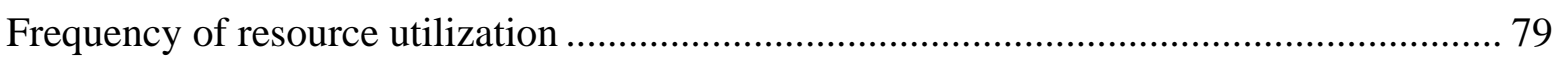

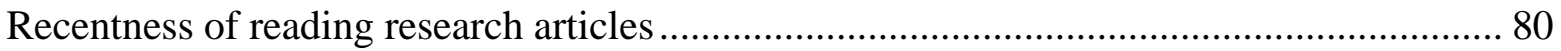

Frequency of using research to develop treatment plans............................................ 80

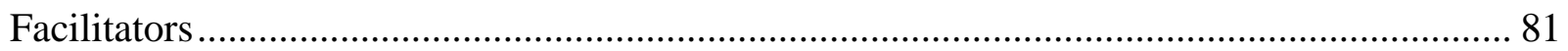

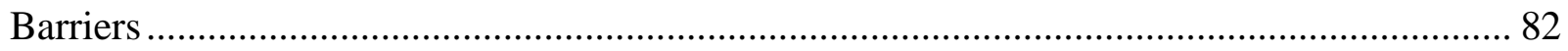

Open Responses of Barriers to Research .................................................................... 86

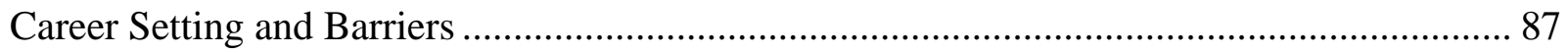

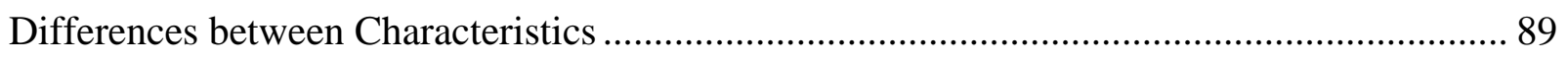

Implications for the Athletic Training Profession ...................................................... 91

Implications for Higher Education Administration.................................................... 92

Recommendations for Future Research ................................................................... 93

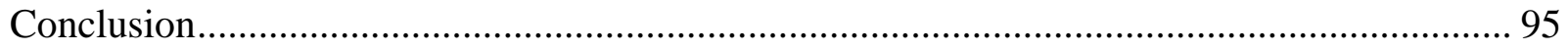

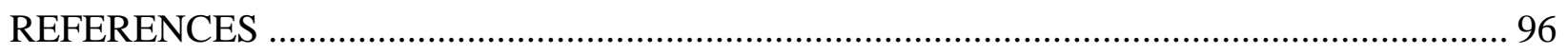

APPENDICES.............................................................. 112 


\section{List of Tables}

Table 1.1 to 1.10 Demographic Characteristics of Participants:

Table 1.1 Gender.............................................................. 126

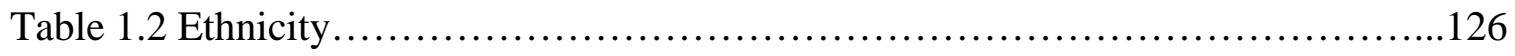

Table 1.3 Certification Route..................................................126

Table 1.4 Years Practicing as an Athletic Trainer..................................127

Table 1.5 Highest Degree Earned...........................................127

Table 1.6 NATA District of Employment.....................................128

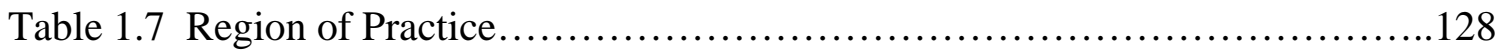

Table 1.8 Career Setting...................................................... 129

Table 1.9 Conducts Patient Care on a Daily Basis...............................129

Table 1.10 Authored a Research Based Publication................................129

Table 2 Frequency of Completing the Steps to EBP over the last year.....................................59

Table 3 Frequency of Resources Used to Access Research.................................................60

Table 4.1 Recentness of Reading Research Articles from an Athletic Training Publication........61

Table 4.2 Recentness of Reading Articles from Publications Not related to Athletic Training...62

Table 5 Number of Times Research was Used to Alter or Develop a Treatment Plan................62

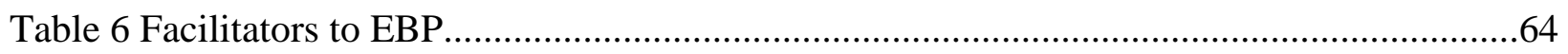

Table 7 Frequency of Rating Facilitators to a Moderate to Great Extent.................................135

Table 8 Frequency of Rating the Three Greatest Facilitators...............................................137

Table 9 Open Responses to Other Facilitators Question and Characteristic...............................67

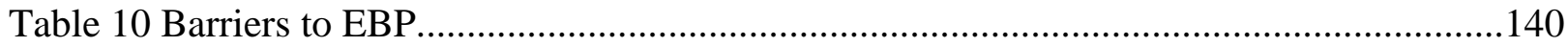

Table 11 Frequency of Rating Barriers to a Moderate to Great Extent...................................142 
Table 12 Frequency of Rating the Three Greatest Barriers...................................................144

Table 13 Open Responses to Other Barriers Question and Subcategories................................146

Table 14 Mean Scores and Standard Deviations for Measures of Barrier Characteristics Related

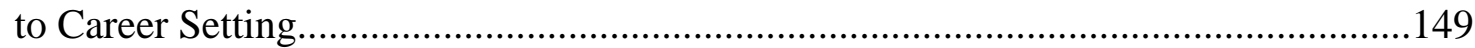

Table 15 Significant Differences of Barriers Associated to the Characteristics of the

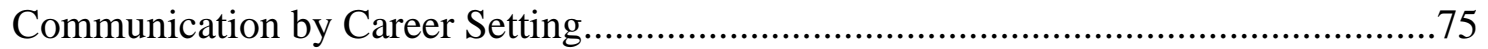

Table 16 Significant Differences of Barriers Associated to the Characteristics of the Adopter by

Career Setting. .151

Table 17 Significant Differences of Barriers Associated to the Characteristics of the Organization

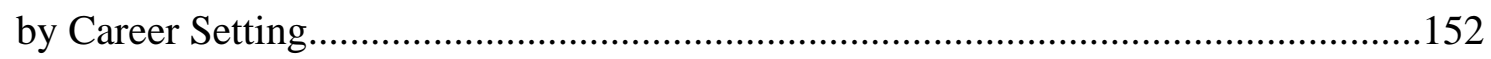

Table 18 Significant Differences of Barriers Associated to the Characteristics of the Research by

Career Setting.

Table 19 One-Way Repeated Analysis of Variance Summary Table for the Effects of Athletic

Trainers' Career Setting on Rating of Barriers to EBP Utilization..............................76

Table 20 Comparison of Athletic Trainers and Nurses rating of top ten barriers to EBP...........154

\section{List of Figures}

Figure 1 Percent of Open Responses: Facilitators.......................................68

Figure 2 Mean Scores of Characteristics...........................................77

Figure 3 Dissertation Concept Map...............................................155

Figure 4 Significant Findings for Frequency of Research..............................156

Figure 5 Significant Findings for Facilitators to EBP Utilization........................157

Figure 6 Significant Findings for Barriers to EBP Utilization............................158 


\section{List of Appendices}

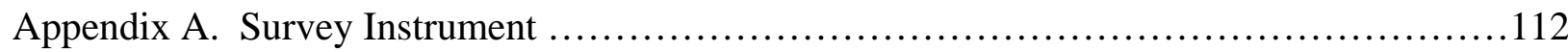

Appendix B. Institutional Review Board at West Virginia University Approval...............123

Appendix C. Survey Cover Letter................................................124

Appendix D. Demographic Tables................................................126

Appendix E. Frequency of Completing Steps to EBP................................ 130

Appendix F. Frequency of Resources Used to Access Research.........................131

Appendix G. Recentness of Reading Research........................................132

Appendix H. Number of Times Research was Used to Develop a Treatment Plan.............133

Appendix I. Facilitators to Evidence Based Practice ...................................134

Appendix J. Frequency of Rating Facilitators to a Moderate to Great Extent..................135

Appendix K. Frequency of Rating the Three Greatest Facilitators........................137

Appendix L. Open Responses of Facilitators........................................139

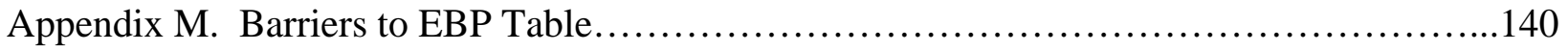

Appendix N. Frequency of Rating Barriers to a Moderate to Great Extent Table..............142

Appendix O. Frequency of Rating the Three Greatest Barriers...........................144

Appendix P. Open Responses of Barriers...........................................146

Appendix Q. MANOVA Mean Scores and Standard Deviation............................149

Appendix R. MANOVA Significant differences...................................151

Appendix S. ANOVA Summary Table.............................................153

Appendix T. Comparison of Athletic Trainers and Nurses Top Ten Barriers.................154

Appendix U. Dissertation Concept Map..........................................155 
Barriers, Facilitators, and Frequency of EBP Use in Athletic Training xii

Appendix V. Significant Findings for Frequency of Research...........................156

Appendix W. Significant Findings for Facilitators to EBP................................157

Appendix X. Significant Findings for Barriers to EBP................................158 


\section{Chapter I \\ Introduction}

\section{The Athletic Training Profession}

Athletic trainers are health care professionals who work under the direction of physicians, as prescribed by state licensure statutes, to provide injury prevention, emergency care, clinical diagnosis, therapeutic intervention and rehabilitation of injuries and medical conditions (National Athletic Trainers' Association, 2014d). Though derived from the profession’s historical roots, the title "athletic trainer" is considered a misnomer as these health care professionals provide services to all types of people, not just athletes participating in sports (National Athletic Trainers' Association, 2014c). One can find athletic trainers at physicians offices as physician extenders, providing services similar to that of a nurse, physician assistant, or other professional clinical personnel. They partner in clinics with specialties in sports medicine, cardiac rehabilitation, medical fitness, wellness and physical therapy. Athletic Trainers provide occupational health services in the commercial setting including manufacturing, distribution and offices to assist with ergonomics. Athletic Trainers provide health care services to police and fire departments and their academies, as well as various branches of the military. Finally, they can be found working in secondary schools, colleges and universities, and professional and Olympic sports (National Athletic Trainers' Association, 2014c).

The Athletic Training profession has grown from 13,500 employed in 2002 (U.S. Bureau of Labor Statistics, 2003) to over 22,300 employed in 2013 (U.S. Bureau of Labor Statistics, 2014). The National Athletic Trainer’s Association (NATA) reports 39,000 members worldwide and estimates that there are 40,000 athletic trainers practicing nationally (National Athletic Trainers' Association, 2014c). The difference in the employment statistics between the U.S. 
Bureau of Labor Statistics and the NATA is the fact that the NATA incorporates the diversity of career settings in which an Athletic Trainer may be employed.

Students enter the profession of Athletic Training through one of over 360 educational programs accredited by the Commission on Accreditation of Athletic Training Education (Commission on Accreditation of Athletic Training Education, 2014). The Commission on Accreditation of Athletic Training Education (CAATE) accredited education programs are required to utilize a competency-based approach in both the didactic and clinical settings (National Athletic Trainers' Association, 2014a). Competency-based education requires students to demonstrate mastery of the knowledge, skills, values and behaviors that are significant to the profession (Baughman, Brumm, \& Mickelson, 2012). The CAATE requires each accredited Athletic Training education program to instruct and evaluate students in competencies associated to eight content areas: evidence based practice, prevention and health promotion, clinical examination and diagnosis, acute care of injury and illness, therapeutic interventions, psychosocial strategies and referral, healthcare administration, and professional development and responsibility (National Athletic Trainers' Association, 2014a).

Students are also required to participate in a minimum of two years of academic clinical education. The clinical experiences provide students with opportunities for real patient care under the direct supervision of an Athletic Trainer or other credentialed health care professional. Accredited programs must ensure that students gain clinical experiences with a variety of patient populations that vary in age and types of activities, including those at risk for both musculoskeletal and general medical conditions (National Athletic Trainers' Association, 2014a). Often referred to as the socialization into the profession, the clinical experience provides students, consciously or subconsciously, with the knowledge, beliefs, values, behaviors, and 
practices that influence the manner in which Athletic Trainers think and act (Hudson \& Irwin, 2010).

At present, the minimum threshold to enter the profession of Athletic Training begins with a baccalaureate degree in Athletic Training from an educational program that is accredited by the Commission on Accreditation of Athletic Training Education (CAATE). Once students graduate from a CAATE accredited education program they become eligible for national certification by successfully completing the NATA Board of Certification, Inc. (BOC) examination (National Athletic Trainers' Association, 2014a).

The strict requirements for entry into Athletic Training mirror Abbott’s (1988) conclusion regarding how an aspiring professional joins an exclusive occupational group by gaining competency in some special skill. The skill is usually abstract and requires extensive training, and that it is not applied in a routine fashion but instead its application is revised on a case by case basis (Abbott, 1988). Johnson and Maclean (2008) propose that the typical characteristics of a profession includes knowledge that is based on empirical techniques. The authors also state that mastery of the knowledge base requires lengthy periods of education and training, of which the specialized training is designed to both equip and socialize the aspiring members of the profession into the culture and symbols of the profession (Johnson \& Maclean, 2008).

Beginning in 2012 with the $5^{\text {th }}$ edition Athletic Training Educational Competencies, CAATE-accredited athletic training education programs were required to make changes to their curricula and students' clinical assessment tools to reflect the incorporation of evidence-based practice. At the same time, practicing Athletic Trainers were required to attain continuing education units (CEUs) in EBP to maintain their certification. The decision to require accredited 
programs to educate students on EBP concepts, as well as clinicians to gain further educational development on the subject, reflects a tendency toward the utilization of evidence to influence decisions. Athletic Training is not alone in the movement to become a research-informed profession, as this trend is evident in many fields including medicine, architecture, education, engineering, and transportation design (Bones, Barrella, \& Amekudzi, 2013; Johnson \& Maclean, 2008).

Evidence-based practice (EBP) is defined as the integration of best research evidence with clinical expertise and patient values to make clinical decisions (Sackett, Straus, Richardson, Rosenberg, \& Haynes, 2000). Many researchers assert that excellence in patient care is the ultimate outcome from the EBP process (Cope, 2003; Hertel, 2005; Neldon, 2009; Prentice, 2011). Athletic trainers consider the use of EBP concepts as a means to promote the profession, not only through improved patient care, but also through increasing the reputation of athletic trainers as cost-effective health care providers (Denegar \& Hertel, 2002; Ingersoll, 2006; Prentice, 2011; Steves \& Hootman, 2004). It is further posited that the use of EBP may advance the profession with licensure, third-party reimbursement, and as a more efficient means of disseminating knowledge (Denegar \& Hertel, 2002; Hertel, 2005; Steves \& Hootman, 2004).

Over the past two decades, EBP has become a common subject of study in health care fields, particularly the barriers and facilitators associated with implementation (Brown, Wickline, Ecoff, \& Glaser, 2009; Bryar et al., 2003; C. Estabrooks, Floyd, Scott-Findlay, O'Leary, \& Gushta, 2003; Frasure, 2008; Funk, Tornquist, \& Champagne, 1995; S. G. Funk, M. T. Champagne, R. A. Wiese, \& E. M. Tornquist, 1991a; Gerrish et al., 2007; Glacken \& Chaney, 2004; Kajermo, Nordström, Krusebrant, \& Björvell, 1998; Miller, Ward, \& Young, 2010; Thompson, McCaughan, Cullum, Sheldon, \& Raynor, 2005). However, the extent of research 
regarding barriers and facilitators to the use of EBP within athletic training lags behind that of other health care professions. Manspeaker and Van Lunen (2011) state that “...no researchers have targeted the Athletic Training population, clinical or didactic, regarding barriers to EBP” (p. 515). In addition, as of the time of this study, no literature exists describing the frequency of research use among athletic trainers.

\section{Statement of Problem and Purpose of Study}

The field of Athletic Training has undergone a professionalization process, characterized, in part, by encouraging practitioners to incorporate evidence into practice. However, there is limited knowledge of the degree to which various organizational factors either facilitate or deter this process. The purpose of this study is to advance the knowledge of the barriers and facilitators athletic trainers may face when trying to implement EBP concepts, whether they serve as instructors or clinicians, in order to develop strategies to overcome these obstacles. To gain a further perspective of the greatest barriers to utilization, the study compares differences in the way athletic trainers rate the barriers according to the characteristics defined by Funk, Champagne, Wiese, and Tornquist (1991a). The study is also intended to advance knowledge of the facilitators to EBP in order to encourage those educational practices that advocates research use among Athletic Trainers. Finally, the study explores the frequency in which athletic trainers conduct and use research in their practice. The study also gathered demographic data to investigate similarities and differences among career setting of Certified-Regular Members of the NATA. The demographic information is used to determine if career setting influences the way athletic trainers rate barriers to EBP utilization. 


\section{Model}

This quantitative study will introduce a questionnaire that was derived from four previous questionnaires to examine the barriers and facilitators to EBP utilization as well as the frequency in which athletic trainers engage in research or other evidence based practices.

\section{Research Questions}

1. What is the frequency by which athletic trainers use research in their practice?

2. What are the perceived facilitators to EBP use by Athletic Trainers? 2(a). How do Athletic Trainers rank the facilitators to their use of EBP?

3. What are the perceived barriers to EBP use by Athletic Trainers? 3(a). How do Athletic Trainers rank the barriers to their use of EBP?

4. Are there differences in Athletic Trainers' perceptions of barriers related to career settings?

5. Are there differences in how Athletic Trainers rate the barriers to EBP utilization related to the characteristics of the adopter, the organization, the innovation, and the communication?

\section{Significance of the Study}

With the eminent move to the $5^{\text {th }}$ edition Athletic Training Educational Competencies, CAATE-accredited athletic training education programs were required to make changes to their curricula and students’ clinical experiences to reflect the incorporation of evidence-based practice. At the same time, practitioners were required to attain continuing education units (CEUs) in EBP to maintain their certification. However, many athletic trainers may not have enough experience with EBP concepts to make such alterations to educational practices or to 
fulfill CEU requirements. Furthermore, no researchers have addressed the Athletic Training population, clinical or didactic, regarding barriers to EBP (Manspeaker \& Van Lunen, 2011).

This study will advance the knowledge of potential barriers and facilitators athletic trainers may face when implementing evidence-based practice concepts. The study will also explore the frequency in which these individuals conduct and use research in their practice. The intent of this study is to provide insight on the barriers, facilitators and frequency of research use by athletic trainers so that this information can be used to create appropriate professional development opportunities that address these needs at all levels of the professionalization and socialization processes.

While the study specifically addresses Athletic Training, the conclusions have external validity to other professional contexts including engineering, education, transportation design, and medicine. In order for any profession to be research-informed, the use of research must become a mindset and not just a mandate. To those ends, the study provides insight into how the use of research and evidence based practices are incorporated into a profession, and how socialization processes advance research as part of the culture.

\section{Operational Definitions}

1. Athletic Trainer (AT) - Health care professionals who collaborates with physicians and provides services comprising of prevention, emergency care, clinical diagnosis, therapeutic intervention and rehabilitation of injuries and medical conditions (National Athletic Trainers' Association, 2014d).

2. Barrier - Any factor that causes difficulty in using research in clinical decision making. There are a number of reported barriers including lack of time, lack of knowledge/skill, limited resources and technology, and difficulty understanding research. 
3. Certified-Regular Member of the NATA - A member of the NATA who holds the credential of ATC (Athletic Trainer, Certified) and is in good standing with the Board of Certification (National Athletic Trainers' Association, 2012a).

4. Characteristics of the Adopter - One of four factors identified in the Barriers Scale Questionnaire; the athletic trainer's research values, skills, and awareness.

5. Characteristics of the Communication - One of four factors identified in the Barriers Scale Questionnaire; the presentation and accessibility of the research.

6. Characteristics of the Organization - One of four factors identified in the Barriers Scale Questionnaire; the barriers and limitations associated with the setting.

7. Characteristics of the Research - One of four factors identified in the Barriers Scale Questionnaire; the qualities of the research.

8. Cochrane Collaborative evidence-based grading - The Cochrane Collaborative is a nonprofit international organization whose goal is to improve healthcare through review of best evidence. The organization conducts systematic reviews of research and produces documents that summarize the results of all research on a specific topic. To promote consumers to make informed decision on their healthcare, the summaries are available to the public at www.thecochranelibrary.com.

9. Evidence Based Practice (EBP) - Also referred to as Evidence Based Medicine (EBM), the mixing of best research evidence with clinical expertise and patient values to make clinical decisions (Dickersin, Straus, \& Bero, 2007; Neldon, 2009; Sackett, et al., 2000; Shaneyfelt et al., 2006; Starkey, Brown, \& Ryan, 2010; Steves \& Hootman, 2004). 
10. Facilitator - Any factor that may encourage the use of research in clinical decision making. There are a number of reported facilitators including administrative support, access to research tools, motivation, and knowledge of the EBP process.

11. National Athletic Trainers' Association (NATA) - A professional membership organization for certified athletic trainers and those who support the athletic training profession. 


\section{Chapter 2 \\ Review of Literature}

\section{History of Athletic Training Education}

The National Athletic Trainers Association (NATA) was formally established in 1950 (Weidner \& Henning, 2002), with the purpose to "build and strengthen the profession of athletic training through the exchange of ideas, knowledge, and methods of athletic training” (Delforge \& Behnke, 1999, p. 53). In 1959, the NATA Board of Directors approved the Committee on Gaining Recognition’s recommendation for the development of an educational program (Delforge \& Behnke, 1999). The Committee on Gaining Recognition would be the forerunner to the NATA Professional Education Committee.

Adopted in 1959, the first curriculum was designed to promote employability in two major areas. The first prepared the student not only as an athletic trainer but also as a high school teacher, primarily in the areas of health and physical education. The second feature of the curriculum was the inclusion of courses that were prerequisites for acceptance into schools of physical therapy. Courses included applied anatomy and kinesiology, two courses in psychology, first aid and safety, nutrition, remedial exercise, personal, community, and school health, basic athletic training, and advanced athletic training (Delforge \& Behnke, 1999; Weidner \& Henning, 2002). However, with the exception of an advanced athletic training course and laboratory practice in athletic training, the proposed curriculum contained few courses that distinguished it from a typical major in physical education (Delforge \& Behnke, 1999). The NATA would not officially recognize the first undergraduate athletic training education programs until 1969 (Delforge \& Behnke, 1999). 
In the 1970s, members of the NATA believed that high school teaching opportunities in physical education and health were limited and concluded that a teaching certificate in the two disciplines served to limit rather than enhance employment of certified athletic trainers at the high school level. In response, the requirement that athletic training students pursue a teaching credential in physical educaiton or health was eliminated (Delforge \& Behnke, 1999).

Futher curricular changes came in the mid 1970s when the NATA Professional Education Committee developed a list of behavioral objectives that identified learning outcomes for the athletic training student based on 11 required courses and a minimum of 600 total clock-hours of clinical experience under the direct supervision of an NATA-certified athletic trainer (Delforge \& Behnke, 1999; Weidner \& Henning, 2002). At the same time, the committee developed a skill competency checklist to guide and monitor the development of the student's clinical skills. These changes to the curriculum would serve as the first steps toward the identification of a specialized body of knowledge for the athletic training profession.

With 600 hours of required patient care, athletic training professional preparation had become immersed in clinical experiences. The primary goal of clinical education was to aid in the acquisition, development, and mastery of clinical proficiencies. This mirrored trends in other health care professions. Weidner and Henning (2002), state that nursing, physical therapy, and athletic training embraced clinical education as part of their curricula as a vitally important experience that spurred the transition from novice to competent practitioner.

The curriculum changed a third time in 1983 when the Professional Education Committee developed the Guidelines for Development and Implementation of NATA Approved Undergraduate Athletic Training Education Programs. These “Guidelines” contained standards for the development of undergraduate programs as academic majors and featured two conceptual 
changes to the curriculum. The first change was the inclusion of specific subject matter requirements, rather than specific courses. The mandated subject matter allowed for greater flexibility in the development of educational experiences, such as the development of separate courses or instructional units as well as degrees of emphasis on specific learning outcomes. The second variation was the inclusion of the Competencies in Athletic Training, which replaced the behavioral objectives. The behavioral objectives developed in the 1970s and "performance domains" of a certified athletic trainer identified in the first role delineation study conducted by the NATA Board of Certification in 1982 would serve as the conceptual framework for the “Competencies” (Delforge \& Behnke, 1999; Weidner \& Henning, 2002). The competencies included prevention of athletic injuries, evaluation and recognition of athletic injuries and medical referral, first aid and emergency care, rehabilitation and reconditioning, organization and administration, and counseling, guidance, and education (Zylks, 1988).

In June 1990, the American Medical Association (AMA) recognized athletic training as an allied health profession (Delforge \& Behnke, 1999; Weidner \& Henning, 2002). However, efforts to obtain AMA recognition began earlier with the NATA Board of Directors deciding to seek accreditation of entry-level programs by the AMA Committee on Allied Health Education and Accreditation (CAHEA). The AMA and NATA immediately appointed representatives to form the Joint Review Committee on Educational Programs in Athletic Training (JRC-AT). Using the "Guidelines" and “Competencies" developed in 1983, the JRC-AT and CAHEA created a new document called Essentials and Guidelines for an Accredited Educational Program for the Athletic Trainer. These efforts would become the fourth major change to athletic training education. The Essentials and Guidelines for an Accredited Educational 
Program for the Athletic Trainer were approved by the AMA Council on Medical Education on December 6, 1991 (Delforge \& Behnke, 1999).

In 1994, the CAHEA was disbanded and athletic training education accreditation would move to an independent agency for accreditation of education programs in the allied health professions called the Commission on Accreditation of Allied Health Education Programs (CAAHEP). However, similarities in review processes allowed accreditation of entry-level athletic training educational programs to continue without interruption during the transition from CAHEA to CAAHEP (Delforge \& Behnke, 1999).

By 1997, the National Athletic Trainers Association Board of Certification (NATABOC) made further changes toward standardization of education requirements by instituting a requirement that limited eligibility for the NATABOC certification to candidates who possessed a baccalaureate degree and successfully completed a CAAHEP-accredited entry-level athletic training education program (Delforge \& Behnke, 1999; Rich, Kedrowski, \& Richter, 2008). Prior to the 1997 mandate, the NATABOC offered two routes to certification. One required matriculation through an approved or accredited educational program along with 600 to 800 clinical-experience hours; the other took a more "hands-on” experience based route by requiring a minimal amount of coursework along with 1800 clinical hours as an apprenticeship student and later 1500 hours as an internship student (Delforge \& Behnke, 1999; Rich, et al., 2008; Weidner \& Henning, 2002).

In 2004, the internship route to certification was eliminated. Students desiring eligibility to sit for the Board of Certification (BOC) examination were required to graduate from an accredited Athletic Training Education Program (ATEP) that provided a comprehensive curriculum leading to a bachelor’s or master’s degree (Delforge \& Behnke, 1999; Rich, et al., 
2008). By consolidating to one method of certification, athletic training as a profession became more standardized and became more consistent with the professional preparation of other allied health disciplines.

\section{Clinical Proficiencies}

Clinical education would see further reform in the late 1990s with the NATA Competencies Committee’s development of 12 athletic training clinical-education-setting standards and associated criteria call the Athletic Training Educational Competencies (Weidner \& Henning, 2002). The “Educational Competencies” described the cognitive, psychomotor, and affective requirements in athletic training professional preparation. The standards served as a guideline, informing programs of clinical setting standards as well as the requirements of clinical education in general. Often referred to as proficiencies, the changes also created a focused approach to clinical education, replacing the random learning experiences of apprenticeships or internships with a supervisor (Weidner \& Henning, 2002).

Similarly to other undergraduate education in the allied health care professions, athletic training education designed its curriculum with the intention of providing students with experiences that help them acquire minimal levels of clinical proficiency in the essential skills of their profession. Clinical proficiencies would replace clinical hours as the measure of student's clinical progression and eligibility to sit for the certification examination. Weidner and Henning (2002) expand upon this by saying, "Proficiencies are now the basis for a student's clinical education, and clinical-experience hours are no longer considered an effective measure of a student’s clinical learning” (p. 226).

The clinical proficiencies represent a listing of the student's clinical training before entering the profession; they should be a measure of real-life application and serve as a guide in 
decision making and skill integration (Baldwin, 2010; Walker, Weidner, \& Armstrong, 2008).

Professional socialization seemed to be the primary role of clinical education prior to the development of clinical proficiencies. While socialization allowed the student to be immersed in the culture of the athletic training profession, including accepting the tradition of the profession and acquiring the group's values and attitudes, interests, skills, and knowledge, socialization is not entirely directed toward the student's learning and understanding (Weidner \& Henning, 2002).

\section{Recent Changes in Athletic Training}

The Commission on Accreditation of Allied Health Education Programs' “Essentials \& Guidelines for an Accredited Educational Program for the Athletic Trainer" was amended in 1997 to include a guideline that certified athletic trainers complete professional training for their role as clinical instructors. CAAHEP formally adopted the Approved Clinical Instructor (ACI) designation in the 2001 revised standards and guidelines (Weidner \& Henning, 2002). In June 2000, the NATA Education Council’s Clinical Education Subcommittee developed and conducted its first seminar for the Clinical Instructor Educator (CIE). The CIE is the program director or clinical-education coordinator who is professionally trained with information and resources to effectively educate Approved Clinical Instructors (ACIs) to teach and evaluate the athletic training clinical proficiencies. The adoption of the ACI training would eliminate the assumption that all certified athletic trainers are naturally qualified to educate students. Weidner and Henning (2002) write, “Just by virtue of being clinicians, certified athletic trainers do not have the knowledge or skills regarding the methods for teaching and evaluating the students under their supervision. The vast majority of athletic trainers have had no previous formal training in these areas” (ps. S-225-S-226). 
The 2001 CAAHEP standards and guidelines also recommended that athletic training clinical education include experiences in sports medicine clinics, physical therapy sites or rehabilitation clinics, college or university health centers, hospital emergency rooms, physicians’ offices, or other appropriate health care settings. The standards and guidelines also diverged from the former obligation to complete clinical experiences with contact and collisions sports to require students gain exposure to upper extremity, lower extremity, equipment-intensive, and general medical experiences with both sexes, marking the first time attention was given to the selection and evaluation of clinical settings, including the appropriate clinical instructor for the student (Weidner \& Henning, 2002).

The last decade has seen many more changes to athletic training education, including an increase in the number of accredited programs from 82 in 1991 to 367 as of November 2010 (Commission on Accreditation of Athletic Training Education, 2010; Rich, et al., 2008). Even more significant was the 2006 disbandment of CAAHEP and replacement by the Commission on Accreditation on Athletic Training Education (CAATE) as the accrediting body for ATEPs (Commission on Accreditation of Athletic Training Education, 2010; Rich, et al., 2008). Much like the two previous changes of accrediting agencies, the most recent reformation to CAATE is not void of major educational changes.

In September 2010, the NATA emailed program directors and athletic training education faculty and staff members a draft of the $5^{\text {th }}$ edition Athletic Training Educational Competencies. Once again, there are two significant aspects of the new version of the "Competencies.” The first change includes removing the word "proficiencies” from clinical education and instead describing the clinical skills as “clinically integrated competencies” (National Athletic Trainers' Association, 2010). The second added a mandate for evidence-based practices to be included in 
the curricula. This created an inclusion of characteristics of educational practices that many athletic trainers may have little to no experience from which to draw upon.

\section{Professionalization}

Professionalization can be defined as the process in which an occupation gains professional status (Dimmitt, 2004). The exact steps in the professionalization process are debated in the literature, however common themes merge. First, professionals must be committed to a calling ("The Professions and Socialization," 2001), members typically exhibit a long-term commitment to the profession and are continuously upgrading their knowledge and skills (Johnson \& Maclean, 2008). Next, professions create exclusive organizations or associations focused on licensure and ethics (Abbott, 1988; Duncan-Hewitt, 2005; "The Professions and Socialization," 2001). These organizations set the profession apart from outsiders through symbolic, ideological, and institutional boundaries (Cahill, 1999; "The Professions and Socialization," 2001).

Professionals contain advanced knowledge and skills that are obtained through specialized training or education (Abbott, 1988; Dimmitt, 2004; Duncan-Hewitt, 2005; Johnson \& Maclean, 2008; "The Professions and Socialization," 2001). The mastery of such knowledge typically requires lengthy periods of education and training that are usually university based (Johnson \& Maclean, 2008). This esoteric knowledge base is designed to both equip and socialize neophytes in the culture and symbols of the profession (Johnson \& Maclean, 2008). Abbott (1988) identifies the importance of specialized education in defining professions as “...exclusive occupational groups applying abstract knowledge to particular cases” (p. 8). He argues that any occupation can obtain licensure or develop a code of ethics. However, to become a profession, it takes a system governed by abstract knowledge to reformulate its problems and 
tasks, defend themselves from interlopers, and embrace new problems. Professionals secure status through control over the recruitment, training, and evaluation of those admitted to practice in the occupation (Abbott, 1988; Freidson, 1994; Larson, 1977); this is accomplished through the institution of credentialing and licensure processes and the development of training programs (Dimmitt, 2004).

The specialization of education also affords professionals with the autonomy to perform tasks by his/her own judgment and authority (Johnson \& Maclean, 2008; "The Professions and Socialization," 2001). Knowledge and skills are not applied in a routine fashion but instead its application is revised case by case (Abbott, 1988). The commitment to their clients' welfare is also a distinguishing feature of a professional (Abbott, 1988; Johnson \& Maclean, 2008; "The Professions and Socialization," 2001). Abbott (1998) states that professionalization requires the client to trust the professional and the professional to respect both client and colleagues. Such relationships are guaranteed by institutional forms such as association, licensure, and ethics codes.

\section{Socialization}

Socialization is the process in which individuals aspiring to a profession learn and adopt the beliefs, norms, standards, expectations, and behaviors that are valued within the profession (Hermanowicz, 2011; Hudson \& Irwin, 2010; Klossner, 2008; "The Professions and Socialization," 2001). The process involves individuals learning knowledge and skills, interacting with faculty and student peers, and becoming integrated into their fields through experiential learning environments such as internships, fieldwork, research collaboration, or clinical experiences (Hermanowicz, 2011; Mazerolle, Bowman, \& Dodge, 2014; Mensch, Crews, \& Mitchell, 2005; The Regents of the University of Colorado, 2014). 
The socialization process is typically described in three phases: recruitment, professional preparation, and organizational socialization (Klossner, 2008; Lawson, 1983a, 1983b; Mensch, et al., 2005). Often referred to as anticipatory socialization, recruitment begins with the student's exploration of professional requirements and comparing these with their personal attributes (Lawson, 1983a, 1983b; Mensch, et al., 2005). Next, professional preparation begins as students enter into formal education programs. Preparatory education includes academic content, specific professional skills, and the context of the profession, designed to prepare the graduate to enter practice at a basic competency level ("The Professions and Socialization," 2001). The third phase of socialization begins as individuals gain real world experiences and are organizationally socialized (Mensch, et al., 2005).

Klossner (2008) states that “clinical education and field experiences are components of the professional education process that are important to the socialization of preprofessional students in various fields...” (p. 384). This comes from the requirement of shared experiences and links with fellow students, faculty mentors, and role models as well as subject mastery and knowledge application ("The Professions and Socialization," 2001). Such experiences define role expectations within a profession (Hudson \& Irwin, 2010), thus giving students a sense of affirmation and transformation from outsider to insider (Klossner, 2008).

Socialization can be an unconscious act as individuals may acquire organizational or professional values without fully understanding the basis for the values or why they are necessary (Hudson \& Irwin, 2010). It is made up of experiences that are commonly and uniformly felt by students and other experiences that are perceived differently by students with different characteristics ("The Professions and Socialization," 2001). Experiences may be repetitive, but each takes the student to a higher level of personal and professional maturity. 
Educators should identify socializing factors within their clinical or field settings to ensure the facilitation of professional growth and socialization of students (Klossner, 2008). Klossner (2008) suggests that the deliberate and planned control of the socialization students during the professional preparation years could not only enhance their overall professional education experience but also potentially lead to improved organizational socialization when these individuals become credentialed members of an organization (Klossner, 2008).

\section{Definition and History of Evidence Based Practice}

Evidence-based practice (EBP) is defined in health fields as the integration of best research evidence with clinical expertise and patient values to make clinical decisions (Dickersin, et al., 2007; Neldon, 2009; Sackett, et al., 2000; Shaneyfelt, et al., 2006; Starkey, et al., 2010; Steves \& Hootman, 2004). This requires clinicians to ascertain clinically relevant research from professional literature on diagnostic tests, treatment techniques, preventative programs, and prognostic markers to make decisions about the clinical care of an individual patient (Ingersoll, 2006; Prentice, 2011; Starkey, et al., 2010; Steves \& Hootman, 2004). The goal of EBP is excellent clinical decision making based on the best available evidence (Neldon, 2009).

"Evidence based practice, including best available research, clinical expertise, and the patient's needs and values, serves as the foundation for best health care practice” (Starkey et al., 2010, p. 46). Therefore, the cornerstone of EBP is providing clinicians with the tools to proficiently find helpful information and then evaluate the quality of that information to apply it to their specific clinical situation (Steves \& Hootman, 2004, p. 83). The clinician’s knowledge, skills, attitudes and practice along with the patient's needs and values are combined to efficiently interpret and integrate published research into a clinical diagnostic approach and the 
determination of a management strategy (Brown et al., 2010; Starkey, et al., 2010; Steves \& Hootman, 2004).

\section{The Recent Focus on EBP}

Evidence Based Practice is a relatively new focal point for athletic training. The process has become increasingly important in health care since the mid-1990s, as it provides a systematic method for clinical problem solving and allows practitioners to keep up-to-date with current best practices in their field (D. Upton \& Upton, 2006a). Evidence based practice came into focus as a result of the recent surge in the cost of healthcare, creating a demand for cost-effective, beneficial patient care (Cope, 2003; Neldon, 2009). Insurance companies questioned the efficacy of some techniques and treatments and began requiring clinicians to prove that procedures being used helped patients improve in a timely and efficient manner (Starkey, et al., 2010). This pressure created a need for EBP to provide a shift in healthcare decision-making away from the "intuitive, authoritative, and subjective towards the scientific and objective" (Dale, 2006, p. 41). Ultimately, improving the care delivered to the patients is the most important reason for using EBP (Steves \& Hootman, 2004).

The greatest number of studies on EBP and its efficacy and barriers have come from the nursing profession. The researchers concluded that the sources of knowledge most valued by nurses were their own experience, information from colleagues, hospital policy and procedures, intuition and the patient's medical record (Brown, et al., 2010; C. Estabrooks, 1998; C. Estabrooks et al., 2005; McKnight, 2006; Thompson et al., 2001). In 2010, Brown et al. found that many decisions in nursing have been derived from ritual, tradition, communication with other nurses, knowledge gained in nursing school or the preferences of medical providers. Pravikoff, Tanner, and Pierce (2005) surveyed 760 clinical nurses across the USA and 
discovered that nurses sought information from colleagues more often than from journal articles. The study illustrated that more than half of the nurses did not use research reports in clinical decisions, and 83\% had never used the hospital library (Pravikoff, Tanner, \& Pierce, 2005). This phenomenon lead Dickersin et al. (2007) to stress that clinicians need more information as they do not get enough from the sources they typically utilize. Even though these studies confirm a lack of EBP by nursing clinicians, Brown et al. (2010) notes that when research is incorporated, “improved patient outcomes have been observed ... in nursing care” (p. 1945).

Neldon (2009) states that “...finding and applying the best available evidence, or research, to support clinical decision-making in medicine, nursing, and other allied health professions, clinicians can provide their patients with high quality healthcare” (p. 1). This is because evidence based medicine promotes critical thinking by clinicians, requires clinicians to have an open-mind and to look for and try new methods that are scientifically supported, and that clinical interventions be scrutinized and proven to be effective (Steves \& Hootman, 2004). According to Steves and Hootman (2004), “evidence based medicine provides clinicians with the tools for finding evidence and for analyzing the quality of that evidence so they can benefit from the work of other clinicians described in the medical literature” (p. 84).

Hertel (2005) and Prentice (2011) warn that clinical health practices are in danger of becoming out of date and may have a negative impact on patient care, if the best available evidence is not utilized. Evidence based practice offers clinicians a way to critically evaluate medical literature for value. Rigorous standards are applied to scientific data to determine whether information has merit and applicability. No longer are interventions accepted simply because another clinician talks about their anecdotal effectiveness (Steves \& Hootman, 2004). Dickersin et al. (2007) stress the value of research by saying, “The systematic synthesis of all 
reliable information on a topic has greater value than traditional reviews... Tragedy can result from paying attention to poor quality evidence instead of good quality evidence” (p. s10).

\section{Evolution of Research}

Research literature is ever changing and expanding. The history of medicine reveals numerous early practices that were later discontinued after scientific study indicated that the practices were ineffective or even dangerous (Neldon, 2009). Previously accepted methods of healthcare may fall out of favor. Also the evidence may demonstrate less harmful and more accurate or effective practices (Steves \& Hootman, 2004). The exponential growth in medical literature has made it impossible for the practitioner to stay abreast of the newest scientific information relevant to daily clinical practice (Dickersin, et al., 2007; Starkey, et al., 2010; Steves \& Hootman, 2004). This has created a need for those dedicated to patient care to develop a commitment to asking well-formed clinical questions prior to seeking answers from contemporary resources and incorporating the published findings into the decision-making process (Starkey, et al., 2010).

Bhargava, Al-Abri, and Bhargava (2010) found that physicians often resolve day-to-day practice dilemmas by consulting their peers or reference books. Their study also found that many physicians will have questions after patient consultations, but they may not search for an answer. Fourty-nine percent of the physicians surveyed agreed that a lack of knowledge about medical aspects of certain cases was the main cause of errors by family physicians (Bhargava, Al-Abri, \& Bhargava, 2010). However, advances in technology has made evidence more accessible and incorporation into practice more likely. Georgiou (2002) states that "advances in information technology have spurred the development of evidence-based medicine, as well as providing the very basis for its realization” (p. 127). 
Literature may provide answers to new and unfamiliar clinical problems that arise in the clinic. Bhargava et al. (2010) states that “Access to knowledge through the internet has spawned a world of online learning, stimulating a new passion for life-long learning in academia, professional environments, work place and at home” (p. 145). The computerization of information, initially bibliographies and then entire journals, along with increased access to the internet allows practitioners to search scientific literature for answers (Rahman \& Applebaum, 2010). The internet is used in evidence based practice to solve clinical dilemmas, resolve differences of opinion, and improve patient management outcomes, standards of care and education (Bhargava, et al., 2010).

Evidence based practice in medicine started with advances in evaluation research, such as randomized controlled trials (Rahman \& Applebaum, 2010). Relevant evidence began coming from "valid results of clinically oriented, primary studies published in peer-reviewed journals, or when available, from systematic reviews that provide comprehensive, rigorous syntheses of the results of primary studies on a particular issue” (C. Johnson, 2006, p. 21). The acceptance of meta-analysis as a method for summarizing research efforts sparked an increase in research reports and journal articles, causing researchers to begin developing a hierarchy of evidence for critically appraising new studies (Rahman \& Applebaum, 2010). Subsequently, it also required clinicians to understand the meaning of reported results and how these results should be interpreted based on the design of the study (McKeon, Medina, \& Hertel, 2006).

\section{Approach to EBP}

There is no "cookbook" on how to conduct evidence-based practice. However it is neither “old-fashion” nor impossible to complete (Sackett \& Rosenberg, 1996). The goal of evidence based practice is the integration of individual clinical expertise with the best available 
external clinical evidence from systematic research and applying this new knowledge to develop effective interventions for daily care (Prentice, 2011; Raina, Massfeller, \& Macarthur, 2004; Reinhardt, 2010; Sackett \& Rosenberg, 1996). Practitioners applying an evidence based approach to medicine find clinically relevant research either from basic sciences of medicine or from patient-centered clinical research to answer questions about specific evaluative tests, certain rehabilitation techniques, or the effectiveness of using therapeutic modalities (McKeon, et al., 2006; Prentice, 2011). The knowledge gained through external evidence may invalidate previously accepted tests and treatments and replace them with new ones that are more powerful, more accurate, more effective, and safer (Casa, 2005; Prentice, 2011; Reinhardt, 2010; Sackett \& Rosenberg, 1996).

In order to efficiently practice evidence based medicine, the clinician must be able to identify the information necessary to solve the problem. An understanding of research methodology is imperative for practitioners in their search to utilizing scientifically based treatment guidelines (Reinhardt, 2010). This includes: (a) the ability to identify the type of study design and where it fits into the hierarchy of clinical evidence, (b) the means of recognizing the type of research being consumed and how the evidence may be incorporated into clinical practice, (c) the capability to understand the meaning of the results reported in scientific journals and (d) how to interpret results based on the design of the study (Cope, 2003; McKeon, et al., 2006; Neldon, 2009; Reinhardt, 2010). Understanding research methodology also helps practitioners to better implement, document, and show how well EBP works in their clinical setting (Reinhardt, 2010).

The rise of evidence based practice does not just affect the role of the clinician. Both practitioners and researchers must be committed to the importance of the work, willingness to 
become educated about the process, and development of skills needed for implementation (Nelson \& Steele, 2007; Reinhardt, 2010). While researchers need not become clinicians and clinicians need not become researchers, the researchers’ understanding of clinical issues is needed to promote development and utilization of EBP. By learning important issues in practice, researchers can address questions that are clinically informed and useful to clinicians, thus forming the design of further research (Reinhardt, 2010).

External clinical evidence can inform, but not replace, clinical expertise, as the clinicians’ experience helps distinguish whether the evidence applies to the individual patient as well as how it should be integrated into the clinical decision. Even the best external evidence can be found to be inapplicable or inappropriate for an individual patient; therefore the clinical skills learned through experience play a vital role in the EBP process (Sackett \& Rosenberg, 1996).

\section{Five Steps to EBP}

Many authors identify the following five steps in the implementation of evidence based practice (Bhargava, et al., 2010; Dale, 2006; Prentice, 2011; Raina, et al., 2004; Sackett \& Rosenberg, 1996; Sackett, et al., 2000; Selvaraj et al., 2010; Steves \& Hootman, 2004; Straus \& Sackett, 1998). First, clinicians must transform the need for information into an answerable question. Next, they must find the best evidence with which to answer that question. Third, clinicians must critically appraise the evidence for its validity, impact, and applicability. Fourth, they must implement the newly acquired information with their clinical expertise and the patient's needs to develop a treatment plan. Finally, clinicians must evaluate the effectiveness and efficiency of executing the first four steps in hopes of improving the process. Bhargava et al. (2010) condenses the five steps of evidence based practice into, “Ask, Acquire, Appraise, Apply, and Evaluate Performance,” (p.146) which are discussed in the following sections. 


\section{Asking the Right Question}

There is a need for information when questions about the best course of action arise or when patients present unusual cases that are rarely seen by the clinician. Steves and Hootman (2004) state that “...every time a clinician sees a patient, some need for information regarding a diagnosis, prognosis, or management is generated” (p. 85). When the needed information is not easily accessible, an answerable question must be formulated to initiate the evidence based learning process. The clinical question must be formulated so that the answers will include relevant and helpful results. Referred to as the acronym PICO, practitioners use four components to pose a clear clinical question. These include the patient population, the intervention or treatment, a comparison group, and the outcome of interest (Prentice, 2011; Starkey, et al., 2010; Steves \& Hootman, 2004).

\section{Acquiring the Best Evidence}

Armed with an answerable, focused, and clinically relevant question, the clinician begins researching journal articles and medical bibliographic databases via the internet (Steves \& Hootman, 2004). Bhargava (2010) found that by searching the internet for the answers in real clinical time and applying the evidence obtained clinicians were able to improve patient outcomes, and standard of care. The research also found that the internet proved to be a very useful learning tool for clinicians. While it takes time and practice to become effective at searching and narrowing literature results, some clinical practices may be found on Google as well as from multiple journal articles using PubMed in only a few minutes (Bhargava et al., 2010).

While clinical expertise and the input from others contributes to best practice; further evidence, or information, should be gathered from non-biased sources such as peer-reviewed 
journals that address the clinical problem (Starkey, et al., 2010). Many clinicians will have access to journal articles through membership in their professional organization. However, "the most common search engine used in the United States to search medical literature is MEDLINE, which can be accessed via PubMed” (Steves \& Hootman, 2004, p. 86). Many other databases are available including the Cochrane Library, Best Evidence, UpToDate, PEDro, and Hooked on Evidence (Steves \& Hootman, 2004). Some clinicians may have access to databases that require an annual subscription fee. SPORT Discus is an online database that indexes more sports medicine publications relevant to athletic training than MEDLINE; however it requires a subscription and is therefore only available to organizations or professionals willing to pay for such services (Steves \& Hootman, 2004).

\section{Critically Appraising Evidence}

As clinicians delve deeper into research it is important to gain an understanding of concepts such as validity, clinical significance, and probability (p) value as this will help them appraise and understand the literature (Steves \& Hootman, 2004). It is also important to understand research design and the hierarchy that exists according to that design. McKeon et al. (2006) illustrates research design hierarchy in sports medicine with a pyramid. Meta-analysis and systematic review sits at the top of the pyramid. Descending the pyramid, McKeon includes randomized controlled trials, then prospective cohort studies and outcomes studies. Next the authors include case-control studies, and fourth is cross-sectional studies, case series, and case studies. Finally, unpublished clinical observations sit at the base of the pyramid.

Some database subscriptions will find relevant articles for a topic, appraise the quality of the studies, and collate the results into a systematic review (Steves \& Hootman, 2004). However, researchers who understand the hierarchy of research design realize that evidence 
based medicine is not limited to randomized trials and meta-analyses; instead it involves searching for the best external evidence to answer clinical questions (Sackett \& Rosenberg, 1996).

Understanding research design also helps clinicians avoid utilizing information gained in biased research. Dickersin (2007) states that:

Bias can explain results in many individual studies, and randomized clinical trials are now recognized as the study design that is best suited to avoid bias in questions of intervention effectiveness, although other types of study may be better for other types of questions. (p. 10)

Therefore, it is vital that clinicians understand where potential bias exists, including studies that are sponsored by a product or company. "We need to alert clinicians and patients to studies showing that reviews sponsored by the industry almost always favour the sponsor's product, whereas those that aren’t sponsored by such companies do not” (Dickersin et al., 2007, p. 10).

\section{Application of Evidence}

After developing a clinical question, conducting research to find relevant information, and appraising the literature, the clinician must decide upon a plan of care or intervention. Consistent with professional values and ethics, this application must be patient-centered, accounting for the patient’s needs, values, and long-term goals (Starkey, et al., 2010). The clinician must rely on their training and experience as well as the patient preferences, cost of treatment, and convenience before making the final decision on care. It must be noted that evidence based medicine does not force a clinician to utilize the methods found in literature. Even though evidence may suggest that a best practice exists, it may not be the correct clinical decision for the individual situation (Steves \& Hootman, 2004). 


\section{Evaluating the EBP Experience}

The final step in the process of evidence based practice is the evaluation of the experience. "Outcome assessment and reevaluation of the process are integral parts of the EBM concept” (Steves \& Hootman, 2004, p. 86). Clinicians who evaluate the process find that their future experiences with EBP are more effective and can be accomplished in a more efficient manner (Steves \& Hootman, 2004).

\section{Evidence Based Practice and Athletic Training}

As individual decisions toward health care options become more prevalent, reputation, such as effectiveness of practices, may affect patients as they decide who will provide their care (Steves \& Hootman, 2004). This has caused health care providers seeking to enhance their reputation within the health field, such as Athletic Trainers, to integrate EBP into clinical care. As more Athletic Trainers bill third-parties for services, scientific evidence will become essential toward obtaining financial reimbursement for such services. Athletic trainers may find difficulties being reimbursed for services or procedures that are not shown to be effective. This is problematic as athletic training lags behind other health professions in published evidence on the effectiveness of treatments and interventions used in daily clinical practice (Steves \& Hootman, 2004). Therefore, some authors considering the demand for enhanced reputation of the profession suggest focusing attention on research examining clinical practice to demonstrate the effectiveness of athletic training methods. They also argue that engaging in research and scholarly publication not only gains visibility and credibility for the profession, but also enhances support scientifically (Ingersoll, 2006; Prentice, 2011; Steves \& Hootman, 2004).

Some of the products used by athletic trainers further compound the need for EBP as many manufacturers are not held accountable or responsible for providing information on the 
therapeutic or protective effects of their products (Ingersoll, 2006). Accountability dictates that health care providers refrain from providing patients with products, treatments, or devices that have no evidence of therapeutic effect. Both manufacturers and clinicians should evaluate products to establish safety and determine therapeutic or prophylactic effects before they are available to consumers (Ingersoll, 2006). Clinicians must recognize that evidence cannot be anecdotal, in-house, unpublished research completed by the manufacturing company; instead it needs to be completed by objective investigators using scientific method (Ingersoll, 2006).

\section{Barriers to Evidence Based Practice}

Currently, a thorough study of the barriers associated with the incorporation of EBP by athletic training practitioners does not exist. A recent article from Manspeaker and Van Lunen (2011) states that:

...no researchers have targeted the Athletic Training population, clinical or didactic, regarding barriers to EBP. We need to identify the potential issues educators may face when trying to implement these concepts, whether they serve as instructors or clinicians, in order to develop strategies to overcome these obstacles. (p. 515)

The study by Manspeaker and Van Lunen (2011) utilized a qualitiative analyses of eight athletic training educators to determine need for EBP as well as the barriers to implementation in undergraduate education. Some of the findings in their study included insufficient time, knowledge, access to reseach materials, confidence in EBP skills, and institutional or employer support.

While further research within the athletic training profession is needed, a significant amount of research focusing on the barriers associated with EBP implementation within the 
nursing profession is available. Some barriers to research use in nursing includes emotional exhaustion, negative attitude toward research, insufficient authority to change practice, lack of administrative support, lack of time, lack of access to resources, poor understanding of statistics, and inconsistent basic knowledge and experience with research (Brown, et al., 2010; Bryar, et al., 2003; C. Estabrooks, et al., 2003; S. Funk, M. Champagne, R. Wiese, \& E. Tornquist, 1991a; Funk, Champagne, Wiese, \& Tornquist, 1991b; Glacken \& Chaney, 2004; Hutchinson \& Johnston, 2004).

The barriers associated with EBP extend beyond the clinician. Rahman and Applebaum (2010) and Starkey et al (2010) conclude that there is often not enough research available to support reported interventions or may not be applicable to the patient. "Quality published research on the clinical signs and symptoms, examination techniques, and management of many conditions may simply not exist” (Starkey et al., 2010, p. 46). In these cases, the clinicians’ judgment, knowledge of the practice, and past experiences serve as the best available evidence (Starkey et al., 2010).

As stated during the discussion of critical appraisal of evidence, randomized control trials and prospective cohort studies sit just below meta-analysis and systematic review in the hierarchy of research design. However, a significant number of athletic training literature are case studies, which have limited generalizability. Perhaps this is due to the population utilized in randomized control trials and prospective cohort studies; typically the participants have some common characteristics or demographics. However, athletic trainers rarely work with large groups of individuals who all suffer from common injuries or illnesses. This makes conducting epidemiological research difficult. Furthermore, the individual nature of patient healing creates challenges with the application of research that is confined to any specific population or 
demographic. Although case studies may have limited external validity, they may offer specific guidance in the treatment of an individual patient's condition, if targeted symptoms are comparable to the case study findings.

Rahman and Applebaum (2010) attribute the limited progress of EBP utilization to differing goals and approaches by the research and practice communities. They feel that tensions exist between practitioners and researchers due to the nature of their roles within the profession. Conflict arises from the researchers' desire for grant-funding opportunities and publications, causing them to address problems that may not intersect with the interests of the practice community. Therefore they publish studies that advance disciplinary knowledge, but may not address the most pressing problems facing practitioners. The problem is compounded when considering the clinicians’ work in imperfect systems, dealing with complex situations with limited resources. This causes little time in the workday for clinicians to read recent research and less time to determine how to implement it into their practice (Rahman \& Applebaum, 2010).

\section{Perceived Complications with EBP}

Though not barriers to the implementation of EBP, some researchers have expressed concern over various complications associated with the evidence based practice process. Perhaps the most important concern is the understanding of the EBP process and subsequent education of both clinicians and students. Denegar and Hertel (2002) ask educators, "How do we best prepare students in the art and science of evidence-based clinical practice?” (p. 127). Rahman and Applebaum (2010) address a similar question by expressing concern that students and newer clinicians may naively accept poorly tested interventions. 
Another concern is why some clinical practices are required to be taught even though there are articles that state the treatments have no further benefit than a placebo (Denegar \& Hertel, 2002). As the profession delves into evidence, researchers and educators may find some common practices that show little to no scientific evidence of effectiveness. This may create a need for change in the athletic training education curriculum. Denegar and Hertel (2002) believe that a consensus among medical professionals as well as a scientific review of efficacy should dictate the clinical practices that should be included in educational programs. And, that if data demonstrate that the clinical practice lacks sufficient efficacy, the practice should be removed so that students can spend their time practicing appropriate skills.

A final concern involves the potential rise in cost of health care associated with incorporating EBP. The concern is that as clinicians identify and apply the most effective interventions to maximize the quality and quantity of life for individual patients through information and practices gleaned from evidence, the patient may see the cost of care increase rather than decrease (Sackett \& Rosenberg, 1996).

\section{Developing EBP Skills}

While some clinical athletic trainers publish case studies, assist in large research studies, and conduct their own research, the studies that are most often published in professional journals are conducted by doctoral students and faculty members in leading graduate AT programs at colleges and universities (Manspeaker \& Van Lunen, 2011). However, for the profession to continue to gain credibility, clinicians in other settings as well must be encouraged to conduct research to determine the effectiveness of current practices (Steves \& Hootman, 2004). Likewise, researchers must begin to publish more systematic reviews of athletic training specific methods and procedures (Steves \& Hootman, 2004). Some authors call for researchers to 
practice more clinically relevant research and that clinicians assist in the research process (Denegar \& Hertel, 2002; Ingersoll, 2006; Manspeaker \& Van Lunen, 2011; Prentice, 2011; Rahman \& Applebaum, 2010). The partnership between researchers and practitioners should be dedicated to critically appraising new programs according to a hierarchy of evidence (Denegar \& Hertel, 2002; Rahman \& Applebaum, 2010).

As stated above, a perceived barrier to EBP is a lack of research skills by clinicians. Therefore, the athletic training profession must begin teaching its clinicians how to scientifically conduct research. The development of such skills may come from interactive workshops and seminars, a dedicated section in journals that reviews published studies relevant to clinical practices, chapters in text books focused on EBP, and websites allowing clinicians easy access to information (Denegar \& Hertel, 2002; Ingersoll, 2006; Prentice, 2011; Rahman \& Applebaum, 2010; Steves \& Hootman, 2004). The process of conducting research as well as the utilization of evidence can be further developed through the teaching of necessary skills and methods in athletic training undergraduate and graduate curricula (Ingersoll, 2006; Manspeaker \& Van Lunen, 2011; Steves \& Hootman, 2004).

Further understanding of the process may come from experience utilizing EBP. In order to ensure clinician involvement, researchers must be more responsive to the needs of the practitioner. This not only includes researching relevant practices but also developing interventions that are effective and simple to understand and implement. The interventions should also be perceived as an improvement by practitioners and clients, be compatible with current practices, and be affordable (Rahman \& Applebaum, 2010). Likewise, providers need to hone their skills in appraising and applying lessons learned from literature. Practitioners must 
continually assess the efficacy of new programs and practices so that problems can be quickly identified and resolved (Rahman \& Applebaum, 2010).

\section{Facilitators to EBP}

It is suggested that facilitators to research utilization exist at both the system level and at the individual level (Dysart \& Tomlin, 2002; Law \& Baum, 1998). Facilitators at the system level include administrative support, accessibility of research tools, and the perception that research findings are applicable to the clinical setting (Alsop, 1997; Boström, Wallin, \& Nordström, 2007; Dysart \& Tomlin, 2002; Egan, Dubouloz, von Zweck, \& Vallerand, 1998; Funk, et al., 1995; Haynes, 1993; Kajermo, Nordström, Krusebrant, \& Björvell, 2000; Kajermo, Nordström, Krusebrant, \& Lutzen, 2001; Nilsson Kajermo et al., 2008; Wangensteen, Johansson, Björkström, \& Nordström, 2011). Factors related to the individual level include motivation, attitude, knowledge and skill (Dysart \& Tomlin, 2002; Funk, et al., 1995; Hatcher \& Tranmer, 1997; Ottenbacher, Barris, \& Van Deusen, 1986; Van Deusen \& Fox, 1981).

Time available to conduct research is by far the most frequently mentioned facilitator to EBP. Dysart and Tomlin (2002) suggest that the time available factor is present in both the system and individual levels. Nearly all articles discussing research utilization mentions time as both a barrier and a facilitator. Time is not defined by the opportunities allotted on site to practitioners for accessing, reviewing, critiquing, and implementing research (Dysart \& Tomlin, 2002; Funk, et al., 1995; Lyons, Brown, Tseng, Casey, \& McDonald, 2011; Majid et al., 2011;

Niederhauser \& Kohr, 2005; P. Upton, Scurlock-Evans, Stephens, \& Upton, 2012). Instead, time includes the ability to attend conferences, trainings or other educational endeavors. Time also includes the ability to have research discussions with colleagues as well as heath care professionals in other fields (Dysart \& Tomlin, 2002; Funk, et al., 1995; Lyons, et al., 2011). 
Administrative support and encouragement includes managerial support for researchbased treatment plans as well as clinicians' feeling that they have the authority to change existing therapeutic procedures based on research findings (Dysart \& Tomlin, 2002). A number of studies suggest that clinicians and managers that are engaged in research utilization, access research findings while on site, and have support from administrators as well as colleagues are good predictors of research use (Boström, et al., 2007; Kajermo, et al., 2001; Nilsson Kajermo, et al., 2008; Wangensteen, et al., 2011). Funk et al. (1995) states that institutions can further encourage research use by creating an environment where clinicians are comfortable questioning and evaluating current practice, feel free to seek out solutions using research, and are able to test new methods using trials. The authors argue that greater authority can be achieved by sharing governance and developing committees that contribute to the responsibility of research use. Administrators may also show their value of research utilization by formalizing expectations through inclusion in performance appraisal, provision for grant funding and criteria for raises (Funk, et al., 1995). The increase in support from administrators fosters a culture of utilization. Wangensteen et al (2011) suggest that support for participation in research activities as well as creating a culture and values toward research are amongst the greatest facilitators to utilization. While supporting a culture of research utilization is important, providing convenient access to resources is imperative (Dysart \& Tomlin, 2002). Resources include, but are not limited to, professional libraries, internet databases, research articles, and continuing education classes (Dysart \& Tomlin, 2002). Institutions should also include user-friendly presentations and research reports and publications that are written for both clinician and patient readability and understanding (Kajermo, et al., 2000; Lyons, et al., 2011; Niederhauser \& Kohr, 2005). Research skills may also be developed through conference attendance as well as in-service 
workshops (Funk, et al., 1995; Kajermo, et al., 1998). A culture of research utilization as well as skill developed may be furthered through workplace innovations focusing on group activities such as journal clubs, research committees, presenting research findings, and consultations with experts (Funk, et al., 1995; Kajermo, et al., 1998).

The clinician's motivation, attitude, willingness to develop research skills, and value for research findings are at the forefront of individual facilitators (Boström, et al., 2007; Dysart \& Tomlin, 2002; C. A. Estabrooks et al., 2008; Hatcher \& Tranmer, 1997; Tranmer, Lochhaus, \& Lam, 2002; Van Deusen \& Fox, 1981; Wangensteen, et al., 2011). Skill development may begin with the clinician developing a sense of comfort using the internet and electronic databases as research tools; this continues with the clinician’s ability to critically appraise the quality of research findings (Dysart \& Tomlin, 2002). Education plays an important role in not only increasing knowledge and skill but also to change attitudes (Dyson, 1997; Kajermo, et al., 2000). Many health care professions are beginning to acknowledge the importance of EBP through curricular changes and higher academic standards. An increased emphasis on EBP has created changes in education and training as well as the adoption and implementation of evidence based practices among newly qualified health care professionals (P. Upton, et al., 2012). Kajermo et al. (2000) suggest that educational programs designed to increase clinicians' competence to read and evaluate research results play a pivotal role in developing positive attitudes towards research participation and utilization.

There may also be a correlation between level of education and research skills. Dysart and Tomlin (2002) found that clinicians holding a master's degree had greater confidence in their research skills than their counterparts who held only bachelor's degrees. The authors also found an inverse relationship between confidence and years of work experience. Clinicians with more 
than five years of experience responded that they felt less confident using the internet as a research tool than those with less years of experience. It was suggested that these findings were linked to changes in educational programs toward an increased emphasis on EBP, research acquisition, critical analysis, and value for research utilization in the clinical setting (Dysart \& Tomlin, 2002; P. Upton, et al., 2012).

\section{Implementation and the National Athletic Trainers Association}

The rise of evidence-based practice in Athletic Training has coincided with a professional recognition that some common practices may be antiquated, ineffective, or perhaps dangerous. Denegar and Hertel (2002) have called for a review of all aspects of athletic training practices, especially evaluation and treatment methods for specific injuries and populations. The evaluation of common procedures will not only create change in the clinical practices of athletic trainers, but also with both undergraduate and graduate curricula. "Critical review is needed to establish guidelines that will define the educational preparation and clinical practice of certified athletic trainers in the $21^{\text {st }}$ century” (Denegar \& Hertel, 2002, p. 128).

Prentice (2011) recommends that every athletic trainer develop some comprehension of basic research design and statistical analysis. Further, he argues that understanding of research design and analysis will allow professionals to be able to interpret and evaluate new research. This deeper understanding of research could encourage athletic trainers to publish literature specific to their own practices, and generate a more robust body of knowledge that will enhance the reputation of the profession (Pitney \& Parker, 2001; Prentice, 2011).

The NATA's commitment to EBP has been further noted through the development of continuing-education opportunities involving EBP, grant funding for EBP-related research, and formatting of position statements to match that of the Cochrane Collaborative evidence-based 
grading (Manspeaker \& Van Lunen, 2011). The NATA website also contains links to EBP articles, reference lists to textbooks dedicated to EBP, web addresses to sites committed to EBP, and webinars and educational courses dedicated to EBP (National Athletic Trainers' Association, 2012b).

\section{Frequency of Research Use by Athletic Trainers}

Despite numerous publications discussing and encouraging the use of evidence-based practice by Athletic Trainers, none document the frequency of research utilization among Athletic Trainers in the United States. The lack of information regarding research use is not limited to this one group, as a number of articles were found discussing the same limitation within other health care professions (Dysart \& Tomlin, 2002; Holm, 2000; McEvoy, Williams, \& Olds, 2010; Tickle-Degnen, 2000a, 2000b, 2000c; P. Upton, et al., 2012). While the frequency which health care providers utilize research was not readily available, a number of articles discussing resources accessed while researching was attainable for various professions. Not surprisingly, a number of studies list journal articles and text books as the most frequently used resources (Davies, Nutley, \& Mannion, 2000; Dysart \& Tomlin, 2002; Nilsson Kajermo, et al., 2008; Pain, Magill-Evans, Darrah, Hagler, \& Warren, 2004; K. Parahoo, Barr, \& McCaughan, 2000; D. Upton \& Upton, 2006b, 2006c). Other common resources mentioned include full-text electronic databases, clinical experiences, interactions with colleagues, conferences and workshops, in-services, discussion groups, and internet web searches (Dysart \& Tomlin, 2002; Heiwe et al., 2011; Pain, et al., 2004; D. Upton \& Upton, 2006b, 2006c; P. Upton, et al., 2012).

\section{Summary}

An understanding of how EBP is being implemented in Athletic Training is not only necessary for the care of patients, but also plays a vital role in the advancement of the profession. 
If patients and insurance companies are not given evidence that athletic training services are cost effective and promote healing, then the profession will fail to advance. As medical treatments and techniques advance, so must the knowledge and skill of the athletic trainer. This can only occur through continuing education and utilization of relevant research. However, the discerning athletic trainer must be aware of which research articles are relevant and which are flawed. This skill can only come from experience and understanding research design and methodology, two factors that may be lacking in some athletic trainers’ repertoire.

In order to fully implement into everyday practice, athletic trainers must first examine the barriers associated with EBP. A thorough examination of EBP barriers, from the perspectives of both educators and clinicians, is needed so that education programs can develop strateges to address and overcome these concerns with their students. While the NATA has made some sources of research available to clinicians, many barriers to utilization still exists. Therefore, an understanding of such barriers must be determined so that they can be overcome.

A greater understanding of the clinicians' attitude toward and daily utilization of EBP skills is also needed so that educational programs can foster a greater understanding of the importance of such skills. This will not only promote patient healing but also advancement of the reputation of the profession. By understanding attitudes associated with EBP, educators will be able to address the negative perceptions, or fears, of clinicians to create a new understanding of skills. The information and experience required to change the perception of EBP may come from course development or through workshop and symposium presentations. 


\section{Chapter 3 \\ Methodology}

\section{Introduction}

This quantitative study surveyed 3000 Certified-Regular Members of the NATA. The five-section questionnaire was developed using sections of questionnaires from four previous studies. The fifth section consisted of demographic questions including career setting, highest degree earned, number of years as a certified athletic trainer, and previous research experience. Data analysis was conducted using a report of descriptive statistics, a Multivariate Analysis of Variance (MANOVA) and a One-way Repeated Measures Analysis of Variance (Repeated Measures ANOVA).

\section{Population}

In August 2012, the National Athletic Trainers’ Association reported 24,527 CertifiedRegular Members; making up 62.67\% of total membership (National Athletic Trainers' Association, 2012a). The organization defines a Certified-Regular Member as an individual who holds the credential of ATC (Athletic Trainer, Certified) and is in good standing with the Board of Certification (National Athletic Trainers' Association, 2012a).

\section{Sample}

Participants of this study were comprised of 3,000 Certified-Regular members of the National Athletic Trainers’ Association. The participants were in three different occupational settings; College/University, Secondary School, or Clinic. These settings were chosen as they characterize the three largest classifications of occupational settings within the profession. Kahanov and Eberman (2011) reported that $70.3 \%$ of athletic trainers worked in one of three 
categories; $24.4 \%$ in College/University, 28.1\% in Clinic, and 17.8\% in Secondary School in 2009.

The researcher gained access to the sample by purchasing the email addresses of 3,000 NATA Certified-Regular Members from across the United States. The researcher specifically asked for an even distribution of athletic trainers working in the three occupational settings listed above. The researcher had no contact with the participants as the NATA randomly selected and emailed 3,000 Certified-Regular Members of their organization. This email consisted of a brief explanation of EBP, a request for participation in the study, and a link to the Qualtrics electronic surveying instrument.

\section{Measurement}

The research utilized a quantitative design using a survey to examine the perceptions regarding the barriers and facilitators to, as well as the frequency of research utilization by athletic trainers. The questionnaire was an adaptation of four previously published surveys. The first questionnaire used was the Barriers to Research Utilization Scale (S. G. Funk, et al., 1991a), which asks participants to rate the extent to which they think each item is a barrier or facilitator to the use of research to change or improve their professional practices. The researcher was granted permission by Dr. Sandra Funk to use and edit the Barriers to Research Utilization Scale. This scale was created by a research team of Funk, Champagne, Tornquist, and Wiese (1991a) to examine the perceptions of barriers to the utilization of research findings within the nursing profession. The second tool used was a portion of the instrument designed by Hutchinson and Johnston (2004) that identifies facilitators to using EBP. The third survey used in this study consisted of two portions of the Evidence-Based Practice Questionnaire (D. Upton \& Upton, 2006a), which examines both facilitators and the day to day use of EBP. The final 
instrument utilized was created by Dysart and Tomlin (2002) which assesses resource access and frequency of resource use. The questionnaire was created in Qualtrics.com to develop an electronic surveying instrument and emailed to 3,000 Certified-Regular Members of the National Athletic Trainers’ Association.

\section{Barriers Scale Questionnaire}

The first section of the questionnaire included a five point Likert scale to measure the responses to 29 questions regarding the participant's perception of barriers associated with research utilization. The participants were asked to rank the greatest to third greatest barriers. Responses were ascertained using a drop down menu of the 29 items listed from the questionnaire as well as the responses from the open ended question above. The research measured the frequency of responses to identify the items perceived to be the greatest barriers to research utilization.

The Barriers Scale utilizes a five point Likert Scale questionnaire ranging from: 1 = To no extent, 2 = To a little extent, 3 = To a moderate extent, $4=$ To a great extent, and $5=$ No opinion. However, the research will move the "No opinion" response to the middle of the scale creating a 5 point Likert scale as follows: 1 = To no extent, 2 = To a little extent, $3=$ No opinion, 4 = To a moderate extent, and 5 = To a great extent. The survey consists of 29 possible barriers that can be organized into four factors: characteristics of the potential adopter, characteristics of the organization in which the research will be utilized, characteristics of the research, and characteristics of the communication of the research.

Factor 1 - Characteristics of the adopter. The athletic trainer's research values, skills, and awareness.

- The athletic trainer does not see the value of research for practice. 
- The athletic trainer sees little benefit for self.

- The athletic trainer is unwilling to change/try new ideas.

- There is not a documented need to change practice.

- The athletic trainer feels the benefits of changing practice will be minimal.

- The athletic trainer does not feel capable of evaluating the quality of the research.

- The athletic trainer is isolated from knowledgeable colleagues with whom to discuss the research.

- The athletic trainer is unaware of the research.

Factor 2 - Characteristics of the organization. Setting barriers and limitations.

- Administration will not allow implementation.

- Physicians will not cooperate with implementation.

- There is insufficient time on the job to implement new ideas.

- Other staff are not supportive of implementation.

- The facilities are inadequate for implementation.

- The athletic trainer does not feel she/he has enough authority to change patient care procedures.

- The athletic trainer does not have time to read research.

- $\quad$ The athletic trainer feels results are not generalizable to own setting.

Factor 3 - Characteristics of the research. Qualities of the research.

- The research has methodological inadequacies.

- The conclusions drawn from the research are not justified. 
- The research has not been replicated.

- The literature reports conflicting results.

- The athletic trainer is uncertain whether to believe the results of the research.

- Research reports/articles are not published fast enough.

Factor 4-Characteristics of the communication. Presentation and accessibility of the research

- Implications for practice are not made clear.

- Research reports/articles are not readily available.

- The research is not reported clearly and readably.

- Statistical analyses are not understandable.

- The relevant literature is not compiled in one place.

- The research is not relevant to the athletic trainer's practice.

Items on the Barriers Scale Questionnaire were developed based upon literature on research utilization, with permission from the Conduct and Utilization of Research in Nursing (CURN) Project Research Questionnaire (Crane, Pelz, \& Horsley, 1977), and from information gained through interviews with nurses (Funk et al., 1991a). The authors utilized the services of research utilization consultants, nursing researchers, practicing nurses, and a psychometrician to gain expert input on their list of potential questionnaire items. Their instrument was then pilottested by graduate school nursing students. Pilot-test participant written and group discussion feedback resulted in the addition of two items as well as minor rewording to the questionnaire (Funk et al., 1991a). The three stage method instrument development, (1) item creation through identifying items from existing scales and constructing additional items, (2) scale development 
and analysis by a panel of judges, and (3) instrument testing with a pilot study has been found to ensure content validity, construct validity, convergent validity for items consistently placed within a specific category and discriminant validity for items that were not consistently placed into a category (Moore \& Benbasat, 1991).

The authors mailed the Barriers Scale Questionnaire to 5,000 Registered Nurses working full time. Participants were found using a stratified random sample of the 1987 American Nursing Association membership roster. The questionnaire was returned by 1,989 individuals. However, 41surveys were eliminated due to participant retirement, changes in full time status or occupation, and incomplete questionnaires (Funk et al., 1991a).

Questionnaire responses were then divided into two groups, 974 per group, so that a factor analysis could be performed on both halves to see if the same factors would be identified. Analysis of the first group identified four factors accounting for $43.4 \%$ of the variance in the data: characteristics of the adopter, characteristics of the organization, characteristics of the institution, and characteristics of the communication. However, the research found that one item did not contain above a $40 \%$ load on any of the four factors ("the amount of research information is overwhelming”); therefore it was eliminated. Upon deriving the four factors, the second group of questionnaire responses was analyzed. Once again the researchers found the four-factor solution accounting for $44.9 \%$ variance. Finally, a full sample factor analysis was completed and results were found to be similar to the original analysis.

The questionnaire asked participants to list any additional barriers they believed were missing from the tool. Responses were analyzed to assess comprehensiveness and content validity of the instrument. The researchers established 21 categories, most of which overlapped existing items. Only two additional barriers were stated by more than $5 \%$ of the sample: the lack 
of administrative support for implementation and the nurse's lack of knowledge about research. However, both concepts were represented in a different form on the tool. Therefore, the researchers state that a lack of specification of additional major barriers lends support to the content validity of the instrument (Funk et al., 1991a). Content validity of the tool is further supported by the panel of experts, pilot study, and factor analysis performed and replicated on randomly chosen halves of the questionnaire participants.

The authors of the Barriers Scale report a Cronbach alpha score for each of the four factors associated with the questionnaire, thus establishing internal consistency reliability (Funk, et al., 1991a). The Cronbach alpha score for factors 1-3, characteristics of the Adopter, characteristics of the Organization, and Characteristics of the Research, were $0.80,0.80$, and 0.72 respectively (Funk et al., 1991a). The alpha level for the fourth scale, characteristics of the Communication, was slightly lower at 0.65 ; however the authors report that the item correlation within the fourth factor to be in an acceptable range and express that a deletion of any item would result in a decline in the alpha coefficient (1991a). Cronbach’s alpha score is considered one of the most commonly utilized measures for scale reliability (Falk \& Savalei, 2011; Field, 2005; Kane, Crooks, \& Cohen, 1999).

\section{Hutchinson and Johnston Questionnaire}

The second section of the research was a collaboration of the facilitator sections of both Hutchinson and Johnston's survey (2004) as well as the Evidence-Based Practice Questionnaire (D. Upton \& Upton, 2006a) utilizing a five point Likert scale to measure the responses to 16 total questions regarding the participant's perception of facilitators associated with research utilization. The participants were asked to list and rate any other facilitators to research utilization that is not listed on the questionnaire. The research measured the frequency of 
responses to identify the items perceived to be the greatest facilitators to research utilization. The facilitator section of the questionnaire utilized a five point Likert Scale questionnaire ranging from: 1 = To no extent, 2 = To a little extent, 3 = No opinion, 4 = To a moderate extent, and 5 = To a great extent.

The study by Hutchinson and Johnston (2004) surveyed 761 nurses working in a 310-bed major teaching hospital in Melbourne, Australia. The first section of their survey included the Barriers Scale mentioned above. The second portion of their study contained eight questions developed by the investigators regarding facilitators to research utilization. These eight questions were used as a portion of the facilitators to research utilization section in this study's questionnaire.

Hutchinson and Johnston (2004) report content validity of their instrument through support by the literature on research utilization, the research utilization questionnaire developed by the Conduct and Utilization of Research in Nursing Project (Crane, et al., 1977), and data gathered from nurses. The authors also gained input from experts in the field of research utilization, nursing research, nursing practice and a psychometrician to establish face and content validity. Finally, the authors report adding two items and making minor edits upon completion of a pilot study.

\section{Evidence Based Practice Questionnaire (EBPQ)}

As mentioned above, a portion of the second section as well as the third section came from questions developed by Upton and Upton (2006a); see above for details of the second section. The third section followed a five point Likert scale to measure the responses to 6 questions regarding the participant's knowledge and skills associated with the steps to EBP established by Sackett et al. (2000). This section's scale differed from the previous sections in 
the identification of the points on the Likert scale: $1=$ Never, $2=$ Rarely, $3=$ Sometimes, $4=$ Often, and 5 = Always.

The EBPQ (Upton \& Upton, 2006a) was developed based on a literature search of key factors influencing EBP, as well as discussions with key health and social care professionals. The initial instrument was piloted and reduced after item analysis and scaling methods. The questionnaire was piloted and revised two more times, by the initial group of healthcare professionals and by a steering group of experts in the field of health and social care policy. The authors state that the use of use of the healthcare professionals and steering group establish content validity to the questionnaire. The initial questionnaire was then sent to a stratified sample of 500 nurses in Wales. The data from the first survey were used to establish the structure of the questionnaire. A new instrument was then sent to 500 different nurses for further refinement and validation.

The authors demonstrate reliability by reporting a Cronbach’s alpha score of 0.87 for the entire questionnaire and a Cronbach's alpha of 0.91 for the knowledge/skills associated with EBP subscale. Construct validity was found through the correlation between questionnaire scores and an independent measure of awareness of EBP; found by asking respondents if they had knowledge of aspects or initiative to promote EBP. Upton and Upton assessed discriminate validity by comparing those with knowledge of local initiative and those without. Finding that those with knowledge of a local initiative had better attitude $(t=2.5$; d.f. $=322 ; P<0.01)$, more frequent practice that was evidence-based $(t=3.2$; d.f. $=360 ; P<0.02)$ and better knowledge of $\operatorname{EBP}(t=5.2 ;$ d.f. $=360 ; P=0.001)$. 


\section{Dysart and Tomlin Questionnaire}

The fourth section of the questionnaire was an adaptation from the questionnaire developed by Dysart and Tomlin (2002) asking the frequency of use of certain research media such as journal articles, electronic databases, and continuing education workshops. This section of the questionnaire was utilized to gain insight on the tools athletic trainers utilize with research and EBP concepts. The first nine questions of this section utilized a scale similar to that of the third section; a five-point Likert scale ranging from "Never" on the left side to "Always" on the right. The section also contained three questions regarding how frequently the respondent utilized research information to alter or develop therapeutic treatment plans, how frequently they read research articles, and how recently the respondent read research articles from both an Athletic Training publication as well as a publication not related to Athletic Training.

Dysart and Tomlin developed the questionnaire to study the prevalence of EBP use among occupational therapists in the United States. A pilot questionnaire was administered to six occupational therapists and revisions were made after receiving their input. The final questionnaire was mailed to 400 participants selected randomly from the Occupational Therapy Association (AOTA) membership list. Inclusion criteria included occupational therapists currently practicing or who had practiced within 3 months prior to the questionnaire being administered. The authors list the lack of testing their instrument's reliability and validity as a limitation to their study.

\section{Demographic Section}

Demographic information was collected in the final section of the questionnaire. Questions including career setting, highest degree earned, number of years as a certified athletic trainer, and previous research experience. The demographic information collected will be used 
for future research considerations, with the exception of career setting which will be utilized to answer the fourth research question. All responses will be collected using an electronic surveying instrument generated in Qualtrics.com.

\section{Pilot Study}

After gaining West Virginia University’s Institutional Review Board for the Protection of Human Subjects approval, the researcher conducted a pilot study to establish content validity as well as to assess the survey's function and formatting. The pilot was conducted using a convenience sampling of six nursing faculty members who met one of the following criteria: 1 ) held a Doctoral degree; 2) was enrolled in a doctoral program; or 3) had experience conducting research. All six nursing faculty members were from the same small liberal arts institution in the north eastern portion of the United States.

The participants were first asked to complete an online version of the questionnaire. Upon completion, the nurses were given a paper copy of the instrument and asked to note any concerns. The researcher then met with the participants to discuss their comments and recommendations. Aside from minor spelling and punctuation errors, the only concern found in the pilot study was the length of time required to complete the survey. Findings of the pilot

study were used to make appropriate changes to the survey instrument, including minor edits for spelling. The final questionnaire was created using Qualtrics electronic surveying instrument.

\section{Procedure}

Upon completion of the pilot study and appropriate edits, the researcher purchased the email addresses of 3,000 participants from the NATA. A cover letter was developed explaining the research and requesting voluntary participation. The researcher offered participants who complete the survey the opportunity to enroll in a drawing to win one of two iPad Minis. This 
incentive was described in both the cover letter and the survey to encourage participation in the study. The cover letter also assured participants of their anonymity and that their responses would be kept confidential. Consent was assumed by the participants’ completion of the questionnaire. Participants received the cover letter and link to the questionnaire via email from the NATA. A follow up email was sent by the NATA two weeks later. The researcher began data collection one month after the initial email; however the questionnaire remained open for responses to encourage maximum participation.

\section{Data Analyses}

The frequency in which athletic trainers used research in their practice was broken down to four subcategories: (1) the frequency of use of EBP concepts; (2) the frequency of using resources to access research; (3) the recentness of reading research articles from Athletic Training publications and publications not related to Athletic Training, and (4) the number of times athletic trainers used research to alter or develop a treatment plan in the last year. A report of descriptive statistics was used to analyze the frequency in which athletic trainers reported using EBP concepts. The Results section contains a table listing the mean, standard deviation, and frequency in which athletic trainers reported utilizing the steps to EBP.

A report of descriptive statistics was also utilized to address the resources athletic trainers used to access research. A table listing the mean, standard deviation, and frequency of resource use is available in the Results section, (see Table 3, p. 60).

A categorical count was used to examine the recentness in which athletic trainers read articles from both an Athletic Training publication and a publication not associated with the profession. Two tables were developed showing the number of times and percentage of respondents that reported how recently they read articles (see Tables 4.1 and 4.2, pp. 61 and 62). 
A categorical count was utilized to investigate the frequency in which athletic trainers used research to alter or develop treatment plans. The Results section contains a table listing the number of times and percentage of respondents that reported how frequently they use research to alter or develop a treatment plan over the past year (see Table 5, p. 62).

The perceived barriers and facilitators to EBP were analyzed using categorical counts. The researcher categorized the responses to four open ended questions regarding perceived barriers and facilitators to EBP; two questions each. Next the responses were categorized according to the four characteristics described by Funk et al. (1991a); characteristics of the adopter, characteristics of the organization, characteristics of the research, and characteristics of the communication. To find reliability, an independent researcher was given the definition of the four categories and asked to classify the responses to the open ended questions accordingly. Tables were then developed showing the participants' responses as well as the characteristic in which each response was categorized.

A report of descriptive statistics was utilized to address both the question regarding how athletic trainers rate the facilitators and how they rate barriers associated with the utilization of research. The Results section contains tables listing the rank order of the results for each question on both the facilitators and the barriers on the questionnaire, their related characteristics, and the means and standard deviations of the ratings (see Tables 6 and 10).

The fourth question, regarding whether the perception of barriers differs according to career setting, was analyzed in SPSS using a Multivariate Analysis of Variance (MANOVA) with $p<0.05$. The data collected from the demographics section ascertained the independent variable, career setting. Independent variables include College/University - Academic only, College/University - Athletic only, College/University - Mixed academic and athletic, Clinic, 
Clinic Outreach - Secondary School, Secondary School, Physician Extender, and Other. The dependent variables for this study were the participant's response to the established questions of the Barriers Scale questionnaire.

A One-way Repeated Measures Analysis of Variance (Repeated Measures ANOVA), $p<$ 0.05, was used to address the last question, which asked if athletic trainers rate barriers to EBP utilization differently according to the four factors defined by the Barriers Scale questionnaire. The four factors, characteristics of adopter, characteristics of organization, characteristics of research, and characteristics of communication, were used as the independent variable; responses were used as the dependent variables to identify whether one or more factors were perceived as greater barriers to research utilization by athletic trainers. The data was formulated in SPSS.

\section{Limitations of the Study}

Participants in this study were limited to 3,000 Certified-Regular members of the National Athletic Trainers' Association (NATA). The NATA is a professional organization; however not all athletic trainers are members of the organization. The NATA reports having just over 24,500 certified members (National Athletic Trainers' Association, 2012a) while the Board of Certification for Athletic Training reports over 41,600 certified athletic trainers (Board of Certification for the Athletic Trainer, 2012).

The questionnaire was developed by the researcher based on findings in the literature as well as previous research instruments; however the questionnaire must be viewed as a limitation of the study. Further analysis of the instrument needs to be completed to ensure reliability and validity.

While participation in the study was voluntary, the researcher offered those who completed the survey an opportunity to enter in a drawing for one of two iPad Minis. Offering 
an incentive such as this was a limitation as it created the potential of a bias as the participants may have included individuals more apt to want or use the technology associated with iPad Minis.

EBP is defined as the integration of best available evidence with clinical experience and patient values to make clinical decisions. This study was only focused on the barriers, facilitators, and frequency of research involved with EBP and did not delve into the clinical experience of Athletic Trainers or the values of their patients. Therefore the study was limited to a third of the factors associated with the definition of EBP.

Finally, the researcher was an athletic trainer which created the possibility of subject bias in interpretation of results. To address this limitation, the researcher conducted peer-audits of interpretations. 


\section{Chapter 4}

\section{Findings}

Three hundred thirteen Certified-Regular Members of the National Athletic Trainers’ Association participated in the study. Journal articles and texts $(\mathrm{M}=3.70, \mathrm{SD}=0.90)$, continuing education workshops $(\mathrm{M}=3.58, \mathrm{SD}=0.90)$ and conference presentations $(\mathrm{M}=3.51$, $\mathrm{SD}=0.92$ ) were found to be the three resources most frequently used to access research. Results indicated that the three greatest barriers to EBP in athletic training include a feeling of being overwhelmed by the amount of research information $(\mathrm{M}=3.18, \mathrm{SD}=1.23)$, a lack of time to read research $(\mathrm{M}=3.12, \mathrm{SD}=1.32)$, and facilities that are inadequate for implementation $(\mathrm{M}=$ $3.12, \mathrm{SD}=1.20)$. The three greatest facilitators were found to be an increased budget for continuing education courses, workshops, or presentations $(\mathrm{M}=4.08, \mathrm{SD}=1.11)$, the availability of research that is applicable to the clinician's needs $(\mathrm{M}=4.02$, SD $=0.92)$, and research that is clinically focused and relevant $(\mathrm{M}=3.86, \mathrm{SD}=1.01)$.

\section{Characteristics of the Population}

Of the 3000 Athletic Trainers in the sample, 313 respondents complete the questionnaire for a $10.43 \%$ return rate. The distribution of gender was even as one half of the respondents were female ( $n=157,50 \%)$. This was consistent with the NATA report that their 2013 demographics consisted of 52.2\% female and 47.8\% male Certified-Regular members (National Athletic Trainers' Association, 2014b). Ethnicity was distributed across seven categories with the overwhelming majority of participants describing themselves as Caucasian $(n=290,93 \%)$. The majority of the sample gained certification upon graduating from an accredited program $(\mathrm{n}=$ 226, 72\%). Approximately a quarter of the respondents reported practicing as an athletic trainer for three to five years ( $n=77,24 \%$ ). The majority of the participants reported that they have 
earned a Master's Degree $(n=214,68 \%)$. Nearly a quarter of the sample work in the states that make up NATA District 4 ( $\mathrm{n}=72,23 \%)$; Illinois, Indiana, Michigan, Minnesota, Ohio, and Wisconsin. A slight majority of the sample reported working in an urban area ( $\mathrm{n}=182,58 \%)$. Career setting was distributed across eight categories with a plurality of respondents reporting that they practice at a college or university athletically only $(n=79,25 \%)$. The vast majority state that they conduct patient care on a daily basis $(n=269,86 \%)$. However, the majority of the sample have never been an author in a research based publication $(\mathrm{n}=239,78 \%)$. Demographic characteristics of participants can be found on Tables 1.1 to 1.10 in Appendix D.

\section{Question One: Frequency of Research}

Descriptive statistics and categorical counts were used to address the first research question, what is the frequency by which athletic trainers use research in their practice? The question was divided into four parts: the frequency in which athletic trainers use EBP concepts, the frequency of resource use, the recentness of reading research articles, and the number of times in the last year that research was used to alter or develop a treatment plan.

Frequency of EBP concept use. Bhargava (2010) breaks the EBP process down into five simple steps: ask, acquire, appraise, apply, evaluate. However, sharing the information with colleagues is sometimes included in the process (D. Upton \& Upton, 2006a). A five point Likert scale was used ranging from: 1 = Never, 2 = Rarely, $3=$ Sometimes, $4=$ Often, and 5 = Always. Table 2 contains the mean, standard deviation, and percentage of time in which athletic trainers report using EBP concepts $(\mathrm{N}=307)$. The two highest rated items were "Integrated the evidence you have found with your expertise” $(\mathrm{M}=3.47, \mathrm{SD}=0.91)$ and "Tracked down the relevant evidence once you have formulated the question $(\mathrm{M}=3.42$, $\mathrm{SD}=0.96)$. Although "Formulated a clearly answerable question as the beginning of the process towards filling this gap” should be 
the first step utilized in the EBP process, it was rated by athletic trainers as the second least frequently completed procedure of the process $(\mathrm{M}=3.13, \mathrm{SD}=0.94)$. "Critically appraised, against set criteria, any literature you have discovered” was found to be the step least frequently completed $(\mathrm{M}=2.78, \mathrm{SD}=1.02)$.

Table 2

Frequency of completing the steps to EBP over the last year $(N=307)$

\begin{tabular}{|c|c|c|c|c|c|c|c|}
\hline EBP Technique & Never & Rarely & Sometimes & Often & Always & M & SD \\
\hline $\begin{array}{l}\text { Formulated a clearly } \\
\text { answerable question as the } \\
\text { beginning of the process } \\
\text { towards filling this gap }\end{array}$ & $\begin{array}{c}16 \\
(5 \%)\end{array}$ & $\begin{array}{c}55 \\
(18 \%)\end{array}$ & $\begin{array}{c}126 \\
(41 \%)\end{array}$ & $\begin{array}{c}94 \\
(31 \%)\end{array}$ & $\begin{array}{c}16 \\
(5 \%)\end{array}$ & 3.13 & 0.94 \\
\hline $\begin{array}{l}\text { Tracked down the relevant } \\
\text { evidence once you have } \\
\text { formulated the question }\end{array}$ & $\begin{array}{c}9 \\
(3 \%)\end{array}$ & $\begin{array}{c}39 \\
(13 \%)\end{array}$ & $\begin{array}{c}103 \\
(34 \%)\end{array}$ & $\begin{array}{c}127 \\
(41 \%)\end{array}$ & $\begin{array}{c}29 \\
(9 \%)\end{array}$ & 3.42 & 0.96 \\
\hline $\begin{array}{l}\text { Critically appraised, against } \\
\text { set criteria, any literature you } \\
\text { have discovered* }\end{array}$ & $\begin{array}{c}31 \\
(10 \%)\end{array}$ & $\begin{array}{c}99 \\
(32 \%)\end{array}$ & $\begin{array}{c}91 \\
(30 \%)\end{array}$ & $\begin{array}{c}76 \\
(25 \%)\end{array}$ & $\begin{array}{c}9 \\
(3 \%)\end{array}$ & 2.78 & 1.02 \\
\hline $\begin{array}{l}\text { Integrated the evidence you } \\
\text { have found with your } \\
\text { expertise** }\end{array}$ & $\begin{array}{c}9 \\
(3 \%)\end{array}$ & $\begin{array}{c}34 \\
(11 \%)\end{array}$ & $\begin{array}{c}94 \\
(31 \%)\end{array}$ & $\begin{array}{c}141 \\
(46 \%)\end{array}$ & $\begin{array}{c}27 \\
(9 \%)\end{array}$ & 3.47 & 0.91 \\
\hline $\begin{array}{l}\text { Evaluated the outcomes of } \\
\text { your practice }\end{array}$ & $\begin{array}{c}22 \\
(7 \%)\end{array}$ & $\begin{array}{c}57 \\
(19 \%)\end{array}$ & $\begin{array}{c}92 \\
(30 \%)\end{array}$ & $\begin{array}{c}101 \\
(33 \%)\end{array}$ & $\begin{array}{c}35 \\
(11 \%)\end{array}$ & 3.23 & 1.10 \\
\hline $\begin{array}{l}\text { Shared this information with } \\
\text { colleagues }\end{array}$ & $\begin{array}{c}22 \\
(7 \%)\end{array}$ & $\begin{array}{c}61 \\
(20 \%)\end{array}$ & $\begin{array}{c}95 \\
(31 \%)\end{array}$ & $\begin{array}{c}100 \\
(33 \%)\end{array}$ & $\begin{array}{c}29 \\
(9 \%)\end{array}$ & 3.17 & 1.08 \\
\hline
\end{tabular}

( ) indicates percentage

* One missing variable $\mathrm{N}=306$

** Two missing variables $\mathrm{N}=305$

$\mathrm{EBP}=$ Evidence-based practice

Frequency of resource use. Descriptive statistics were used to find the frequency in which athletic trainers used ten different resources to access research. Participants reported the frequency in which they used each item on a five point Likert scale ranging from "Never" to 
“Always”. Table 3 shows the mean, standard deviation, and frequency in which athletic trainers reported using each resource $(\mathrm{N}=311)$. Only five of the items were found to have a mean score above 3.0. "Journal articles and texts" had the greatest mean $(\mathrm{M}=3.70, \mathrm{SD}=0.90)$ followed by “Continuing education workshops” $(\mathrm{M}=3.58, \mathrm{SD}=0.90)$ and “Conference presentations” $(\mathrm{M}=$ 3.51, SD $=0.92)$. The three resources least frequently used included a "Research specialist” (M $=1.72, \mathrm{SD}=0.96)$, “Internet discussion groups” $(\mathrm{M}=2.01, \mathrm{SD}=1.02)$, and “A university or professional library” $(\mathrm{M}=2.31, \mathrm{SD}=1.19)$ respectively.

Table 3

Frequency of resources used to access research $(N=311)$

\begin{tabular}{lccccccc}
\hline \multicolumn{1}{c}{ Research Source } & Never & Rarely & Sometimes & Often & Always & M & SD \\
\hline Journal articles and texts & 3 & 26 & 90 & 135 & 57 & 3.70 & 0.90 \\
$\begin{array}{l}\text { A university or professional } \\
\text { library }\end{array}$ & 90 & 113 & 50 & 39 & 19 & 2.31 & 1.19 \\
$\begin{array}{l}\text { Electronic databases limited } \\
\text { to citations or abstracts }\end{array}$ & 9 & 48 & 91 & 117 & 46 & 3.46 & 1.01 \\
$\begin{array}{l}\text { Full text electronic databases } \\
\text { Internet discussion groups }\end{array}$ & 50 & 78 & 74 & 76 & 33 & 2.88 & 1.25 \\
$\begin{array}{l}\text { Internet websites } \\
\text { Continuing education }\end{array}$ & 120 & 105 & 55 & 26 & 5 & 2.01 & 1.02 \\
$\begin{array}{l}\text { workshops } \\
\text { Conference presentations }\end{array}$ & 11 & 21 & 89 & 156 & 33 & 3.58 & 0.90 \\
$\begin{array}{l}\text { In-services, discussion groups } \\
\text { and work meetings }\end{array}$ & 40 & 67 & 109 & 78 & 17 & 2.89 & 1.09 \\
\begin{tabular}{l} 
Research specialist \\
\hline
\end{tabular} & 171 & 80 & 37 & 19 & 3 & 1.72 & 0.96 \\
\hline
\end{tabular}

Recentness of reading research articles. A categorical count was used to show the recentness in which athletic trainers reported reading research articles from both Athletic Training publications $(\mathrm{N}=312)$ and publications not related to Athletic Training $(\mathrm{N}=311)$; 
Tables 4.1 and 4.2 respectively. Data showed that 32\% $(n=101)$ of participants reported reading research articles from an Athletic Training publication within a week of responding to the survey. A total of $71 \%(n=222)$ of participants reported reading an article from an Athletic Training publication within a month of completing the survey. Only $12 \%(n=37)$ reported having read similar articles six months or longer prior to participating in this study. One percent $(n=2)$ reported that they never read articles from Athletic Training publications.

Table 4.1

Recentness of reading research articles from an

Athletic Training publication $(N=312)$

\begin{tabular}{lcc}
\hline Survey Response & $\mathrm{n}$ & $\%$ \\
\hline Never & 2 & $1 \%$ \\
1 year ago or more & 17 & $5 \%$ \\
6 months ago or more & 18 & $6 \%$ \\
3 months ago or more & 10 & $3 \%$ \\
1 month to 3 months ago & 43 & $14 \%$ \\
Last month & 69 & $22 \%$ \\
Two weeks ago & 52 & $17 \%$ \\
Within the last week & 101 & $32 \%$ \\
\hline
\end{tabular}

A categorical count was used to find the recentness in which athletic trainers reported reading research articles from publications not related to Athletic Training $(\mathrm{N}=311)$. Twenty one percent of respondents $(n=66)$ reported that they read such an article within a week of completing the survey. Only 43\% $(n=133)$ reported reading articles from publications not related to Athletic Training within a month of participating in this study. While 32\% $(n=100)$ reported reading similar articles six months or longer before completing the survey. Seven percent $(n=21)$ reported never reading articles from publications not related to Athletic Training. 
Table 4.2

Recentness of reading research articles from a

publication not related to Athletic Training $(N=311)$

\begin{tabular}{lcc}
\hline Survey Response & $\mathrm{n}$ & $\%$ \\
\hline Never & 21 & $7 \%$ \\
1 year ago or more & 53 & $17 \%$ \\
6 months ago or more & 26 & $8 \%$ \\
3 months ago or more & 29 & $9 \%$ \\
1 month to 3 months ago & 49 & $16 \%$ \\
Last month & 41 & $13 \%$ \\
Two weeks ago & 26 & $8 \%$ \\
Within the last week & 66 & $21 \%$ \\
\hline
\end{tabular}

Frequency of using research to alter or develop a treatment plan. A categorical

count was used to find the number of times athletic trainers used research to alter or develop treatment plans within the past year $(\mathrm{N}=311)$, Table 5. Thirty four percent $(n=106)$ of participants reported that they used research to alter or develop a treatment plan " 3 to 5” times within the last year. Only $13 \%(n=41)$ reported using research more than 10 times to influence a treatment plan, while $7 \%(\mathrm{n}=22)$ reported never using research.

Table 5

Number of times research was used to alter or develop a treatment plan in the past year $(N=311)$

\begin{tabular}{lcc}
\hline Survey Item & $\mathrm{n}$ & $\%$ \\
\hline None & 22 & $7 \%$ \\
1 to 2 & 84 & $27 \%$ \\
3 to 5 & 106 & $34 \%$ \\
6 to 10 & 58 & $19 \%$ \\
11 to 20 & 26 & $8 \%$ \\
21 to 30 & 6 & $2 \%$ \\
More than 30 & 9 & $3 \%$ \\
\hline
\end{tabular}




\section{Research Question Two: Facilitators to EBP}

Research question two was divided into two parts: 1) what are the perceived facilitators to EBP use by Athletic Trainers, and 2) how do Athletic Trainers rank the facilitators to their use of EBP? Participants were asked to rate, rank, and identify other facilitators to the use of EBP. The survey contained sixteen items that are believed to facilitate the use of research in clinical decision making as well as two open ended questions asking participants to list any other items that they would consider to be facilitators to the use of research at a moderate to great extent. Descriptive statistics found that all sixteen items had a mean score above 3.0 on a 5-point Likert scale $(\mathrm{N}=313)$. Two items had a mean score above 4.0; 'increased budget for continuing education workshops, courses, or presentations' $(\mathrm{M}=4.08, \mathrm{SD}=1.11)$ and 'availability of research that is relevant to clinical needs' $(\mathrm{M}=4.02, \mathrm{SD}=0.92)$.

Four of the top ten facilitators were attributed to the characteristics of the organization subcategory: 'increased budget for continuing education workshops, courses, or presentations' $(\mathrm{M}=4.08, \mathrm{SD}=1.11)$, 'enhancing the dissemination of new ideas about patient care to colleagues' $(\mathrm{M}=3.68, \mathrm{SD}=0.93)$, 'providing colleague support/mechanism’ $(\mathrm{M}=3.65, \mathrm{SD}=$ 1.00), and 'increasing the time available for reviewing and implementing research findings' (M $=3.62, \mathrm{SD}=1.05)$. Only one of the top ten facilitators came from the characteristics of the adopter subcategory; ‘improving ability to critically analyze evidence against set standards’ $(\mathrm{M}=$ 3.53, $\mathrm{SD}=1.09)$. The mean and standard deviation as well as the associated characteristic of each facilitator can be found on Table 6, p 64. 
Table 6

Facilitators to $\operatorname{EBP}(N=313)$

\begin{tabular}{|c|c|c|c|c|}
\hline Rank & Facilitator & Characteristic & $\mathrm{M}$ & SD \\
\hline 1 & $\begin{array}{l}\text { Increased budget for continuing education courses, } \\
\text { workshops, or presentations }\end{array}$ & Organization & 4.08 & 1.11 \\
\hline 2 & $\begin{array}{l}\text { Availability of research that is relevant to clinical } \\
\text { needs }\end{array}$ & Research & 4.02 & 0.92 \\
\hline 3 & $\begin{array}{l}\text { Conducting more clinically focused and relevant } \\
\text { research }\end{array}$ & Research & 3.86 & 1.01 \\
\hline 4 & Improving the understandability of research reports & Communication & 3.80 & 1.08 \\
\hline 5 & $\begin{array}{l}\text { Enhancing the dissemination of new ideas about } \\
\text { patient care to colleagues }\end{array}$ & Organization & 3.68 & 0.93 \\
\hline 6 & $\begin{array}{l}\text { Improving availability and accessibility of research } \\
\text { reports }\end{array}$ & Communication & 3.66 & 1.12 \\
\hline 7 & Providing colleague support network/mechanisms & Organization & 3.65 & 1.00 \\
\hline 8 & $\begin{array}{l}\text { Increasing the time available for reviewing and } \\
\text { implementing research findings }\end{array}$ & Organization & 3.62 & 1.05 \\
\hline 9 & $\begin{array}{l}\text { Improving ability to critically analyze evidence } \\
\text { against set standards }\end{array}$ & Adopter & 3.53 & 1.09 \\
\hline 10 & $\begin{array}{l}\text { Opportunity for research collaboration with } \\
\text { colleagues }\end{array}$ & Research & 3.53 & 1.09 \\
\hline 11 & $\begin{array}{l}\text { Advanced education to increase your research } \\
\text { knowledge base }\end{array}$ & Adopter & 3.52 & 1.14 \\
\hline 12 & $\begin{array}{l}\text { Improving awareness of major information types and } \\
\text { sources }\end{array}$ & Communication & 3.47 & 1.09 \\
\hline 13 & $\begin{array}{l}\text { Advanced education to better improve understanding } \\
\text { of the evidence-based practice process }\end{array}$ & Adopter & 3.44 & 1.17 \\
\hline 14 & $\begin{array}{l}\text { Enhancing managerial/administrative support and } \\
\text { encouragement of research implementation }\end{array}$ & Organization & 3.42 & 1.15 \\
\hline 15 & $\begin{array}{l}\text { Employing athletic trainers with research skills to } \\
\text { serve as role models }\end{array}$ & Organization & 3.05 & 1.26 \\
\hline 16 & $\begin{array}{l}\text { Advanced education to better convert your } \\
\text { information needs into a research question }\end{array}$ & Adopter & 3.03 & 1.18 \\
\hline
\end{tabular}


The frequency in which participants rated items on facilitators as "to a moderate extent" and "to a great extent" is presented in Table 7 in the Appendix. The item 'availability of research that is relevant to clinical needs' was rated as a moderate to great barrier by $84 \%$ ( $n=$ 258) of the participants. This was followed closely by 'increased budget for continuing education courses, workshops, and presentation' with $80 \%(n=245)$ moderate or great extent responses and ‘conducting more clinically focused and relevant research’ with 78\% ( $\mathrm{n}=239)$. The two facilitators that received the fewest moderate or great responses were 'employing athletic trainers with research skills to serve as role models' and 'advanced education to better convert your research needs into a research question' with $44 \%(n=135)$ and $43 \%(n=133)$ respectively.

Two hundred eighty one (91\%) Athletic Trainers completed the question asking them to choose the three greatest facilitators. The two items most frequently rated as one of the top three facilitators were associated with the subcategory characteristics of the organization. Forty three percent of responses listed 'increased budget for continuing education workshops, courses, or presentations' as one of the three greatest facilitators with 'increasing the time available for reviewing and implementing research findings' following with $36 \%$ of total responses. The frequency in which items were selected as the three greatest facilitators can be found in Table 8, p. 66. 
Table 8

Frequency of rating the three greatest facilitators $(N=281)$

\begin{tabular}{|c|c|c|c|}
\hline $\begin{array}{l}\text { Rank } \\
\text { order }\end{array}$ & Facilitator & Characteristic & $\begin{array}{c}\text { Item rated in } \\
\text { three greatest } \\
\text { facilitators } \\
\text { n (\%) }\end{array}$ \\
\hline 1 & $\begin{array}{l}\text { Increased budget for continuing education courses, } \\
\text { workshops, or presentations }\end{array}$ & Organization & $121(43 \%)$ \\
\hline 2 & $\begin{array}{l}\text { Increasing time available for reviewing and } \\
\text { implementing research findings }\end{array}$ & Organization & $102(36 \%)$ \\
\hline 3 & $\begin{array}{l}\text { Conducting more clinically focused and relevant } \\
\text { research }\end{array}$ & Research & $93(33 \%)$ \\
\hline 4 & $\begin{array}{l}\text { Availability of research that is relevant to clinical } \\
\text { needs }\end{array}$ & Research & $70(25 \%)$ \\
\hline 5 & $\begin{array}{l}\text { Improving the understandability of research } \\
\text { reports }\end{array}$ & Communication & $63(22 \%)$ \\
\hline 6 & $\begin{array}{l}\text { Improving availability and accessibility of } \\
\text { research reports }\end{array}$ & Communication & $61(22 \%)$ \\
\hline 7 & $\begin{array}{l}\text { Advanced education to increase your research } \\
\text { knowledge base }\end{array}$ & Adopter & $44(16 \%)$ \\
\hline 8 & $\begin{array}{l}\text { Enhancing the dissemination of new ideas about } \\
\text { patient care to colleagues }\end{array}$ & Organization & $38(14 \%)$ \\
\hline 9 & $\begin{array}{l}\text { Improving ability to critically analyze evidence } \\
\text { against set standards }\end{array}$ & Adopter & $37(13 \%)$ \\
\hline 10 & Providing colleague support network/mechanisms & Organization & $35(12 \%)$ \\
\hline
\end{tabular}

Note: Full table available in appendices

Open Responses for Facilitators. The questionnaire asked participants to list any other facilitator that they would rate to a moderate/great extent; unfortunately only twelve responses were generated $(\mathrm{N}=12)$. A categorical analysis by both the researcher and an independent researcher found that half of the responses were associated with the characteristics of the organization subcategory. Responses included 'funding', 'incentives', 'time', 'administrative support', 'facilities', and 'a budget line to purchase research articles'. A quarter of the responses were found to be related to the characteristics of the communication, including 'free 
access to other professional journals', ‘...EBM would be less intimidating if it were presented in a different way', and 'reimbursement for downloading articles'. The full list of responses, their subcategories, and percent of responses can be found on Table 9 and Figure 1.

Table 9

Open responses to other facilitators question and characteristic $(N=12)$

\begin{tabular}{|c|c|}
\hline Response & Characteristic \\
\hline Better research info at conferences & Adopter \\
\hline Funding & Organization \\
\hline Incentives & Organization \\
\hline Time & Organization \\
\hline Administrative support & Organization \\
\hline A budget line to purchase research articles & Organization \\
\hline Facilities & Organization \\
\hline $\begin{array}{l}\text { There are some athletic trainers who are meant to be in research and some } \\
\text { meant to do the job, those two groups can work together to better patient } \\
\text { care }\end{array}$ & Research \\
\hline Engagement in/with an academic environment & Research \\
\hline Free access to other professional journals & Communication \\
\hline $\begin{array}{l}\text { EBM should not be just focused on reading research articles and writing } \\
\text { research articles, EBM would be less intimidating if it were presented in a } \\
\text { different way. }\end{array}$ & Communication \\
\hline Reimbursement for downloading articles & Communication \\
\hline
\end{tabular}


Figure 1

\section{Percent of Open Responses: Facilitators}

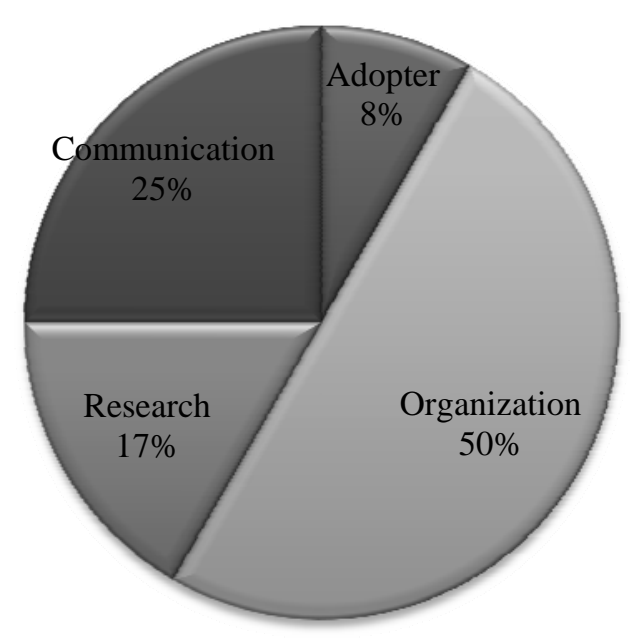

\section{Research Question Three: Barriers to EBP}

Descriptive statistics were used to address to address both parts of research question

three: 1) what are the perceived barriers to EBP use by Athletic Trainers, and 2) how do Athletic Trainers rank the barriers to their use of EBP? Scores below 2.0 represent the two Likert scale options of "to no extent” and “to little extent," while scores above 3.0 represent the two Likert scale options of "to a moderate extent" and "to great extent." Table 10 contains the rank order, mean, standard deviation and associated characteristic of each barrier $(\mathrm{N}=313)$. Only five items contained a mean score above a 3.0 with "the amount of research information is overwhelming” ranking highest $(\mathrm{M}=3.18, \mathrm{SD}=1.23)$. Two of the top five barriers are listed as characteristics of the organization, "the Athletic Trainer does not have time to read research" $(\mathrm{M}=3.12, \mathrm{SD}=$ 1.32) and "the facilities are inadequate for use $(M=3.12, S D=1.20)$. Two of the top five items were also associated with the characteristics of the communication, "statistical analyses are not understandable” $(\mathrm{M}=3.10, \mathrm{SD}=1.22)$ and "relevant literature is not compiled in one place” ( $\mathrm{M}$ 
$=3.08, \mathrm{SD}=1.16)$. Only one item was found to have a mean score below 2.0, "the Athletic

Trainer does not see the value of research for practice” $(\mathrm{M}=1.93, \mathrm{SD}=1.14)$.

Table 10

Barriers to $\operatorname{EBP}(N=313)$

\begin{tabular}{|c|c|c|c|c|}
\hline Rank & Barrier & Characteristic & M & SD \\
\hline 1 & The amount of research information is overwhelming & Not Listed & 3.18 & 1.23 \\
\hline 2 & The athletic trainer does not have time to read research & Organization & 3.12 & 1.32 \\
\hline 3 & The facilities are inadequate for use & Organization & 3.12 & 1.20 \\
\hline 4 & Statistical analyses are not understandable & Communication & 3.10 & 1.22 \\
\hline 5 & Relevant literature is not compiled in one place & Communication & 3.08 & 1.16 \\
\hline 6 & $\begin{array}{l}\text { The athletic trainer feels results are not generalizable } \\
\text { to own setting }\end{array}$ & Organization & 2.96 & 1.17 \\
\hline 7 & The athletic trainer is unaware of the research & Adopter & 2.95 & 1.34 \\
\hline 8 & The literature reports conflicting results & Research & 2.92 & 1.09 \\
\hline 9 & There is insufficient time on the job to use new ideas & Organization & 2.89 & 1.34 \\
\hline 10 & The research has not been replicated & Research & 2.89 & 1.03 \\
\hline
\end{tabular}

Note: Full table available in appendices

The frequency in which participants rated items on the Barriers Scale as "to a moderate extent" and "to a great extent" is presented in Table 11. The item 'the amount of research information is overwhelming' was rated as a moderate to great barrier by $52 \%$ of the participants. This was followed closely by the two items, 'statistical analysis that is not understandable' and ‘the Athletic Trainers not having time to read research’ (51\% each). 
Table 11

Frequency of Rating Barriers to a Moderate or Great Extent $(N=313)$

\begin{tabular}{|c|c|c|c|c|}
\hline $\begin{array}{l}\text { Rank } \\
\text { order }\end{array}$ & Barrier & Characteristic & $\begin{array}{c}\text { Items rated } \\
\text { as a great } \\
\text { or } \\
\text { moderate } \\
\text { barrier } \\
\text { n (\%) }\end{array}$ & $\begin{array}{l}\text { No } \\
\text { Opinion } \\
\mathrm{n}(\%)\end{array}$ \\
\hline 1 & $\begin{array}{l}\text { The amount of research information } \\
\text { is overwhelming }\end{array}$ & Not listed & $161(52 \%)$ & $33(11 \%)$ \\
\hline 2 & $\begin{array}{l}\text { Statistical analyses are not } \\
\text { understandable }\end{array}$ & Communication & $160(51 \%)$ & $21(7 \%)$ \\
\hline 3 & $\begin{array}{l}\text { The athletic trainer does not have } \\
\text { time to read research }\end{array}$ & Organization & 160 (51\%) & $15(5 \%)$ \\
\hline 4 & $\begin{array}{l}\text { The athletic trainers is unaware of the } \\
\text { research }\end{array}$ & Adopter & $146(47 \%)$ & $17(5)$ \\
\hline 5 & $\begin{array}{l}\text { Relevant literature is not compiled in } \\
\text { one place }\end{array}$ & Communication & $141(45 \%)$ & $66(21 \%)$ \\
\hline 6 & The facilities are inadequate for use & Organization & $140(45 \%)$ & $66(21 \%)$ \\
\hline 7 & $\begin{array}{l}\text { The athletic trainer feels results are } \\
\text { not generalizable to own setting }\end{array}$ & Organization & $137(44 \%)$ & $35(11 \%)$ \\
\hline 8 & $\begin{array}{l}\text { There is insufficient time on the job } \\
\text { to use new ideas }\end{array}$ & Organization & $127(41 \%)$ & $31(10 \%)$ \\
\hline 9 & $\begin{array}{l}\text { Implications for practice are not } \\
\text { made clear }\end{array}$ & Communication & $125(40 \%)$ & $25(8 \%)$ \\
\hline 10 & $\begin{array}{l}\text { The athletic trainer does not feel } \\
\text { capable of evaluating the quality of } \\
\text { the research }\end{array}$ & Adopter & 119 (38\%) & $32(10 \%)$ \\
\hline
\end{tabular}

Note: Full table available in appendices

Nine of the items on the Barrier Scale were rated as great to moderate by $40 \%$ or more of the Athletic Trainers (See table 11.1). Four of these items referred to the characteristic of the organization subscale and another three items came from the characteristic of the communication subscale.

More than $20 \%$ of athletic trainers chose the 'no opinion' answer for five of the six items associated with the characteristics of the research subscale. Four of these five items were most frequently rated 'no opinion' by the participants, with 'the research has methodological 
inadequacies’ rated as no opinion by 39\% of Athletic Trainers. See rank order 12, 18, 23, 27 and 29 in Table 11, p.142 of the Appendix.

Two hundred eighty three (91\%) Athletic Trainers completed the question asking them to choose the three greatest barriers. The barrier most frequently chosen was 'the Athletic Trainer does not have time to read research', stated by $29 \%$ of the respondents. The other most frequently selected items were as follows: 'the Athletic Trainer is unaware of the research' (24\%), and 'facilities are inadequate for implementation' (18\%). The frequency in which items were selected as the three greatest barriers can be found in Table 12.

Table 12

Frequency of rating the three greatest barriers $(N=283)$

\begin{tabular}{|c|c|c|c|}
\hline $\begin{array}{l}\text { Rank } \\
\text { order }\end{array}$ & Barrier & Characteristic & $\begin{array}{c}\text { Item rated in } \\
\text { three } \\
\text { greatest } \\
\text { barriers } \\
\mathrm{n}(\%) \\
\end{array}$ \\
\hline 1 & $\begin{array}{l}\text { Athletic Trainer does not have time to read } \\
\text { research }\end{array}$ & Organization & $82(29 \%)$ \\
\hline 2 & Athletic Trainer is unaware of the research & Adopter & $68(24 \%)$ \\
\hline 3 & Facilities are inadequate for implementation & Organization & $52(18 \%)$ \\
\hline 4 & $\begin{array}{l}\text { The amount of research information is } \\
\text { overwhelming }\end{array}$ & Not Listed & $48(17 \%)$ \\
\hline 5 & Statistical analyses are not understandable & Communication & $43(15 \%)$ \\
\hline 6 & $\begin{array}{l}\text { There is insufficient time on the job to } \\
\text { implement new ideas }\end{array}$ & Organization & $43(15 \%)$ \\
\hline 7 & The literature reports conflicting results & Research & $39(14 \%)$ \\
\hline 8 & Implications for practice not made clear & Communication & $38(13 \%)$ \\
\hline 9 & $\begin{array}{l}\text { Relevant literature is not compiled in one } \\
\text { place }\end{array}$ & Communication & $36(13 \%)$ \\
\hline 10 & $\begin{array}{l}\text { Athletic Trainer feels results are not } \\
\text { generalizable to own setting }\end{array}$ & Organization & $36(13 \%)$ \\
\hline
\end{tabular}

Note: Full table available in the appendices 
Open Responses for Barriers. The study yielded only $45(\mathrm{~N}=45)$ responses to the question asking participants to list any other barriers to research use that they could rate from moderate to great extent. The full list of responses along with their associated subcategories can be found in Table 13, p. 146. The percent of responses associated with a further breakdown of each subcategory can be found in Figures 1-5.

Although the list of open responses listing other barriers to EBP was not extensive, a categorical count found that $47 \%$ of responses were associated with items listed in the characteristic of the organization subcategory. Further breakdown of this subcategory showed three common themes that the researcher and an independent researcher identified as cost/resources, time, and colleagues. The most common theme identified by Athletic Trainers was associated with a lack of resources or the cost of implementation. Comments included, “lack of equipment for rehab”, “cost of equipment or additional training”, “computer access”, “facilities available”, and "inadequate resources to perform the studies needed to identify best practices”.

Another 33\% of the responses associated with the characteristics of the organization identified a lack of time as a moderate to great barrier in the use of EBP. Comments in this theme included, “time constraints treating athletes”, “time management”, “often too much research to take the time to search through to find one answer", and "time to conduct and report the research".

The characteristic of the communication subcategory followed with $24 \%$ of the responses. Further breakdown of this subcategory found two common themes, lack of access and patient limitations. The lack of access to research information attributed to $73 \%$ of the responses in the characteristics of the communication subcategory. Comments included, "access 
to free databases, to seek out data, is not available”, "lack of free research articles”, "lack of access to other professional journals”, and “the expense of paying for articles”.

Comments regarding the barriers related to the characteristics of the research attributed to $16 \%$ of the total responses to the open ended question identified above. Three themes were identified within this subcategory; quality of research, understanding, and relevance. The quality of research was identified in $57 \%$ of the comments made in this subcategory.

Thirteen percent of participant responses were attributed to the characteristics of the adopter; these were equally divided into two common themes; values and skills. Responses associated with the values of the adopter included, "no incentive”, “importance to me”, and "not expected to use research in practice”. Comments associated with skills included, “current practitioners who did not study EBP in graduate school do not feel adequately prepared to read and implement the research" and "limited opportunities to use research in setting to personally evaluate their benefit”.

\section{Research Question Four: Barriers and Career Setting}

The fourth research question asked are there are differences in Athletic Trainers' perceptions of barriers related to career settings? A multivariate analysis of variance (MANOVA) was conducted using career setting as the independent variable and the participants' responses as the dependent variables. The MANOVA was chosen to contrast group differences among the multiple dependent variables. The simultaneous nature of this test is done to decrease the chances of making a Type I error, which can be inflated when completing multiple ANOVAs on the same data (Field, 2005).

Participants' responses were separated by the four characteristics of barriers described by Funk et al. (1991a). The scores for each response associated with each characteristic were then 
averaged for each participant, creating four dependent variables. Career setting was used as the independent variable. Table 14 in the appendix contains the mean scores and standard deviations for barrier characteristics related to career setting.

A Box’s Test for homogeneity of variance showed a value of 78.667 with a $p>.05$ ( $p=$ 0.146), therefore the assumption of homogeneity was met (Field, 2005). A one-way multivariate analysis of variance (MANOVA) was conducted to test the hypothesis that there would be one or more mean differences between career setting and perceived barriers to EBP. A statistically significant MANOVA effect was obtained as Pillai's Trace was found to be significant with a $p$ $<0.05$, Pillai's Trace $=.159, F(28,1144)=1.687, p=.014$. Therefore it can be concluded that there is a difference in perceptions of barriers in relation to career setting. Pillai's Trace was utilized in the multivariate test because it has been found to be accurate when sample sizes are not equal (Field, 2005).

Levene's F test of equality of variances was found to be non-significant, $p>0.05$, for all dependent variables, confirming the assumption of homogeneity of variance had been met and strengthening the assumption that the multivariate test statistics are robust. The non- significant nature of Levene's F test also gives confidence in the reliability of the univariate tests that will follow.

The tests of between subjects effects was found to be significant for barriers associated with the characteristics of the communication, $p=0.004$, however it was found to be nonsignificant for the other three characteristics, $p>0.05$. Gabriel's Post-Hoc test was utilized for responses that were found to be significant. Field (2005) states that Gabriel's pairwise test was designed to be utilized when population variances differ, similar to the situation found with career setting. Gabriel's Post-Hoc test of the barriers associated with the characteristics of the 
communication found three groups with significant differences in responses related to career setting. The first difference was found between participants who reported their career setting as Clinic and those who reported their setting to be College/University Athletic only, $p=0.002$. The second significant difference was between Clinic and College/University Mixed academic and athletic, $p=0.024$. The final significant difference was between those working in a Clinic and those who reported "Other" as their career setting, $p=0.027$. Table 15 shows the significant differences of barriers associated with the characteristics of the communication by career setting $(p<.05)$. Tables 16 - 18 in the appendices show the $p$ values for barriers associated with the other three characteristic subgroups.

Table 15

Significant differences of barriers associated to the characteristics of the communication by career setting

\begin{tabular}{lccccccc}
\hline & 1 & 2 & 3 & 4 & 5 & 6 & 7 \\
\hline $\begin{array}{l}\text { 1. College/University - } \\
\text { Academic }\end{array}$ & & & & & & & \\
2. College/University - Athletic & 1.000 & & & & & & \\
3. College/University - Mixed & 1.000 & 1.000 & & & & & \\
4. Clinic & 0.299 & $0.002^{*}$ & $0.024^{*}$ & & & & \\
5. Clinic Outreach & 1.000 & 1.000 & 1.000 & 0.062 & & & \\
(Secondary Schools) & & & & & & & \\
6. Secondary School & 1.000 & 0.983 & 1.000 & 0.082 & 1.000 & & \\
7. Physician Extender & 0.909 & 0.301 & 0.578 & 1.000 & 0.731 & 0.801 & \\
8. Other & 0.947 & 0.998 & 0.988 & $0.027 *$ & 0.931 & 0.773 & 0.332 \\
\hline
\end{tabular}

$* p<.05$ 


\section{Research Question Five: Barriers related to Characteristics}

A one-way repeated measures analysis of variance (ANOVA) was conducted to evaluate the fifth research question which asked are there were differences in how Athletic Trainers rate the barriers to EBP utilization related to the characteristics of the adopter, the organization, the research, and the communication $(N=295)$ ? The results of the one-way repeated ANOVA indicated a significant effect on the four characteristics, Wilks' Lambda $=.805, F(3,292)=$ 23.613, $p<.01, \eta^{2}=.195$. Therefore, there is evidence to reject the null hypothesis that there is no significant difference in the way Athletic Trainers would rate the barriers to EBP utilization related to the four characteristics.

Mauchley's test indicated that the assumption of sphericity had been violated, $X^{2}(5)=$ $15.50, p<.05$, therefore degrees of freedom were corrected using Greenhouse-Geisser estimates of sphericity, $\varepsilon=.97$ (Field, 2005). The results of the tests within subjects show that there were significant differences between how Athletic Trainers rate the four characteristics of barriers to EBP, $F(2.90,851.92)=24.50, p<.05, \eta^{2}=.08$. See Table 19.

Table 19

One-Way Repeated Analysis of Variance Summary Table for the Effects of Athletic Trainers' Rating of Barriers to EBP Utilization

\begin{tabular}{lcccccc}
\hline \multicolumn{1}{c}{ Source } & $d f$ & SS & MS & F & $p$ & $\eta^{2}$ \\
\hline Between-group & 2.90 & 19.54 & 6.74 & 24.50 & .000 & .08 \\
Within-group & 851.92 & 234.55 & 0.28 & & & \\
Total & 854.82 & 254.10 & & & & \\
\hline
\end{tabular}


Bonferroni's procedure for post hoc testing was conducted, as Fields (2005) suggests that Bonferroni's procedure seems to be the most robust is terms of power and control of Type I error when sphericity is violated. Follow up comparisons indicated pairwise differences that were significant, $p<.05$, between the characteristics of the communication and the characteristics of the research, the characteristics of the communication and the characteristics of the adopter, the characteristics of the adopter and characteristics of the organization, and the characteristics of the adopter and characteristics of the research. The characteristic of the adopter was found to be rated significantly lower than the other three characteristics. This indicates that Athletic Trainers' own research values, skills, and awareness are viewed as less of a barrier than the other characteristics. All of these findings are discussed further in chapter 5.

Figure 2

\section{Mean scores for characteristics}

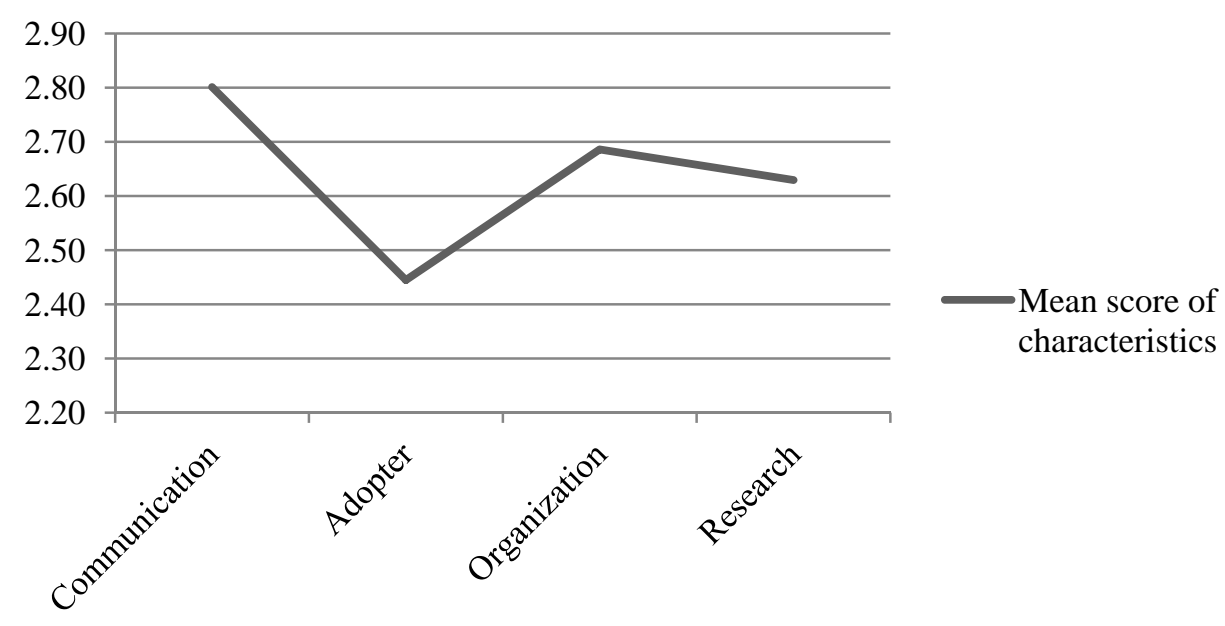




\section{Chapter 5}

\section{Conclusions, Implications, and Recommendations}

This chapter provides a detailed discussion of the research results and their implications. This study investigated the barriers to, and facilitators for, the use of research use by athletic trainers. A recent change to the Athletic Training Educational Competencies requires CAATEaccredited athletic training education programs to make changes to their curricula and students' clinical assessment tools to reflect the incorporation of evidence-based practice. At the same time, Athletic Trainers will be required to attain continuing education units (CEUs) in EBP to maintain their certification. However, many athletic trainers may not have enough experience with EBP concepts to make such alterations to educational practices or to fulfill CEU requirements. Furthermore, to date no researchers have addressed the Athletic Training population, clinical or didactic, regarding barriers to EBP. This dissertation was therefore oriented toward addressing the overall barriers to EBP concepts that athletic trainers have encountered as well as addressing any significant difference in barriers according to career setting.

\section{Significant Findings}

\section{Frequency of Research Use}

The first research question explored the frequency in which athletic trainers use research in their practice. This question contains four parts: the frequency in which athletic trainers use EBP concepts, the frequency of resource use, the recentness of reading research articles, and the number of times in the last year that research was used to alter or develop a treatment plan. 
Frequency of EBP concept use. Many authors identify five main steps in the implementation of EBP; ask, acquire, appraise, apply and evaluate (Bhargava, et al., 2010; Dale, 2006; Prentice, 2011; Raina, et al., 2004; Sackett \& Rosenberg, 1996; Sackett, et al., 2000; Selvaraj, et al., 2010; Steves \& Hootman, 2004; Straus \& Sackett, 1998). Bhargava et al. (2010) condensed the five steps into, “Ask, Acquire, Appraise, Apply, and Evaluate Performance” (p. 146). Although transforming the need for information into an answerable question is the first step in EBP, only 36\% of athletic trainers in this study reported 'often' or 'always' conducting this procedure. However, 50\% of the respondents reported that they 'often’ or 'always' track down evidence once a question has been formulated. An earlier discussion of the study found that both a lack of understanding of statistical analyses and the feeling of not being capable to evaluate research to be among the top ten barriers to EBP. These perceptions may explain why only $28 \%$ of athletic trainers reported 'often' or 'always' critically appraising literature. The frequency in which athletic trainers reported completing the steps to EBP over the past year can be found on Table 2 .

Frequency of resource utilization. The study asked respondents to report the frequency in which they used various resources to access research findings. One hundred ninety two athletic trainers reported that they ‘often' or 'always' use journal articles and texts $(\mathrm{N}=311)$. This finding was closely followed by the utilization of 'continuing education workshops' and ‘conference presentations', which found 189 and 176 responses of ‘often’ or 'always', respectively. Some concern should be drawn in the finding of the fourth most frequently used resource (163), 'electronic databases limited to citations or abstracts', as the clinician would have difficulty evaluating the quality of research based solely on an abstract or citation. Of additional note, is the fact that only 109 athletic trainers reported 'often' or 'always' using full text 
electronic databases. Not surprising, was the finding that athletic trainers utilized 'research specialists' and 'internet discussion groups' least frequently with 251 and 225 respondents reporting 'rarely' to 'never' using these resources respectively. The frequency of resources used to access research can be found on Table 3.

Recentness of reading research articles. Due to trends in other fields, the researcher anticipated that journal articles and texts would be reported as the most frequently utilized source of research information. For this reason, the survey asked respondents about the recentness in which they read research articles from an Athletic Training source as well as from a publication not related to Athletic Training. The data showed that $49 \%$ of athletic trainers read an article from an Athletic Training publication within two weeks of completing the survey. However, only $29 \%$ read an article from a publication not related to Athletic Training within that same timeframe. Furthermore, only 1\% of respondents reported that they 'never' read articles from Athletic Training publications while 7\% reported the ‘never’ reading articles from other publications. The difference in frequency in which athletic trainers read Athletic Training verses other publications is not surprising as members of the NATA are granted digital access to the Journal of Athletic Training, however they may or may not have access to any other professional journals or databases. The recentness in which athletic trainers read publications can be found in Tables 4.1 and 4.2 .

Frequency of using research to develop treatment plans. Respondents were asked to identify the number of times they specifically used current research information to alter or develop a treatment plan within the last year. One hundred six (34\%) athletic trainers responded that they utilized research ' 3 to 5' times in the development of treatment plans in the past year ( $\mathrm{N}$ = 311). Meanwhile, only 13\% of respondents constructed treatment plans for their patients based 
on research findings more than ten times during the same timeframe, and $7 \%$ of athletic trainers reported that they did not use research to alter or develop a patient's treatment plan. The study did not inquire into the number of treatment plans developed per year. Further information regarding the number of times athletic trainers used research to alter or develop a treatment plan can be found on Table 5 .

\section{Facilitators}

The second research question examined the perceived facilitators to research use by Athletic Trainers. The survey contained sixteen items that are believed to facilitate the use of research in clinical decision making. Participants were asked to rate and rank these items as well as to identify any other facilitators to research utilization.

The participants' response of an 'increased budget for continuing education courses, workshops, or presentations’ rated as the greatest facilitator to research use amongst athletic trainers $(\mathrm{M}=4.08, \mathrm{SD}=1.11)$. This is not surprising as there is a tradition of athletic trainers attending conferences and workshops to gain information and Continuing Education Units. For

example, it was estimated that over 11,000 athletic trainers would attend the $65^{\text {th }}$ Annual NATA Clinical Symposia and Athletic Training Expo in late June 2014 in Indianapolis, IN (Events In America, 2014). With a registration fee over \$200, and further expenses such as hotel, food, and travel, an athletic trainer needs a significant budget to participate in such an endeavor. The national symposia is not the only convention in which athletic trainers may attend as state and district divisions of the NATA also offer annual workshops and meetings, creating further opportunities for certified athletic trainers to become abreast of current trends within the profession. Though it is expensive to attend a convention, many athletic trainers overcome this hurdle to gain access to the research information necessary to incorporate EBP concepts. 
Many of the participants' top ten rated facilitators corresponded with the findings of the top barriers such as the 'availability of research that is relevant to clinical needs' $(\mathrm{M}=4.02$, SD $=0.92)$, 'improving understandability of research reports' $(\mathrm{M}=3.80, \mathrm{SD}=1.08)$, and ‘improving availability and accessibility of research reports’ $(\mathrm{M}=3.66, \mathrm{SD}=1.12)$.

One important finding appeared to be that 'increasing time available for reviewing and implementing research findings' rated eighth on the 16 item list $(\mathrm{M}=3.62, \mathrm{SD}=1.05)$. This seemed to be a low rating when considering that the lack of time to read research was rated as the second greatest barrier by the same group $(\mathrm{M}=3.12$, $\mathrm{SD}=1.32)$. However, the next question in the survey asked participants to rate the three greatest facilitators. This question found that $36 \%$ of athletic trainers rated 'increasing time available for reviewing and implementing research findings' among their top three facilitators. This item was the only one that showed a significant difference between the rating of the item and the frequency in which it was rated as one of the three greatest facilitators. This difference may be explained by survey fatigue due to the great number of barrier and facilitator items on the survey. Table 6 contains a rating of the facilitators with mean and standard deviation, while Table 8 lists the frequency in which participants rated each item in the three greatest facilitators.

\section{Barriers}

The third research question explored athletic trainers’ perceived barriers to research utilization. Participants were asked to rate and rank 29 items that were believed to be barriers to research use and identify any other barriers.

The barrier items rated in the top ten from this study can be compared to the findings by Kajermo et al. (2010) findings of nursing implantation of EBP (see Table 20). The athletic trainers who participated in this study rated the item 'The amount of research information is 
overwhelming' as the top barrier $(\mathrm{M}=3.18, \mathrm{SD}=1.23)$. This is interesting as it is the only item that Funk et. al. (1991a) was not able to place into a characteristic subcategory. Therefore, the item is commonly excluded from surveys by other researchers. Of the 53 studies reported by Kajermo et al. (2010), only 27 studies included the item. However, the item rated in the top ten barriers by nurses in 13 of the 27 studies in which it was included. Finding that the amount of research information is overwhelming is of particular interest to athletic training as a number of studies have suggested that quality published research in athletic training practices, including evaluation techniques and management of conditions, either lags behind other health care professions or does not exist (Rahman \& Applebaum, 2010; Starkey, et al., 2010; Steves \& Hootman, 2004). Past difficulties in finding studies on the upper portion of the hierarchy of design in athletic training has lead the researcher to speculate that perhaps it is not the amount of research that is truly overwhelming, but instead it is the difficulty in which finding research that is relevant to one's specific need that creates a sense of being overwhelmed.

The study found that athletic trainers listed four barriers items out of the subcategory associated with the characteristics of the organization in the top ten ratings. 'Not enough time to read research’ $(M=3.12, S D=1.32)$ and ‘inadequate facilities’ $(M=3.12, S D=1.20)$ was rated second and third respectively. The other two items from the characteristics of the organization subcategory included the feeling that 'results are not generalizable to own setting' $(\mathrm{M}=2.96$, SD $=1.17)$ and 'insufficient time on the job to use new ideas' $(\mathrm{M}=2.89, \mathrm{SD}=1.34)$, rated at sixth and ninth respectively. This differs slightly from the findings reported by Kajermo et al. (2010), as nurses were reported to have most frequently rated six barrier items from the organization subscale in their top ten. 
One item associated with characteristics of the organization subscale was found to be of particular interest. Nurses rated the feeling that there is not enough authority to change patient care procedures among the top ten barrier items in 43 studies; this is the third most frequently rated in their top ten. This differs greatly from the athletic trainers' rating as the item was $22^{\text {nd }}$ in the rank order of barrier items $(\mathrm{M}=2.39, \mathrm{SD}=1.30)$. This may be due to the independent nature associated with athletic training. Although athletic trainers practice under the direction of physicians, many prescriptions include treatment options that are vague such as "increase range of motion”, “decrease swelling”, or “return neuromuscular control.” Physician’s orders such as these allow the athletic trainer some freedom to incorporate their own skills and experience into the patient's care plan. This may not be the case with nursing as prescriptions may be more specific, such as a certain dosing for a medication or a specific procedure required for administration of a treatment plan.

Both this study and Kajermo et al.'s found two items associated with the characteristics of the communication subscale that were rated in the top ten barriers. These items were 'statistical analyses are not understandable' $(\mathrm{M}=3.10, \mathrm{SD}=1.22)$ and 'relevant literature is not compiled in one place' $(\mathrm{M}=3.08, \mathrm{SD}=1.16)$. The results suggest that athletic trainers need further education in statistical analysis and research methods. As mentioned in the second chapter, the Commission on Accreditation of Athletic Training Education (CAATE) has mandated that accredited education programs incorporate EBP into their curriculum. This was followed by the Board of Certification (BOC) requiring all certified athletic trainers to complete ten continuing education units (CEUs) on the subject of EBP by December 31, 2015. These mandates may help athletic trainers gain the skills required to enhance their ability to acquire, appraise, and apply research to their patient care. Furthermore, with a greater number of athletic 
trainers seeking information, there may be a greater need for a repository of EBP research to be developed specifically for the profession. This will place relevant literature in a single place.

Athletic trainers were also similar to nurses in being unaware of the research $(M=2.95$, $\mathrm{SD}=1.34)$. This barrier item corresponds with the characteristic of the adopter subscale and was rated as the seventh greatest barrier by athletic trainers and amongst the top ten barriers in 27 nursing studies. Once again, the recent requirement to incorporate EBP into the curriculum as well as with acquiring CEUs associated with EBP to maintain certification through the BOC may help alleviate this issue amongst athletic trainers. Many authors have suggested that further knowledge and skill can be developed through interactive workshops and seminars, a dedicated section in journals that reviews published studies relevant to clinical practices, chapters in text books focused on EBP, and websites allowing clinicians easy access to information (Denegar \& Hertel, 2002; Ingersoll, 2006; Prentice, 2011; Rahman \& Applebaum, 2010; Steves \& Hootman, 2004).

Finally, athletic trainers rated two items associated with the characteristics of the research subscale in their top ten barriers. Athletic trainers rated 'the literature reports conflicting results' $(\mathrm{M}=2.92, \mathrm{SD}=1.09)$ and 'the research has not been replicated' $(\mathrm{M}=2.89$, $\mathrm{SD}=1.03$ ) as the eighth and tenth greatest barrier items respectively. Findings indicate that athletic trainers lack trust in the literature that is being published in the field. This may be due to the limited number of researchers or institutions that conduct and publish research. Those institutions that do publish tend to have a tradition of doing so and the resources necessary to complete such a task. Though it is viewed as imperative to conduct and replicate controlled studies to expand the knowledge base of the profession, the role of many collegiate athletic trainers is primarily that of a clinician who does not receive funding or release time to conduct 
research. Their institutions may not see the value of research in the Athletic Training field, but are more concerned with the health care needs of their student-athletes.

\section{Open Responses of Barriers to Research}

The study received 45 responses to the open ended question that asked participants to list any other barriers to research use that they considered to be rated as to moderate to great extent. The majority of these responses, $47 \%$, were associated with the characteristics of the organization subcategory. The researcher, along with an independent researcher, broke down these responses to three further subcategories of cost/resources, time, and colleague support. Of the three further subcategories, participants listed items that fell in the cost/resources further subcategory ten times (48\%). Responses included comments regarding the cost of equipment or implementation, and the availability, or lack of availability, to computers and equipment. With fewer resources available in secondary schools, the researcher anticipated that the lack of resources would be rated as a greater barrier amongst individuals working in this setting. However, this was not the case as the rating of this item was not significantly different between any of the career settings; this will be further expanded upon later in this chapter.

Twenty-four percent of responses fell into the characteristic of the communication subcategory. Participant responses related to a lack of access to research made up $73 \%$ of the responses within the communication subcategory. Such comments included, “access to free databases to seek out research is not available," "lack of free research articles,” and "lack of access to other professional journals.” There are vast differences in resources available across career settings, which is discussed in the next section. In addition, athletic trainers who are members of the NATA have access to the Journal of Athletic Training. However, not every athletic trainer is a member of the NATA. Furthermore, the research needs of a health care 
profession are unlikely to be contained within the archives of one publication. Therefore, leading Athletic Training organizations need to advocate for broader access to research for its members if it truly intends to facilitate EBP procedures.

Finally, the researcher found a comment out of the characteristics of the adopter subcategory of interest; “current practitioners who did not study EBP in graduate school do not feel adequately prepared to read and implement the research.” This comment is of note as there is a debate over the entry level degree for athletic trainers (Oliaro \& Winterstein, 2014;

Richardson, 2014). Some feel that the profession should maintain the status quo by requiring a bachelor's degree prior to attempting the BOC examination. Others feel that athletic training should follow that of other health care professions and require students to obtain a master's degree in athletic training to be eligible to sit for the exam. While the topic of appropriate entry level degree is not the focus of this study, it is important to realize that research experience may be correlated to degree status (Dysart \& Tomlin, 2002) and crucial to facilitating EBP techniques in the clinical practice.

\section{Career Setting and Barriers}

The fourth research question examined if there were differences in Athletic Trainers’ perception of barriers according to career setting. The data was analyzed using a multivariate analyses of variance (MANOVA) with the participants' mean response scores for each of the four characteristics of barriers as the dependent variable and their career setting as the independent variable. The MANOVA was chosen for data analysis as it has a decreased chance of a Type I error compared to an ANOVA (Field, 2005).

As stated in chapter four, a statistically significant MANOVA effect was obtained as Pillai's Trace was found to be significant with a $p<0.05$, Pillai's Trace $=.159, F(28,1144)=$ 
1.687, $p=.014$. Therefore it is concluded that there is a difference in perceptions of barriers in relation to career setting.

A test of between subjects effects was conducted and found that only the responses in one characteristic subcategory was found to have a significant difference in relation to career setting, the characteristic of the communication $(p=0.004)$. Gabriel's Post-Hoc test was chosen to identify the significant differences within career setting as it was designed to be utilized when population variances differ, such as the case with this research (Field, 2005). Gabriel's test found three groups with significant differences. All three groups involved participants who reported their career setting as Clinic. Group differences were found in the following: Clinic to College/University - Athletic Only $(p=0.002)$, Clinic to College/University - Mixed Athletic and Academic ( $p=0.024)$, and Clinic to Other $(p=0.027)$.

The characteristic of the communication subcategory relates to the presentation and accessibility of the research. The BARRIERS Scale questionnaire consists of six items within this subcategory; items include 'implications for practice not made clear', 'research not readily available', 'research not reported clearly or readably', 'statistical analyses that is not understandable', 'relevant literature not compiled in one place' and 'research that is not relevant to the athletic trainer's practice'.

Participants who reported their career setting as 'Clinic' were found to have a lower mean score for barriers within the characteristics of the communication subscale than their colleagues who reported their career setting as College/University Athletic only, College/University Mixed Athletic and Academic, and Other. The finding indicates that the participants working in the clinic rated items associated with communication to be significantly less of a barrier than that of the counterpart groups listed above. The rationale for why such a difference exists may be the 
greater likelihood of working with other health care professionals in the clinic, an increased variance in patient population and need for care, and greater knowledge of or access to resources due to collaborations with other health care providers. It also suggests that the college setting may be more isolating for athletic trainers. To address this issue, athletic trainers working at the collegiate setting may consider collaborating with colleagues from their respective athletic conferences, peers from nearby institutions, and clinicians working in other settings such as local clinics and secondary schools. These athletic trainers may also benefit from opportunities to conduct research alongside graduate faculty and students.

There were no significant differences found between career settings for the three remaining barrier subcategories. This finding suggests that the setting of employment does not influence the way athletic trainers rate the barriers to research use for the characteristics of the adopter, of the organization, and of the research. This lack of significant differences indicates that future programs designed to encourage the use of EBP in clinical decision making need not focus on the career setting.

\section{Differences between Characteristics}

The fifth research question asks if there were differences in how Athletic Trainers rated the barriers to EBP utilization related to the characteristics of the adopter, the organization, the research, and the communication. A one-way repeated ANOVA yielded evidence to reject the null hypothesis that there is no significant difference in the way Athletic Trainers would rate the barriers to EBP utilization related to the four characteristics, Wilks’ Lambda $=.805, F(3,292)=$ 23.613, $p<.01, \eta^{2}=.195$. Follow up comparisons indicated pairwise differences that were significant, $p<.05$, between four groups; the characteristics of the communication and the 
characteristics of the research, and the characteristics of the adopter and all three of the other characteristic subcategories.

The characteristics of the adopter subcategory was found to have a significantly lower rating as barriers than its three counterparts. This was not surprising as only one item in the adopter subcategory was rated in the top ten barriers, 'the athletic trainer is unaware of the research'. Furthermore, the three items rated as having the least extent of being a barrier came from the characteristics of the adopter subcategory: 'the athletic trainer sees little benefit for self', 'the athletic trainer is unwilling to change/try new ideas', and 'the athletic trainer does not see value of research for practice'. These findings indicate that the NATA's recent push toward the use of EBP, as well as the requirement to gain continuing education units focused on EBP to maintain certification, is working as athletic trainers see value in the use of research in their clinical practice. Furthermore, the study indicates that athletic trainers are willing to try new techniques to improve patient care, and they see that they may benefit from a higher quality of care. However, the study also indicates that athletic trainers do not feel confident with their ability to evaluate the quality of research, nor are they aware of the research that exists. Therefore, if the profession is to move forward with the incorporation of EBP techniques in patient care, it is imperative that athletic trainers become aware of where to find research, how to understand common statistics associated with research, how to evaluate the quality of research, and how research can be used to change patient care.

The researcher was surprised that, overall, athletic trainers did not perceive any characteristics as moderate or great barriers (see Figure 2, p. 77). The results indicate that barriers to research utilization have minimal influence over the implementation of EBP by athletic trainers. One possible reason for these unexplained findings may be that research is not 
part of the participants’ daily athletic training practices and therefore they may not have had strong opinions in mind when answering these questions. In fact, 39\% of athletic trainers responded to at least one item in the characteristics of the research subscale as having 'no opinion'. Meanwhile, this subscale contains specific questions regarding the qualities of research, such as 'the research has methodological inadequacies' and 'the literature has not been replicated'. The frequent response of ‘no opinion' may have influenced the mean score for barriers to utilization. The lack of opinion may really indicate a decrease of understanding, especially amongst athletic trainers may not utilize research in their daily practice. The high rate of 'no opinion' response is consistent with previous studies conducted in the nursing profession (Brown, et al., 2010; McCleary \& Brown, 2003; Kader Parahoo, 2000).

\section{Implications for the Athletic Training Profession}

This research provides many contributions to the field of athletic training as it is the first to identify the barriers and facilitators to research utilization within the profession. The results of this study may serve as a source of information for the development of future EBP technique workshops, presentations, and programs. For example, the study found that educational programs need not focus on differences within career setting but instead focus on how to develop athletic trainers' skills in evaluating quality of research. This research also found that athletic trainers are not aware of a primary source for gaining relevant information and that there is a need for athletic trainers to have greater access to literature from other health care professions. The study also found the need for research that is generalizable to the clinicians needs and written in a clear and understandable manner.

The rising cost of medical procedures as well as increase in individual healthcare options has caused health care providers seeking to enhance their reputation within the health field, such 
as Athletic Trainers, to integrate EBP into clinical care. This comes from the belief that the use of research to influence clinical decisions may increase patient satisfaction through a decrease in time lost due to injury, as well as a decline in complications due to improper or delayed healing. The use of evidence in clinical decision making may also positively affect accountability, as the products, treatment plans, or devices that clinicians implement will be proven to be cost efficient and effective.

While professional organizations associated with Athletic Training have required students and practitioners to gain an understanding of EBP, there is still a void in information regarding the difficulties practitioners experience when trying to find, read, and apply research. The information found in this study may fill that gap by increasing the knowledge of barriers, facilitators, and frequency of research use by professionals. The study may also help educators design workshops, presentations, and educational programs that can be used to further promote the use of research in practice so that EBP may someday be part of the culture of the profession.

\section{Implications for Higher Education Administration}

Athletic Training is not alone in the movement to become a research-informed profession, as this trend is evident in many fields including medicine, architecture, education, engineering, and transportation design (Bones, et al., 2013; Johnson \& Maclean, 2008). The information gleaned in this study may be relatable to other professions as the study found a number of similarities to barriers identified by studies previously conducted with other health care professions. Such similarities include a lack of time to read research, the feeling that the amount of research is overwhelming, a poor understanding of statistics, a perception of not being capable of evaluating the quality of research, and an impression that facilities are inadequate to incorporate research into practice. However, some findings were unique to the profession, such 
as the heavy reliance on continuing education workshops and presentations as a source of current research information and the feeling that EBP will not hinder the athletic trainer's authority to change practice.

As professions move toward utilizing research to make informed decisions, higher education may be required to meet stakeholders’ desire for graduates with experience using research in practice. Major stakeholders may include professional associations, accrediting bodies, businesses, government officials, alumni and other members of the campus community. The increased desire to be evidence-informed will cause a greater need for access to research, causing administrators to alter the way they allocate resources. Program directors may also be affected as educators will need to alter or develop their curricula to implement the use of research throughout the students’ academic career.

The data found in this study may assist administrators and educators in the development of educational programs. The increase in knowledge of barriers and facilitators offered by this study may inform university officials to the needs of their students and stakeholders, thus influencing the allocation of resources. Furthermore, the use of research must be evident in the professionalization and socialization of students for professions to move toward an evidenceinformed culture.

\section{Recommendations for Future Research}

The study was limited by time and the honest responses of the participants. The researcher began data collection 30 days after the participants received the questionnaire. Future studies should consider allowing a longer time frame for participation. The questionnaire used by this study was robust as it included sections on barriers, facilitators, frequency of EBP concepts and research use, and demographics; many of these sections contained multiple 
questions or a high volume of responses. The length of the questionnaire may have limited the number of completions. Therefore, it is recommended that future research consider creating a questionnaire that would not require as much time or as many responses by participants.

Researchers may also consider breaking the questionnaire up into a few different studies.

The participants in this study were limited to Certified-Regular members of the NATA. While this population is made up of a significant number of athletic trainers, findings may not represent the perceptions and experiences of the full body of the profession. Therefore, future research should expand the sample to include students in the professional phase of education as well as athletic trainers who are not members of the NATA.

While this study focuses on the profession of Athletic Training, the results found may have implications for professions aspiring to make the transition to an evidence-informed profession. Therefore, this study should be replicated by future researchers with practitioners in other professions such as medicine, architecture, education, engineering, and transportation design as sample populations.

The researcher suggests that future studies focus not just on the differences in barriers to, facilitators of, and frequency of research use by career setting, but also on differences that may be found due to other variables such as, years of experience, age of the participant, highest degree earned, whether that degree was from an accredited program or in another field, and experience with research during undergraduate or graduate education.

Other studies may also focus on the exact publications, databases, websites, and other sources of research used by practitioners and students. Finally, the researcher believes that his study should be replicated in the future to see if the requirement for EBP focused continuing 
education units and subsequent increase in EBP workshops influences the barriers to research use among athletic trainers.

\section{Conclusion}

The information gained in this study revealed a number of factors that should be addressed in order to promote the use of research by Athletic Trainers. First, practitioners need a greater understanding of research utilization and the steps to EBP concepts. Specifically, Athletic Trainers need to know how to begin the EBP process by writing an answerable question. These professionals must also further understand the implication of research use in practice, increase their comprehension of statistical analysis, and improve their ability to critically analyze evidence. Next, there needs to be improved availability and access to research, preferably existing in one location. The research must also be clinically focused and relevant to the needs of the practitioner. Organizations should consider increasing the time available for clinicians to review and implement research. Professionals should also be given a greater opportunity to enhance knowledge through continuing education, workshops, and presentations. Collaboration with experienced researchers and the development of a colleague support network may also advance research comprehension.

Athletic Training developed from a need to provide health care services for studentathletes in colleges and universities (Ebel, 1999). Hudson and Irwin (2010) suggest that the profession's history has caused it to adopt the beliefs, values, and assumptions that are consistent with the organizational culture of college sports, rather than the beliefs, values, and assumptions held by other health care providers. Practitioners' use of research to make informed decisions may be a catalyst to transform the Athletic Trainer's culture away from that of collegiate athletics and toward that of other healthcare professions. 


\section{References}

Abbott, A. (1988). The System of Professions: An Essay on the Division of Expert Labor. Chicago: The University of Chicago Press.

Alsop, A. (1997). Evidence-based practice and continuing professional development. British Journal of Occupational Therapy, 60, 503-508.

Baldwin, S. L. (2010). The use of a proficiency-based clinical tool in the evaluation of clinical knowledge and skills in the athletic training setting. Masters of Science in Athletic Training master's thesis, West Virginia University, Morgantown, WV. Dissertation Abstract Database database.

Baughman, J., Brumm, T., \& Mickelson, S. (2012). Student professional development: Competency-based learning and assessment. [Case Study]. Journal of Technology Studies, 38(2), 115-127.

Bhargava, D., Al-Abri, R., \& Bhargava, K. (2010). Evolving Trends in Evidence Based Practice: Use of Internet to Retrieve Evidence at Point of Care. [Article]. Oman Medical Journal, 25(2), 1-3. doi: 10.5001/omj.2010.41

Board of Certification for the Athletic Trainer. (2012). The BOC 2012 Annual Report. Omaha: Board of Certification, Inc.

Bones, E. J., Barrella, E. M., \& Amekudzi, A. A. (2013). Implementation of evidence-based design approaches in transportation decision making. [Article]. Transportation Research Part A: Policy \& Practice, 49, 317-328. doi: 10.1016/j.tra.2013.01.017

Boström, A.-M., Wallin, L., \& Nordström, G. (2007). Evidence-based practice and determinants of research use in elderly care in Sweden. Journal of Evaluation in Clinical Practice(13), 665-673. 
Brown, C. E., Ecoff, L., Kim, S. C., Wickline, M. A., Rose, B., Klimpel, K., \& Glaser, D. (2010). Multi-institutional study of barriers to research utilisation and evidence-based practice among hospital nurses. [Article]. Journal of Clinical Nursing, 19(13/14), 19441951. doi: 10.1111/j.1365-2702.2009.03184.x

Brown, C. E., Wickline, M. A., Ecoff, L., \& Glaser, D. (2009). Nursing practice, knowledge, attitudes and perceived barriers to evidence-based practice at an academic medical center. [Article]. Journal of Advanced Nursing, 65(2), 371-381. doi: 10.1111/j.13652648.2008.04878.x

Bryar, R., Closs, S., Baum, G., Cooke, J., Griffiths, J., Hostick, T., . . Thompson, D. (2003). The Yorkshire BARRIERS project; A diagnostic analysis of barriers to research utilization. International Journal of Nursing Studies, 40, 73-84.

Cahill, S. E. (1999). The boundaries of professionalization: The case of North American funeral direction. [Article]. Symbolic Interaction, 22(2), 105-119.

Casa, D. J. (2005). Question Everything: The Value of Integrating Research Into an Athletic Training Education, Editorial, Journal of Athletic Training, pp. 138-138. Retrieved from http://search.ebscohost.com/login.aspx?direct=true\&db=a9h\&AN=19163901\&site=ehost -live

Commission on Accreditation of Athletic Training Education. (2010). Accredited Programs Retrieved Novemeber 28, 2010, from http://caate.net/

Commission on Accreditation of Athletic Training Education. (2014). Additional outcome information Retrieved September 7, 2014, from http://caate.net/additional-outcomeinformation/ 
Cope, D. (2003). Evidence-based practice: Making it happen in your clinical setting. Clinical Journal of Oncology Nursing, 7(1), 97-99.

Crane, J., Pelz, D., \& Horsley, J. A. (1977). CURN project research utilization questionnaire. Ann Arbor, MI: Conduct and Utilization of Research in Nursing Project, School of Nursing, University of Michigan.

Dale, A. E. (2006). Determining guiding principles for evidence-based practice. Nursing Standard, 20(25), 41-46.

Davies, H., Nutley, S., \& Mannion, R. (2000). Organisational culture and quality of health care. Quality in Healthcare(9), 111-119.

Delforge, G. D., \& Behnke, R. S. (1999). The history and evolution of athletic training education in the United States. [Article]. Journal of Athletic Training, 34(1), 53.

Denegar, C., \& Hertel, J. (2002). Clinical education reform and evidence-based clinical practice guidelines. Journal of Athletic Training, 37(2), 127.

Dickersin, K., Straus, S. E., \& Bero, L. A. (2007). Increasing, not dictating, choice. [Article]. BMJ: British Medical Journal (International Edition), 334, s10.

Dimmitt, M. A., Jr. (2004). Organizational culture, faculty culture, and faculty professionalization in an urban community college system. 3145959 Doctoral Dissertation, University of Missouri - Kansas City, Ann Arbor.

Duncan-Hewitt, W. (2005). The Development of a Professional: Reinterpretation of the Professionalization Problem From the Perspective of Cognitive/Moral Development. American Journal of Pharmaceutical Education, 69(1-5), 44-54. 
Dysart, A. M., \& Tomlin, G. S. (2002). Factors related to evidence-based practice among US occupational therapy clinicians. American Journal of Occupational Therapy, 56(3), 275284.

Dyson, J. (1997). Research: promoting positive attitudes through education. [Article]. Journal of Advanced Nursing, 26(3), 608-612. doi: 10.1111/1365-2648.ep4514145

Ebel, R. (1999). Far Beyond the Shoe Box: Fifty Years of the National Athletic Trainers' Association. New York: Forbes Cutom Publishing.

Egan, M., Dubouloz, C., von Zweck, C., \& Vallerand, J. (1998). The client-centered evidencebased practice of occupational therapy. Canadian Journal of Occupational Therapy, 65, 136-143.

Estabrooks, C. (1998). Will evidence-based nursing practice make practice perfect? Canadian Journal of Nursing Research, 30, 15-36.

Estabrooks, C., Floyd, J., Scott-Findlay, S., O'Leary, K., \& Gushta, M. (2003). Individual determinants of research utilization: a systemic review. Journal of Advanced Nursing, 43, 506-520.

Estabrooks, C., Rutakumwa, W., O'Leary, K., Profetto-McGrath, J., Milner, M., Levers, M., \& Scott-Findlay, S. (2005). Sources of practice knowledge among nurses. Qualitative Health Research, 15, 460-476.

Estabrooks, C. A., Scott, S., Squires, J. E., Stevens, B., O'Brien-Pallas, L., Watt-Watson, J., .. . Williams, J. (2008). Patterns of research utilization on patient care units. [Article]. Implementation Science, 3, 1-16. doi: 10.1186/1748-5908-3-31

Events In America. (2014). NATA 65th Annual Meeting and Clinical Symposia Retrieved August 1, 2014, from http://www.eventsinamerica.com/events/nata-65th-annual-meeting- 


\section{and-clinical-symposia-national-athletic-trainers-}

\section{association/ev4c62f56eee148/\#.U9wS060jwVA}

Falk, C. F., \& Savalei, V. (2011). The Relationship Between Unstandardized and Standardized Alpha, True Reliability, and the Underlying Measurement Model. [Article]. Journal of Personality Assessment, 93(5), 445-453. doi: 10.1080/00223891.2011.594129

Field, A. (2005). Discovering Statistics Using SPSS (2nd ed.). London: SAGE Publications Ltd.

Frasure, J. (2008). Analysis of instruments measuring nurses' attitudes towards research utilization: a systematic review. Journal of Advanced Nursing, 61(1), 5-18. doi: 10.1111/j.1365-2648.2007.04525.x

Freidson, E. (1994). Professionalism reborn: Theory, prophecy and policy. Chicago: University of Chicago Press.

Funk, S., Champagne, M., Wiese, R., \& Tornquist, E. (1991a). BARRIERS: the barriers to reseach utilization scale. Applied Nursing Research, 4, 39-45.

Funk, S., Champagne, M., Wiese, R., \& Tornquist, E. (1991b). Barriers to using research findings in practice: the clinician's perspective. Applied Nursing Research, 4, 90-95.

Funk, S., Tornquist, E., \& Champagne, M. (1995). Barriers and facilitators of research utilization: An integrative review. Nursing Clinics of North America, 30(3), 395-407.

Funk, S. G., Champagne, M. T., Wiese, R. A., \& Tornquist, E. M. (1991a). Barriers: The barriers to research utilization scale. Applied Nursing Research, 4(1), 39-45. doi: 10.1016/s08971897(05)80052-7

Georgiou, A. (2002). Data, information and knowledge: the health informatics model and its role in evidence-based medicine. [Article]. Journal of Evaluation in Clinical Practice, 8(2), 127-130. doi: 10.1046/j.1365-2753.2002.00345.x 
Gerrish, K., Ashworth, P., Lacey, A., Bailey, J., Cooke, J., Kendall, S., \& McNeilly, E. (2007). Factors influencing the development of evidence-based practice: a research tool. [Article]. Journal of Advanced Nursing, 57(3), 328-338. doi: 10.1111/j.13652648.2006.04112.x

Glacken, M., \& Chaney, D. (2004). Perceived barriers and facilitators to implementing research findings in the Irish practice setting. Journal of Clinical Nursing, 13, 731-740.

Hatcher, S., \& Tranmer, J. (1997). A survey of variables related to research utilization in nursing practice in the acure care setting. Canadian Journal of Nursing Administration, 10, 3153.

Haynes, R. B. (1993). SOme problems in applying evidence in clinical practice. Annals of the New York Academy of Sciences, 703, 210-225.

Heiwe, S., Kajermo, K. N., Tyni-Lenné, R., Guidetti, S., Samuelsson, M., Andersson, I.-L., \& Wengström, Y. (2011). Evidence-based practice: attitudes, knowledge and behaviour among allied health care professionals. [Article]. International Journal for Quality in Health Care, 23(2), 198-209.

Hermanowicz, J. (Ed.). (2011). The American Academic Profession: Transformation in Contemporary Higher Education. Baltimore: The Johns Hopkins Press.

Hertel, J. (2005). Research Training for Clinicians: The Crucial Link Between Evidence-Based Practice and Third-Party Reimbursement, Editorial, Journal of Athletic Training, pp. 6970. Retrieved from http://search.ebscohost.com/login.aspx?direct=true\&db=a9h\&AN=17462254\&site=ehost $\underline{\text {-live }}$ 
Holm, M. (2000). Our mandate for the new millennium: Evidence-based practice, 2000 Eleanor Clarke Slagle lecture. American Journal of Occupational Therapy, 54, 575-585.

Hudson, M. B., \& Irwin, Z. (2010). Uncovering organizational culture: A necessary skill for Athletic Trainers. [Article]. Athletic Therapy Today, 15(1), 4-8.

Hutchinson, A. M., \& Johnston, L. (2004). Bridging the divide: a survey of nurses' opinions regarding barriers to and facilitators of reseach utilization in the prctice setting. Journal of Clinical Nursing, 13, 304-315.

Ingersoll, C. D. (2006). It's Time for Evidence. [Article]. Journal of Athletic Training, 41(1), 7-7.

Johnson, \& Maclean, R. (Eds.). (2008). Teaching: Professionalization, Development and Leadership. Bonn, Germany: Springer.

Johnson, C. (2006). Getting started in evidence-based practice for childhood speech-language disorders. American Journal of Speech-Language Pathology, 15, 20-35.

Kahanov, L., \& Eberman, L. E. (2011). Age, Sex, and Setting Factors and Labor Force in Athletic Training. [Article]. Journal of Athletic Training, 46(4), 424-430.

Kajermo, K. N., Nordström, G., Krusebrant, Å., \& Björvell, H. (1998). Barriers to and facilitators of research utilization, as perceived by a group of registered nurses in Sweden. [Article]. Journal of Advanced Nursing, 27(4), 798-807.

Kajermo, K. N., Nordström, G., Krusebrant, Å., \& Björvell, H. (2000). Perceptions of research utilization: comparisons between health care professionals, nursing students and a reference group of nurse clinicians. Journal of Advanced Nursing, 31(1), 99-109. doi: 10.1046/j.1365-2648.2000.01255.x 
Kajermo, K. N., Nordström, G., Krusebrant, Å., \& Lutzen, K. (2001). Nurses' experiences of research utilization within the framework of an educational programme. Journal of Clinical Nursing(10), 671-681.

Kane, M., Crooks, T., \& Cohen, A. (1999). Validating measures of performance. Educational Measurement: Issues and Practices, 18(2), 5-17.

Klossner, J. (2008). The role of legitimation in the professional socialization of second-year undergraduate Athletic Training students. [Article]. Journal of Athletic Training, 43(4), 379-385.

Larson, M. (1977). The rise of professionalism. Berkeley: University of California Press.

Law, M., \& Baum, C. (1998). Evidence-based occupational therapy. Canadian Journal of Occupational Therapy, 65, 131-135.

Lawson, H. A. (1983a). Toward a Model of Teacher Socialization in Physical Education: Entry into Schools, Teachers' Role Orientations, and Longevity in Teaching (Part 2). Journal of Teaching in Physical Education, 3(1), 3-15.

Lawson, H. A. (1983b). Toward a Model of Teacher Socialization in Physical Education: The Subjective Warrant, Recruitment, and Teacher Education. Journal of Teaching in Physical Education, 2(3), 3-16.

Lyons, C., Brown, T., Tseng, M. H., Casey, J., \& McDonald, R. (2011). Evidence-based practice and research utilisation: Perceived research knowledge, attitudes, practices and barriers among Australian paediatric occupational therapists. [Article]. Australian Occupational Therapy Journal, 58(3), 178-186. doi: 10.1111/j.1440-1630.2010.00900.x

Majid, S., Foo, S., Luyt, B., Xue, Z., Yin-Leng, T., Yun-Ke, C., \& Mokhtar, I. A. (2011). Adopting evidence-based practice in clinical decision making: nurses' perceptions, 
knowledge, and barriers. [Article]. Journal of the Medical Library Association, 99(3), 229-236. doi: 10.3163/1536-5050.99.3.010

Manspeaker, S., \& Van Lunen, B. L. (2011). Overcoming barriers to implementation of evidence-based practice concepts in athletic training education: Perceptions of select educators. Journal of Athletic Training, 46(5), 514-522.

Mazerolle, S. M., Bowman, T. G., \& Dodge, T. M. (2014). The professional socialization of the Athletic Trainer serving as a preceptor. [Article]. Journal of Athletic Training, 49(1), 7582. doi: $10.4085 / 1062-6050-48.6 .16$

McCleary, L., \& Brown, G. T. (2003). Barriers to paediatric nurses' research utilization. Journal of Advanced Nursing, 42(4), 364-372. doi: 10.1046/j.1365-2648.2003.02628.x

McEvoy, M. P., Williams, M. T., \& Olds, T. S. (2010). Development and psychometric testing of a trans-professional evidence-based practice profile questionnaire. [Article]. Medical Teacher, 32(9), e366-e373. doi: 10.3109/0142159x.2010.494741

McKeon, P., Medina, J. M., \& Hertel, J. (2006). Hierarchy of Research Design in EvidenceBased Sports Medicine. [Article]. Athletic Therapy Today, 11(4), 42-45.

McKnight, M. (2006). The information seeking of on-duty critical care nurses: evidence from participant obervation and in-context interviews. Journal of the Medical Library Association: JMLA, 94, 145-151.

Mensch, J., Crews, C., \& Mitchell, M. (2005). Competing perspectives during organizational socialization on the role of Certified Athletic Trainers in high school settings. [Article]. Journal of Athletic Training, 40(4), 333-340.

Miller, L. L., Ward, D., \& Young, H. M. (2010). Evidence-Based Practices in Nursing. [Article]. Generations, 34(1), 72-77. 
Moore, G. C., \& Benbasat, I. (1991). Development of an Instrument to Measure the Perceptions of Adopting an Information Technology Innovation. Information Systems Research, 2(3), 192-222. doi: 10.2307/23010883

National Athletic Trainers' Association. (2010). Athletic Training Educational Competencies (Draft) Retrieved from http://cf.nata.org/ns/educationalcompetencies/5thEdCompetencies_Draft.pdf

National Athletic Trainers' Association. (2012a). August 2012 NATA Membership by Class and District. Retrieved from National Athletic Trainers Association website: http://members.nata.org/members1/documents/membstats/2012-08.htm

National Athletic Trainers' Association. (2012b). Evidence based education Retrieved February 2, 2012, from http://www.nata.org/EvidenceBasedEdu

National Athletic Trainers' Association. (2014a). Athletic Training Education Overview Retrieved September 6, 2014, from http://www.nata.org/sites/default/files/AT$\underline{\text { EducationOverview.pdf }}$

National Athletic Trainers' Association. (2014b). Membership Statistics: 2013 Year-End Statistics Retrieved November 10, 2014, from http://members.nata.org/members1/documents/membstats/2013EOY-stats.htm National Athletic Trainers' Association. (2014c). Profile of Athletic Trainers Retrieved September 5, 2014, from http://www.nata.org/sites/default/files/Athletic_Trainer_Profile.pdf

National Athletic Trainers' Association. (2014d). Terminology Retrieved January 21, 2014, from http://www.nata.org/athletic-training/terminology 
Neldon, G. B. (2009). Electronic clinical journaling: The use of Weblogs to support evidencebased practice in doctor of audiology students Doctor of Education Dissertation, West Virginia University, Morgantown.

Nelson, T. D., \& Steele, R. G. (2007). Predictors of Practitioner Self-reported Use of EvidenceBased Practices: Practitioner Training, Clinical Setting, and Attitudes Toward Research. [Article]. Administration \& Policy in Mental Health \& Mental Health Services Research, 34(3), 319-330. doi: 10.1007/s10488-006-0111-X

Niederhauser, V. P., \& Kohr, L. (2005). Research endeavors among pediatric nurse practitioners (REAP) study. Journal of Pediatric Health Care, 19(2), 80-89. doi: http://dx.doi.org/10.1016/j.pedhc.2004.08.007

Nilsson Kajermo, K., Unden, M., Gardulf, A., Eriksson, L., Orton, M., Arnetz, B., \& Nordström, G. (2008). Predictors of nurses' perceptions of barriers to research utilization. Journal of Nursing Management(16), 305-314.

Oliaro, S., \& Winterstein, A. (2014). The Education Debate Continues. NATA News, March 2014, $8-11$.

Ottenbacher, K., Barris, R., \& Van Deusen, J. (1986). Some issues related to research utilization in occupational therapy. American Journal of Occupational Therapy, 40, 111-116.

Pain, K., Magill-Evans, J., Darrah, J., Hagler, P., \& Warren, S. (2004). Effects of profession and facility type on research utilization by rehabilitation professionals. Journal of Allied Health, 33(1), 3-9.

Parahoo, K. (2000). Barriers to, and facilitators of, research utilization among nurses in Northern Ireland. Journal of Advanced Nursing, 31(1), 89-98. doi: 10.1046/j.13652648.2000.01256.x 
Parahoo, K., Barr, O., \& McCaughan, E. (2000). Research utilization and attitudes towards research among learning disability nurses in Northern Ireland. Journal of Advanced Nursing, 31(3), 607-613. doi: 10.1046/j.1365-2648.2000.01316.x

Pitney, W. A., \& Parker, J. (2001). Qualitative Inquiry in Athletic Training: Principles, Possibilities, and Promises. [Article]. Journal of Athletic Training, 36(2), 185.

Pravikoff, D. S., Tanner, A. B., \& Pierce, S. T. (2005). Readiness of U. S. Nurses for EvidenceBased Practice. [Article]. American Journal of Nursing, 105(9), 40-51.

Prentice, W. E. (2011). Principles of Athletic Training: A Competency-Based Approach (14 ed.). New York: McGraw-Hill.

The Professions and Socialization. (2001). [Article]. ASHE-ERIC Higher Education Report, 28(3), 1.

Rahman, A., \& Applebaum, R. (2010). What's All This about Evidence-Based Practice? The roots, the controversies, and why it matters. [Article]. Generations, 34(1), 6-12.

Raina, P., Massfeller, H., \& Macarthur, C. (2004). Athletic Therapy and Injury Prevention: Evidence-Based Practice. [Article]. Athletic Therapy Today, 9(6), 10-14.

Reinhardt, J. P. (2010). Research Methods in Evidence-Based Practice: Understanding the Evidence. [Article]. Generations, 34(1), 36-42.

Rich, V. J., Kedrowski, J. J., \& Richter, S. (2008). Institutional profiles of CAATE accredited entry-level athletic training educatin programs in the United States. Athletic Training Education Journal, 3(Jul-Sep), 108-114.

Richardson, R. (2014). An Update on the Professional Degree Debate. NATA News, March 2014, $12-15$. 
Sackett, D. L., \& Rosenberg, W. M. C. (1996). Evidence based medicine: What it is and what it isn't. [Article]. BMJ: British Medical Journal (International Edition), 312(7023), 71-72.

Sackett, D. L., Straus, S. E., Richardson, W. S., Rosenberg, W., \& Haynes, R. B. (2000). Evidence-Based Medicine: How to Practice and Teach EBM (2 ed.). Edinburgh: Churchill Livingstone.

Selvaraj, S., Kumar, N. N. T. Y., Elakiya, M., Saraswathi, C. P., Balaji, D., P, N., \& Mohan, S. K. (2010). Evidence-based medicine - a new approach to teach medicine: a basic review for beginners. [Article]. Biology \& Medicine, 2(1), 1-5.

Shaneyfelt, T., Baum, K. D., Bell, D., Feldstein, D., Houston, T. K., Kaatz, S., . . Green, M. (2006). Instruments for Evaluating Education in Evidence-Based Practice. [Article]. JAMA: Journal of the American Medical Association, 296(9), 1116-1127.

Starkey, C., Brown, S. D., \& Ryan, J. (2010). Examination of Orthopedic and Athletic Injuries (3 ed.). Pennsylvania: F.A. Davis Company.

Steves, R., \& Hootman, J. M. (2004). Evidence-Based Medicine: What Is It and How Does It Apply to Athletic Training? [Article]. Journal of Athletic Training, 39(1), 83-87.

Straus, S. E., \& Sackett, D. L. (1998). Using research findings in clinical practice. [Article]. BMJ: British Medical Journal (International Edition), 317(7154), 339-342.

The Regents of the University of Colorado. (2014). What is experiential learning? Retrieved September 12, 2014, from http://www.ucdenver.edu/life/services/ExperientialLearning/about/Pages/WhatisExperien $\underline{\text { tialLearning.aspx }}$ 
Thompson, C., McCaughan, D., Cullum, N., Sheldon, T., Mulhall, A., \& Thompson, D. (2001). Research information in nurses' clinical decision-making: what is useful? Journal of Advanced Nursing, 36, 376-388.

Thompson, C., McCaughan, D., Cullum, N., Sheldon, T., \& Raynor, P. (2005). Barriers to evidence-based practice in primary care nursing - why viewing decision-making as context is helpful. [Article]. Journal of Advanced Nursing, 52(4), 432-444. doi: 10.1111/j.1365-2648.2005.03609.x

Tickle-Degnen, L. (2000a). Evidence-Based Practice Forum - Gathering current research evidence to enhance clinical reasoning. American Journal of Occupational Therapy, 54, 102-105.

Tickle-Degnen, L. (2000b). Evidence-Based Practice Forum - Monitoring and documenting evidence during assessment and invervention. American Journal of Occupational Therapy, 52, 434-436.

Tickle-Degnen, L. (2000c). Evidence-Based Practice Forum - What is the best evidence to use in practice? American Journal of Occupational Therapy, 54, 218-221.

Tranmer, J., Lochhaus, J., \& Lam, M. (2002). The effect of staff nurse participation in a clinical nursing research project on attitude towards, access to, support of and use of research in the acure care setting. Canadian Journal of Nursing Leadership(15), 18-26.

U.S. Bureau of Labor Statistics. (2003). 2002 National Occupational Employment and Wage Estimates Healthcare Practitioner and Technical Occupations Retrieved September 2, 2014, from http://www.bls.gov/oes/2002/oes_29He.htm 
U.S. Bureau of Labor Statistics. (2014). Occupational Employment and Wages, May 2013 Retrieved September 2, 2014, from

\section{http://www.bls.gov/oes/current/oes299091.htm\#\%281\%29}

Upton, D., \& Upton, P. (2006a). Development of an evidence-based practice questionnaire for nurses. [Article]. Journal of Advanced Nursing, 53(4), 454-458. doi: 10.1111/j.13652648.2006.03739.x

Upton, D., \& Upton, P. (2006b). Knowledge and Use of Evidence-based Practice by Allied Health and Health Science Professionals in the United Kingdom. Journal of Allied Health, 35(3), 127-133.

Upton, D., \& Upton, P. (2006c). Knowledge and use of evidence-based practice of GPs and hospital doctors. [Article]. Journal of Evaluation in Clinical Practice, 12(3), 376-384. doi: 10.1111/j.1365-2753.2006.00602.x

Upton, P., Scurlock-Evans, L., Stephens, D., \& Upton, D. (2012). The adoption and implementation of evidence-based practice (EBP) among allied health professions. [Article]. International Journal of Therapy \& Rehabilitation, 19(9), 497-503.

Van Deusen, J., \& Fox, J. (1981). Occupational therapy theory development: Knowledge and values held by recent graduates. Occupational Therapy Journal of Research, 1, 79-93.

Walker, S. E., Weidner, T. G., \& Armstrong, K. J. (2008). Evaluation of Athletic Training Students' Clinical Proficiencies. Journal of Athletic Training, 43(4), 386-395.

Wangensteen, S., Johansson, I. S., Björkström, M. E., \& Nordström, G. (2011). Research utilisation and critical thinking among newly graduated nurses: predictors for research use. A quantitative cross-sectional study. Journal of Clinical Nursing, 20(17/18), 24362447. doi: 10.1111/j.1365-2702.2010.03629.x 
Weidner, T. G., \& Henning, J. M. (2002). Historical perspective of athletic training clinical education. Journal of Athletic Training, 37(4 Supplement), S222-S228.

Zylks, D. R. (1988). The importance of educational competencies in athletic training as perceived by selected certified athletic trainers. 8913476 Ph.D., Texas A\&M University, Ann Arbor. ProQuest Dissertations \& Theses Full Text database. 


\section{Appendix A. Survey Instrument}

Evidence based practice (EBP) has been defined as the the integration of best research evidence with clinical expertise and patient values to make clinical decisions. EBP has become a key topic of discussion within the athletic training profession. Some researchers believe that the use of current research to make clinical decisions is needed to continue the development of our profession. Establishing a culture of research use may enhance our reputation as effective health care providers and possibly lead to the establishment of third-party reimbursement.

In order to develop a culture of research use, we must first understand what barriers or complications slow the process. Likewise, we need to understand what tools or concepts help facilitate or assist the process of using research in clinical decisions. Finally, we need to understand the amount or frequency of research being read and used by athletic trainers.

The following survey will consist of four sections: barriers to research use, facilitators of research use, frequency of research use, and demographics.

While the researchers believe it is the duty of all athletic trainers to do what they can to enhance the profession, we understand that our colleagues are sometimes inundated by questionnaires and surveys. Therefore, as an incentive, we are offering all participants who complete the questionnaire an opportunity to enroll in a drawing for one of two iPad minis.

The researchers are also willing to share findings upon completion of the study. 
There are a number of reasons why athletic trainers in practice do not use the results of research to help guide their practice. We would like to know the extent to which you think each of the following situations is a barrier to athletic trainers' use of research to alter/enhance their practice.

If you currently hold a position in a clinical setting, please answer the questions in relation to your current work setting. If you do not currently practice, you may refer to your last clinical experience or provide your general perceptions.

For each item, select the response that best represents your view. Thank you for sharing your views with us.

\begin{tabular}{|c|c|c|c|c|c|c|}
\hline & & $\begin{array}{l}\text { To No } \\
\text { Extent }\end{array}$ & $\begin{array}{c}\text { To a } \\
\text { Little } \\
\text { Extent }\end{array}$ & $\begin{array}{c}\text { No } \\
\text { Opinion }\end{array}$ & $\begin{array}{c}\text { To a } \\
\text { Moderate } \\
\text { Extent }\end{array}$ & $\begin{array}{c}\text { To a } \\
\text { Great } \\
\text { Extent }\end{array}$ \\
\hline 1 & $\begin{array}{l}\text { Research reports/articles are not readily } \\
\text { available. }\end{array}$ & & & & & \\
\hline 2 & Implications for practice are not made clear. & & & & & \\
\hline 3 & Statistical analyses are not understandable. & & & & & \\
\hline 4 & $\begin{array}{l}\text { The research is not relevant to the athletic } \\
\text { trainer's practice. }\end{array}$ & & & & & \\
\hline 5 & The athletic trainer is unaware of the research. & & & & & \\
\hline 6 & $\begin{array}{l}\text { The facilities are inadequate for } \\
\text { implementation. }\end{array}$ & & & & & \\
\hline 7 & $\begin{array}{l}\text { The athletic trainer does not have time to read } \\
\text { research. }\end{array}$ & & & & & \\
\hline 8 & The research has not been replicated. & & & & & \\
\hline 9 & $\begin{array}{l}\text { The athletic trainer feels the benefits of } \\
\text { changing practice will be minimal. }\end{array}$ & & & & & \\
\hline 10 & $\begin{array}{l}\text { The athletic trainer is uncertain whether to } \\
\text { believe the results of the research. }\end{array}$ & & & & & \\
\hline 11 & The research has methodological inadequacies. & & & & & \\
\hline 12 & $\begin{array}{l}\text { The relevant literature is not compiled in one } \\
\text { place. }\end{array}$ & & & & & \\
\hline 13 & $\begin{array}{l}\text { The athletic trainer does not feel she/he has } \\
\text { enough authority to change patient care }\end{array}$ & & & & & \\
\hline
\end{tabular}




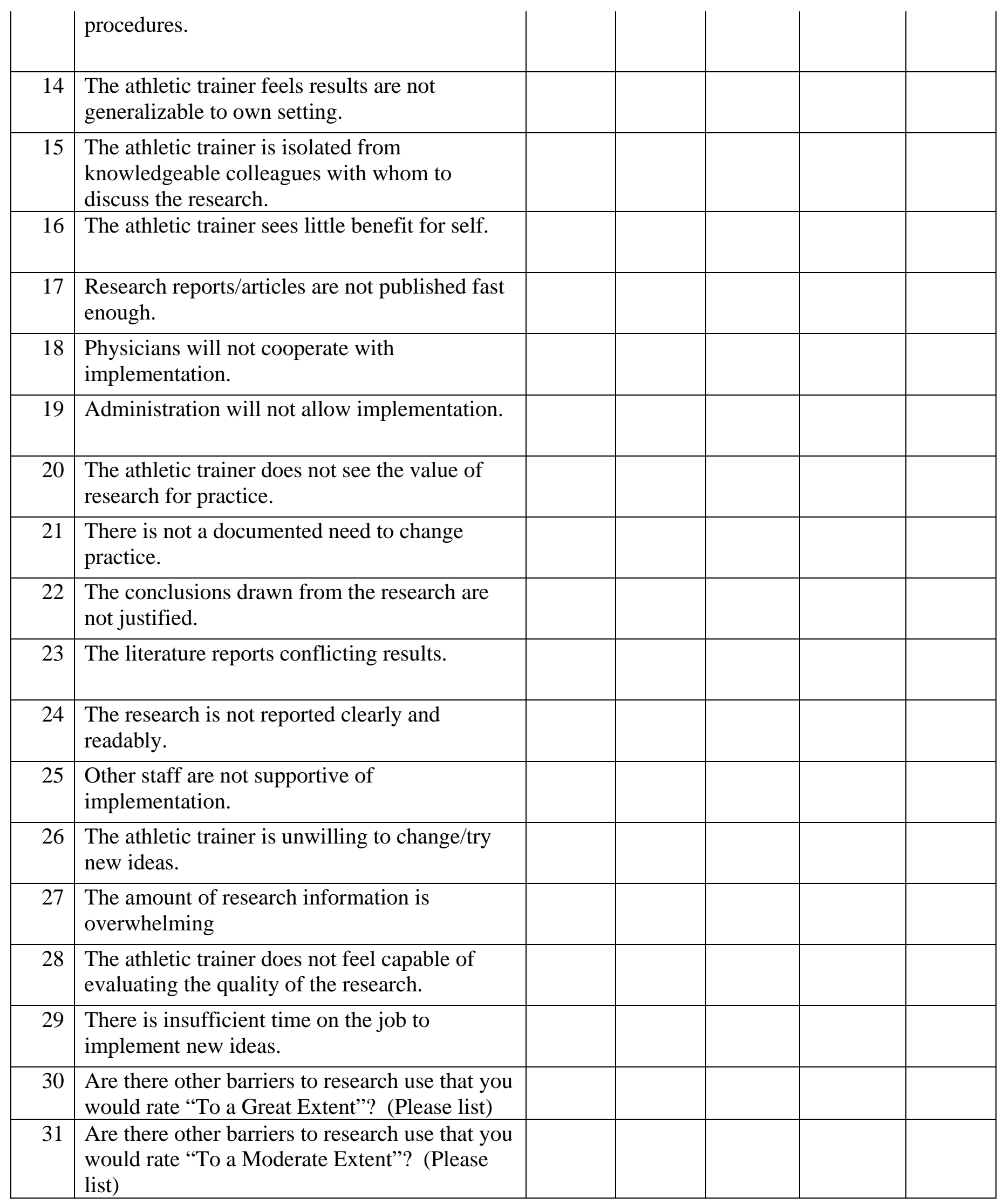


Which of the above items do you feel are the three greatest barriers to athletic trainers' use of research?

Greatest Barrier. .Item \#

Second Greatest Barrier. .Item \#

Third Greatest Barrier. Item \#

Several studies have tried to identify personal or environmental factors that may encourage the use the research in making clinical decisions; these are often referred to as facilitators. This section is designed to help identify what factors athletic trainers view as facilitators to the use of research.

If you currently hold a position in a clinical setting, please answer the questions in relation to your current work setting. If you do not currently practice, you may refer to your last clinical experience or provide your general perceptions.

For each item, select the response that best represents your view of the following facilitators. Thank you for sharing your views with us.

\begin{tabular}{|r|l|l|l|l|l|l|}
\hline 1 & $\begin{array}{l}\text { Increasing the time available for reviewing and } \\
\text { implementing research findings }\end{array}$ & $\begin{array}{c}\text { To No } \\
\text { Extent }\end{array}$ & $\begin{array}{c}\text { To attle } \\
\text { Extent }\end{array}$ & $\begin{array}{c}\text { No } \\
\text { Opinion }\end{array}$ & $\begin{array}{c}\text { To a } \\
\text { Moderate } \\
\text { Extent }\end{array}$ & $\begin{array}{c}\text { To a } \\
\text { Great } \\
\text { Extent }\end{array}$ \\
\hline 2 & $\begin{array}{l}\text { Conducting more clinically focused and } \\
\text { relevant research }\end{array}$ & & & & & \\
\hline 3 & $\begin{array}{l}\text { Providing colleague support } \\
\text { network/mechanisms }\end{array}$ & & & & & \\
\hline 4 & $\begin{array}{l}\text { Advanced education to increase your research } \\
\text { knowledge base }\end{array}$ & & & & & \\
\hline 5 & $\begin{array}{l}\text { Enhancing managerial/administrative support } \\
\text { and encouragement of research implementation }\end{array}$ & & & & & \\
\hline 6 & $\begin{array}{l}\text { Improving availability and accessibility of } \\
\text { research reports }\end{array}$ & & & & & \\
\hline
\end{tabular}






Which of the above items do you feel are the three greatest facilitators to athletic trainers' use of research?

Greatest Facilitator. .Item \#

Second Greatest Facilitator .................Item \#

Third Greatest Facilitator ..................Item \# 
This section is designed to identify how athletic trainers access clinically relevant research literature and incorporate research findings into practice.

If you currently hold a position in a clinical setting, please answer the questions in relation to your current work setting. If you do not currently practice, you may refer to your last clinical experience or provide your general perceptions.

Considering your practice in relation to an individual patient's care over the past year, how often have you done the following in response to a gap in your knowledge? Thank you for sharing your views with us.

\begin{tabular}{|r|l|l|l|l|l|l|}
\hline & & Never & Rarely & Sometimes & Often & Always \\
\hline 1 & $\begin{array}{l}\text { Formulated a clearly answerable question as } \\
\text { the beginning of the process towards filling this } \\
\text { gap }\end{array}$ & & & & & \\
\hline 2 & $\begin{array}{l}\text { Tracked down the relevant evidence once you } \\
\text { have formulated the question }\end{array}$ & & & & & \\
\hline 3 & $\begin{array}{l}\text { Critically appraised, against set criteria, any } \\
\text { literature you have discovered }\end{array}$ & & & & & \\
\hline 4 & $\begin{array}{l}\text { Integrated the evidence you have found with } \\
\text { your expertise }\end{array}$ & & & & & \\
\hline 5 & Evaluated the outcomes of your practice & & & & & \\
\hline 6 & Shared this information with colleagues & & & & & \\
\hline
\end{tabular}

For each item, please select the appropriate answer indicating how often you read or use the resource to access research findings.

\begin{tabular}{|r|l|l|l|l|l|l|}
\hline & & Never & Rarely & Sometimes & Often & Always \\
\hline 1 & Journal articles and texts & & & & & \\
\hline 2 & A university or professional library & & & & & \\
\hline
\end{tabular}




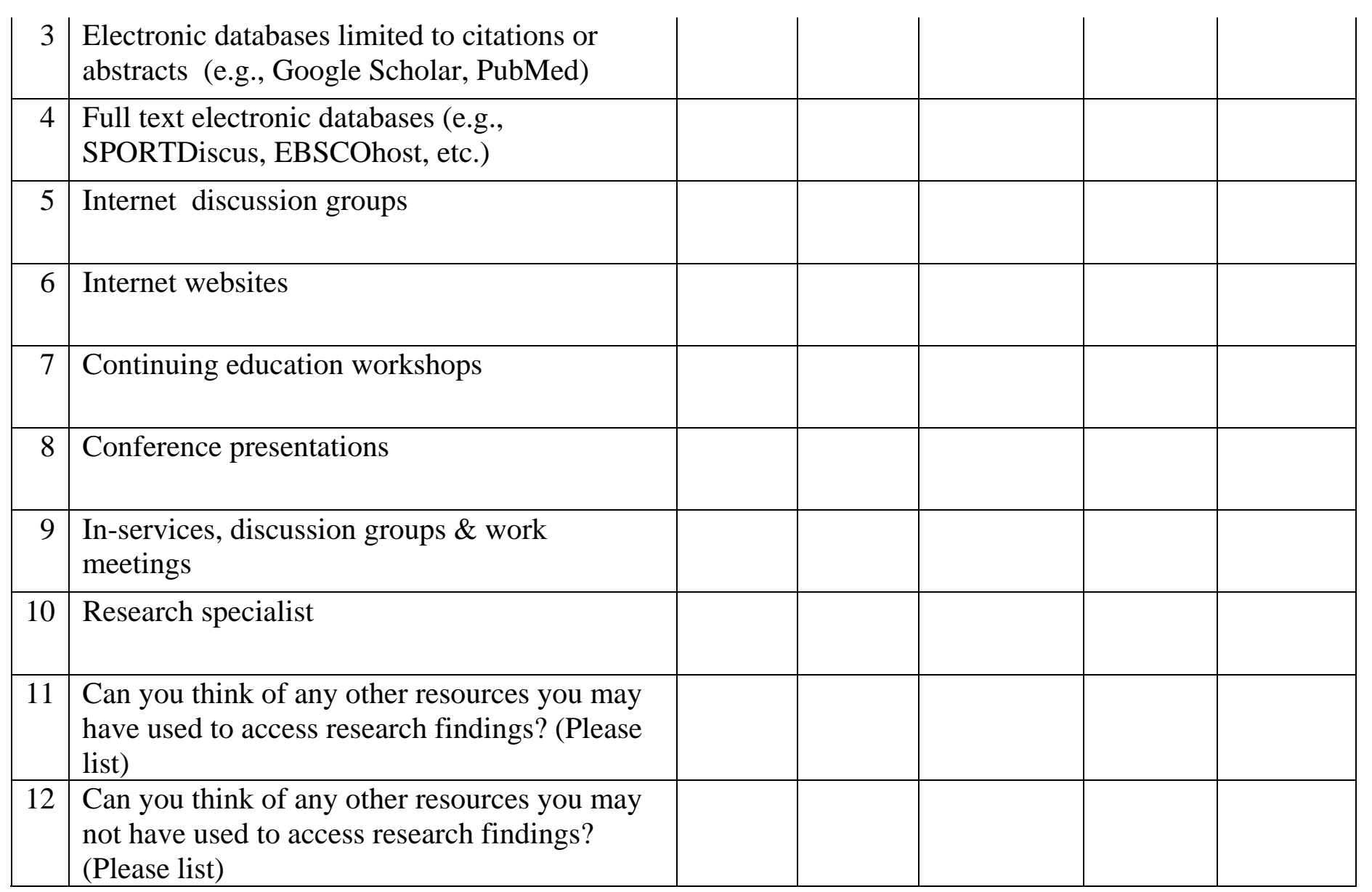

In the past year, how many times have you specifically used current research information to alter or develop therapeutic treatment plans?

(Choose one)

- None

- 1 to 2

- 3 to 5

- 6 to 10

- 11 to 20

- 21 to 30

- More than 30 
How recently have you read a research article from a publication not related to Athletic Training?

(Choose one)

- Never

- 1 year ago or more

- 6 months ago or more

- 3 months ago or more

- 1 month to 3 months ago

- Last month

- 2 weeks ago

- Within the last week

How recently have you read a research article from an Athletic Training publication? (Choose one)

- Never

- 1 year ago or more

- 6 months ago or more

- 3 months ago or more

- 1 month to 3 months ago

- Last month

- 2 weeks ago

- Within the last week

The following section is for Demographic Information.

As a Thank You for your time, at the end of the section you will have the opportunity to enter the drawing for one of two iPad Minis.

\section{Gender}

- Male

- Female 


\section{Ethnicity (Choose one)}

- African American

- Asian

- Caucasian

- Latin American

- Native American

- Pacific Islander

- Other (please specify)

How many years have you been practicing as a BOC certified Athletic Trainer? (Choose one)

- Less than 1 year

- 1 to 2 years

- 3 to 5 years

- 6 to 8 years

- 9 to 12 years

- 13 to 18 years

- 19 to 24 years

- 25 to 30 years

- 31 to 35 years

- 36 to 40 years

- More than 40 years

How many years have you been a Certified-Regular Member of the NATA? (Choose one)

- Less than 1 year

- 1 to 2 years

- 3 to 5 years

- 6 to 8 years

- 9 to 12 years

- 13 to 18 years

- 19 to 24 years

- 25 to 30 years

- 31 to 35 years

- 36 to 40 years

- More than 40 years 
In what NATA District are you employed?

(Choose one)

- District 1 (CT, ME, MA, NH, RI, VT)

- District 2 (DE, NJ, NY, PA)

- District 3 (DC, MD, NC, SC, VA, WV)

- District 4 (IL, IN, MI, MN, OH, WI)

- District 5 (IA, KS, MO, NE, ND, OK, SD)

- District 6 (AR, TX)

- District 7 (AZ, CO, NM, UT, WY)

- District 8 (CA, HI, NV)

- District 9 (AL, FL, GA, KY, LA, MS, TN)

- District 10 (AK, ID, MT, OR, WA)

- Other - please explain

Which best describes your region of practice?

(Choose one)

- Rural

- Urban

\section{Highest degree earned}

(Choose one)

- Bachelor's Degree

- Master's Degree

- Doctoral Degree

Professional Credentials

(Choose all that apply)

- ATC

- CSCS

- EMT

- MD

- OT

- PA

- PT

- PTA

- Other (please specify)

BOC Certification Route (Choose one)

- Internship athletic training program

- Accredited athletic training program 


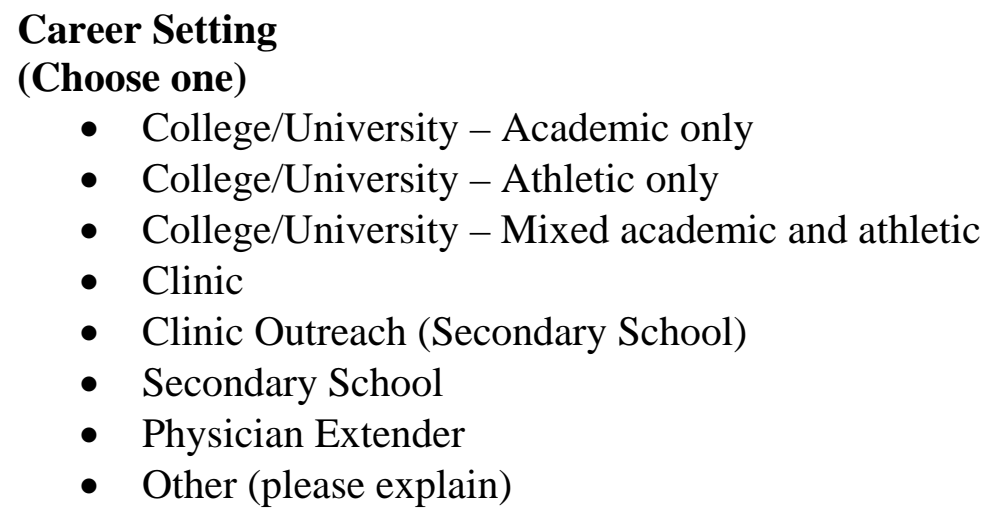

Do you conduct patient care on a weekly basis?

- Yes, I am involved with patient care

- No, I am not involved with patient care

\section{Have you ever been an author in a research based publication? (Please select all that apply) \\ - No \\ - Yes \\ - If yes, how many journal articles have you authored? \\ - If yes, how many chapters have you authored? \\ - If yes, how many books have you authored?}

Occasionally, researchers want to expand upon the knowledge gained in a survey. If for some reason we would like to expand upon the information gleaned through this survey, may we contact you via email? If yes, please put your email address in the text box below. If you would not like to be contacted, skip this item.

As stated above, all participants who completed the survey are eligible to enter into a drawing for one of two iPad Minis. If you would like to be in the drawing, please put your email information in the space available below. If you would not like to be part of the drawing, skip this item.

Thank you. Your time and input are greatly appreciated. 


\title{
Appendix B. Institutional Review Board at West Virginia University Approval
}

\author{
WestVirginiaUniversity; \\ Ollice of Research Integrity and Compliance

$\begin{array}{ll} & \text { Acknowledgement Letter Exempt Initial Protocol Review } \\ \text { To } & \text { Daniel Hursh } \\ \text { From } & \text { WVU Office of Research Integrity and Compliance } \\ \text { Approval Period } & 02 / 06 / 2014 \text { Expiration Date 02/05/2017 } \\ \text { Subject } & \text { Acknowledgement Letter Exempt Initial Protocol Review } \\ \text { Protocol Tracking } & \begin{array}{l}1401180325 \\ \text { Title }\end{array} \\ & \begin{array}{l}\text { Bamiers, Facilitators, and Frequency of Evidence-Based Practice by Athletic } \\ \text { Trainers }\end{array}\end{array}$

The above-referenced study was reviewed by the West Virginia University Institutional Review Board IRB and was granted exemption in accordance with 45 CFR 46.101 .

- This research study was granted an exemption because the Research involves educational tests, survey procedures, interview procedures or observation of public behavior and (i) information obtained is recorded in such a manner that human subjects cannot be identified, directly or through identifiers linked to the subjects; and (ii) any disclosure of the human subjects responses outside the research could not reasonably place the subjects at risk of criminal or civil liability or be damaging to the subjects financial standing, employability, or reputation [45 CFR 46.101(2)]. All exemptions are only good for three years. If this research extends more than three years beyond the approved date, then the researcher will have to request another exemption. The following documents have been acknowledged for use in this study and are available in the WVU+kc system:

Documents for use in this study have been acknowledged and validated and are available in the WVUkc system in the Notes and Attachments section of your protocol.

If you have any questions, please contact the IRB at 3042937073.

Thank you.

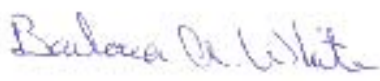

Board Designee Barbara White 


\section{Appendix C. Survey Cover Letter}

Dear Athletic Trainer,

You are being asked to participate in a research project as part of a doctoral studies dissertation conducted through West Virginia University's College of Education and Human Services. This Study titled, Barriers, Facilitators, and Frequency of Evidence-Based Practice Use In Athletic Training, will take approximately 15-20 minutes to complete. As a "Thank You" for participating, you will be offered a chance to enter a drawing for one of two iPad Minis! To participate and enter the drawing, please read the remainder of this letter and then click on the link to the survey.

Evidence-based practice (EBP) is defined as the blending of best research evidence with clinical expertise and patient values to make clinical decisions. Many researchers believe that excellence in patient care is the ultimate outcome of the EBP process. Those in athletic training consider the use of EBP concepts as a means to promote the profession, not only through improved patient care, but also through increasing the reputation of athletic trainers as costeffective health care providers. It is further believed that the use of EBP may advance the profession with licensure, third-party reimbursement, and a more efficient means of disseminating knowledge.

Over the past two decades EBP has become a common term and subject of study for many health care professions, particularly the barriers and facilitators associated with implementation. However, the extent of research regarding barriers to and facilitators of the use of EBP within athletic training lags behind that of other health care professions. Of greater concern, no literature exists describing the frequency of research use among athletic trainers.

The purpose of this study is to examine the barriers, facilitators, and frequency of research use by Athletic Trainers. Therefore, each participant will be asked to rate barriers to and facilitators of research use. They will also be asked to identify the resources used as well as frequency with which they find, read and implement research. Finally, participants will be asked for demographic information followed by the opportunity to enter the drawing for one of two iPad Minis.

Anyone who agrees to participate in this study has the right to withdraw from completing the study at any time with no penalty. Each participant while taking the survey can decide not to 
complete any question within the electronic survey if he or she desires, without penalty. Upon completion and submission of the electronic survey, you will have the ability to request the results from this study. Refusal to participate in this study will have no effect on any future services you may be entitled to from West Virginia University or the researcher.

I want to thank you in advance for your willingness to participate in this study. It is hoped that the information gained from this study will benefit the athletic training profession by enhancing our ability to implement research in clinical practice.

The link below will direct you to the survey. When you click on the link, your consent will be assumed. If you have any questions, comments, or technical difficulties, please contact me at 304-641-1208, or contact the chair of my dissertation committee, Dr. Daniel Hursh at 304293-2076.

\section{https://wvuhre.qualtrics.com/SE/?SID=SV_9Y8ICg9z0xmiyH3}

Respectfully,

Michael Boehke, MS, ATC

Doctoral Student

West Virginia University

304-641-1208

boehkemj@ab.edu

“This student survey is not approved or endorsed by NATA. It is being sent to you because of NATA's commitment to athletic training education and research.” 


\section{Appendix D. Demographic Tables}

Table 1.1

Demographic Characteristics of Participants: Gender $(N=313)$

\begin{tabular}{lcc}
\hline Characteristic & $\mathrm{n}$ & $\%$ \\
\hline Male & 156 & 50 \\
Female & 157 & 50 \\
\hline
\end{tabular}

Table 1.2

Demographic Characteristics of Participants: Ethnicity $(N=313)$

\begin{tabular}{lcc}
\hline Characteristic & $\mathrm{n}$ & $\%$ \\
\hline African American & 6 & 2 \\
Asian & 3 & 1 \\
Caucasian & 290 & 93 \\
Latin American & 7 & 2 \\
Native American & 2 & .6 \\
Pacific Islander & 1 & .3 \\
Other & 4 & 1 \\
\hline
\end{tabular}

Table 1.3

Demographic Characteristics of Participants: Certification Route $(N=313)$

\begin{tabular}{lcc}
\hline Certification Route & $\mathrm{n}$ & $\%$ \\
\hline Internship & 87 & 28 \\
Accredited program & 226 & 72 \\
\hline
\end{tabular}


Table 1.4

Demographic Characteristics of Participants: Years Practicing as an Athletic Trainer $(N=313)$

\begin{tabular}{lcc}
\hline Characteristic & $\mathrm{n}$ & $\%$ \\
\hline 2 years or less & 19 & 6 \\
3 to 5 years & 77 & 25 \\
6 to 8 years & 38 & 12 \\
9 to 12 years & 42 & 13 \\
13 to 18 years & 53 & 17 \\
19 to 24 years & 31 & 10 \\
25 to 30 years & 23 & 7 \\
31 to 35 years & 18 & 6 \\
More than 35 years & 9 & 3 \\
\hline
\end{tabular}

Table 1.5

Demographic Characteristics of Participants: Highest Degree

Earned $(N=313)$

\begin{tabular}{lcc}
\hline Characteristic & $\mathrm{n}$ & $\%$ \\
\hline Bachelor's & 69 & 22 \\
Master's & 214 & 68 \\
Doctoral & 29 & 9 \\
\hline
\end{tabular}


Table 1.6

Demographic Characteristics of Participants: NATA District of

Employment $(N=313)$

\begin{tabular}{lcc}
\hline Characteristic & $\mathrm{n}$ & $\%$ \\
\hline District 1 (CT, ME, MA, NH, RI, VT) & 22 & 7 \\
District 2 (DE, NJ, NY, PA) & 35 & 11 \\
District 3 (DC, MD, NC, SC, VA, WV) & 50 & 16 \\
District 4 (IL, IN, MI, MN, OH, WI) & 72 & 23 \\
District 5 (IA, KS, MO, NE, ND, OK, SD) & 24 & 8 \\
District 6 (AR, TX) & 11 & 4 \\
District 7 (AZ, CO, NM, UT, WY) & 14 & 5 \\
District 7 (AZ, CO, NM, UT, WY) & 28 & 9 \\
District 9 (AL, FL, GA, KY, LA, MS, TN) & 42 & 13 \\
District 10 (AK, ID, MT, OR, WA) & 15 & 5 \\
\hline
\end{tabular}

Table 1.7

Demographic Characteristics of Participants: Region of Practice $(N=313)$

\begin{tabular}{lcc}
\hline Characteristic & $\mathrm{n}$ & $\%$ \\
\hline Rural & 131 & 42 \\
Urban & 182 & 58 \\
\hline
\end{tabular}


Table 1.8

Demographic Characteristics of Participants: Career Setting $(N=313)$

\begin{tabular}{lcc}
\hline Characteristic & $\mathrm{n}$ & $\%$ \\
\hline College/University - Academic only & 28 & 9 \\
College/University - Athletic only & 79 & 25 \\
College/University - Mixed academic and athletic & 50 & 16 \\
& 22 & 7 \\
Clinic & 51 & 16 \\
Clinic Outreach (Secondary School) & 69 & 22 \\
Secondary School & 4 & 1 \\
Physician Extender & 9 & 3 \\
Other & & \\
\hline
\end{tabular}

Table 1.9

Demographic Characteristics of Participants: Conducts Patient Care on a Daily Basis $(N=313)$

\begin{tabular}{lcc}
\hline Characteristic & $\mathrm{n}$ & $\%$ \\
\hline Yes involved in patient care & 269 & 86 \\
No not involved in patient care & 42 & 13 \\
\hline
\end{tabular}

Table 1.10

Demographic Characteristics of Participants: Authored a Research Based Publication $(N=313)$

\begin{tabular}{lcc}
\hline Characteristic & $\mathrm{n}$ & $\%$ \\
\hline Authored & 70 & 23 \\
Never Authored & 237 & 77 \\
\hline
\end{tabular}




\section{Appendix E. Frequency of Completing Steps to EBP}

Table 2

Frequency of completing the steps to EBP over the last year $(N=307)$

\begin{tabular}{|c|c|c|c|c|c|c|c|}
\hline EBP Technique & Never & Rarely & Sometimes & Often & Always & $\mathrm{M}$ & SD \\
\hline $\begin{array}{l}\text { Formulated a clearly } \\
\text { answerable question as the } \\
\text { beginning of the process } \\
\text { towards filling this gap }\end{array}$ & $\begin{array}{c}16 \\
(5 \%)\end{array}$ & $\begin{array}{c}55 \\
(18 \%)\end{array}$ & $\begin{array}{c}126 \\
(41 \%)\end{array}$ & $\begin{array}{c}94 \\
(31 \%)\end{array}$ & $\begin{array}{c}16 \\
(5 \%)\end{array}$ & 3.13 & 0.94 \\
\hline $\begin{array}{l}\text { Tracked down the relevant } \\
\text { evidence once you have } \\
\text { formulated the question }\end{array}$ & $\begin{array}{c}9 \\
(3 \%)\end{array}$ & $\begin{array}{c}39 \\
(13 \%)\end{array}$ & $\begin{array}{c}103 \\
(34 \%)\end{array}$ & $\begin{array}{c}127 \\
(41 \%)\end{array}$ & $\begin{array}{c}29 \\
(9 \%)\end{array}$ & 3.42 & 0.96 \\
\hline $\begin{array}{l}\text { Critically appraised, against } \\
\text { set criteria, any literature you } \\
\text { have discovered* }\end{array}$ & $\begin{array}{c}31 \\
(10 \%)\end{array}$ & $\begin{array}{c}99 \\
(32 \%)\end{array}$ & $\begin{array}{c}91 \\
(30 \%)\end{array}$ & $\begin{array}{c}76 \\
(25 \%)\end{array}$ & $\begin{array}{c}9 \\
(3 \%)\end{array}$ & 2.78 & 1.02 \\
\hline $\begin{array}{l}\text { Integrated the evidence you } \\
\text { have found with your } \\
\text { expertise** }\end{array}$ & $\begin{array}{c}9 \\
(3 \%)\end{array}$ & $\begin{array}{c}34 \\
(11 \%)\end{array}$ & $\begin{array}{c}94 \\
(31 \%)\end{array}$ & $\begin{array}{c}141 \\
(46 \%)\end{array}$ & $\begin{array}{c}27 \\
(9 \%)\end{array}$ & 3.47 & 0.91 \\
\hline $\begin{array}{l}\text { Evaluated the outcomes of } \\
\text { your practice }\end{array}$ & $\begin{array}{c}22 \\
(7 \%)\end{array}$ & $\begin{array}{c}57 \\
(19 \%)\end{array}$ & $\begin{array}{c}92 \\
(30 \%)\end{array}$ & $\begin{array}{c}101 \\
(33 \%)\end{array}$ & $\begin{array}{c}35 \\
(11 \%)\end{array}$ & 3.23 & 1.10 \\
\hline $\begin{array}{l}\text { Shared this information with } \\
\text { colleagues }\end{array}$ & $\begin{array}{c}22 \\
(7 \%)\end{array}$ & $\begin{array}{c}61 \\
(20 \%)\end{array}$ & $\begin{array}{c}95 \\
(31 \%)\end{array}$ & $\begin{array}{c}100 \\
(33 \%)\end{array}$ & $\begin{array}{c}29 \\
(9 \%)\end{array}$ & 3.17 & 1.08 \\
\hline
\end{tabular}

( ) indicates percentage

* One missing variable $\mathrm{N}=306$

** Two missing variables $\mathrm{N}=305$

$\mathrm{EBP}=$ Evidence-based practice 


\section{Appendix F. Frequency of Resources Used to Access Research}

Table 3

Frequency of resources used to access research $(N=311)$

\begin{tabular}{lccccccc}
\hline \multicolumn{1}{c}{ Research Source } & Never & Rarely & Sometimes & Often & Always & M & SD \\
\hline Journal articles and texts & 3 & 26 & 90 & 135 & 57 & 3.70 & 0.90 \\
$\begin{array}{l}\text { A university or professional } \\
\text { library }\end{array}$ & 90 & 113 & 50 & 39 & 19 & 2.31 & 1.19 \\
$\begin{array}{l}\text { Electronic databases limited } \\
\text { to citations or abstracts }\end{array}$ & 9 & 48 & 91 & 117 & 46 & 3.46 & 1.01 \\
$\begin{array}{l}\text { Full text electronic databases } \\
\text { Internet discussion groups }\end{array}$ & 50 & 78 & 74 & 76 & 33 & 2.88 & 1.25 \\
$\begin{array}{l}\text { Internet websites } \\
\text { Continuing education }\end{array}$ & 120 & 105 & 55 & 26 & 5 & 2.01 & 1.02 \\
$\begin{array}{l}\text { workshops } \\
\text { Conference presentations }\end{array}$ & 11 & 21 & 89 & 156 & 33 & 3.58 & 0.90 \\
$\begin{array}{l}\text { In-services, discussion groups } \\
\text { and work meetings }\end{array}$ & 40 & 67 & 109 & 78 & 17 & 2.89 & 1.09 \\
Research specialist & 171 & 80 & 37 & 19 & 3 & 1.72 & 0.96 \\
\hline
\end{tabular}




\section{Appendix G. Recentness of Reading Research}

Table 4.1

Recentness of reading research articles from an

Athletic Training publication $(N=312)$

\begin{tabular}{lcc}
\hline Survey Response & $\mathrm{n}$ & $\%$ \\
\hline Never & 2 & $1 \%$ \\
1 year ago or more & 17 & $5 \%$ \\
6 months ago or more & 18 & $6 \%$ \\
3 months ago or more & 10 & $3 \%$ \\
1 month to 3 months ago & 43 & $14 \%$ \\
Last month & 69 & $22 \%$ \\
Two weeks ago & 52 & $17 \%$ \\
Within the last week & 101 & $32 \%$ \\
\hline
\end{tabular}

Table 4.2

Recentness of reading research articles from a publication not related to Athletic Training $(N=311)$

\begin{tabular}{lcc}
\hline Survey Response & $\mathrm{n}$ & $\%$ \\
\hline Never & 21 & $7 \%$ \\
1 year ago or more & 53 & $17 \%$ \\
6 months ago or more & 26 & $8 \%$ \\
3 months ago or more & 29 & $9 \%$ \\
1 month to 3 months ago & 49 & $16 \%$ \\
Last month & 41 & $13 \%$ \\
Two weeks ago & 26 & $8 \%$ \\
Within the last week & 66 & $21 \%$ \\
\hline
\end{tabular}




\section{Appendix H. Number of Times Research was Used to Alter or Develop a Treatment Plan}

\section{Table 5}

Number of times research was used to alter or develop a treatment plan in the past year $(N=311)$

\begin{tabular}{lcc}
\hline Survey Item & $\mathrm{n}$ & $\%$ \\
\hline None & 22 & $7 \%$ \\
1 to 2 & 84 & $27 \%$ \\
3 to 5 & 106 & $34 \%$ \\
6 to 10 & 58 & $19 \%$ \\
11 to 20 & 26 & $8 \%$ \\
21 to 30 & 6 & $2 \%$ \\
More than 30 & 9 & $3 \%$ \\
\hline
\end{tabular}




\section{Appendix I. Facilitators to Evidence Based Practice}

Table 6

Facilitators to $\operatorname{EBP}(N=313)$

\begin{tabular}{|c|c|c|c|c|}
\hline Rank & Facilitator & Characteristic & M & SD \\
\hline 1 & $\begin{array}{l}\text { Increased budget for continuing education courses, } \\
\text { workshops, or presentations }\end{array}$ & Organization & 4.08 & 1.11 \\
\hline 2 & $\begin{array}{l}\text { Availability of research that is relevant to clinical } \\
\text { needs }\end{array}$ & Research & 4.02 & 0.92 \\
\hline 3 & $\begin{array}{l}\text { Conducting more clinically focused and relevant } \\
\text { research }\end{array}$ & Research & 3.86 & 1.01 \\
\hline 4 & Improving the understandability of research reports & Communication & 3.80 & 1.08 \\
\hline 5 & $\begin{array}{l}\text { Enhancing the dissemination of new ideas about } \\
\text { patient care to colleagues }\end{array}$ & Organization & 3.68 & 0.93 \\
\hline 6 & $\begin{array}{l}\text { Improving availability and accessibility of research } \\
\text { reports }\end{array}$ & Communication & 3.66 & 1.12 \\
\hline 7 & Providing colleague support network/mechanisms & Organization & 3.65 & 1.00 \\
\hline 8 & $\begin{array}{l}\text { Increasing the time available for reviewing and } \\
\text { implementing research findings }\end{array}$ & Organization & 3.62 & 1.05 \\
\hline 9 & $\begin{array}{l}\text { Improving ability to critically analyze evidence } \\
\text { against set standards }\end{array}$ & Adopter & 3.53 & 1.09 \\
\hline 10 & $\begin{array}{l}\text { Opportunity for research collaboration with } \\
\text { colleagues }\end{array}$ & Research & 3.53 & 1.09 \\
\hline 11 & $\begin{array}{l}\text { Advanced education to increase your research } \\
\text { knowledge base }\end{array}$ & Adopter & 3.52 & 1.14 \\
\hline 12 & $\begin{array}{l}\text { Improving awareness of major information types and } \\
\text { sources }\end{array}$ & Communication & 3.47 & 1.09 \\
\hline 13 & $\begin{array}{l}\text { Advanced education to better improve understanding } \\
\text { of the evidence-based practice process }\end{array}$ & Adopter & 3.44 & 1.17 \\
\hline 14 & $\begin{array}{l}\text { Enhancing managerial/administrative support and } \\
\text { encouragement of research implementation }\end{array}$ & Organization & 3.42 & 1.15 \\
\hline 15 & $\begin{array}{l}\text { Employing athletic trainers with research skills to } \\
\text { serve as role models }\end{array}$ & Organization & 3.05 & 1.26 \\
\hline 16 & $\begin{array}{l}\text { Advanced education to better convert your } \\
\text { information needs into a research question }\end{array}$ & Adopter & 3.03 & 1.18 \\
\hline
\end{tabular}




\section{Appendix J. Frequency of Rating Facilitators to a Moderate to Great Extent}

Table 7

Frequency of Rating Facilitators to a Moderate to Great Extent $(N=313)$

\begin{tabular}{|c|c|c|c|c|}
\hline $\begin{array}{l}\text { Rank } \\
\text { order }\end{array}$ & Facilitators & Characteristic & $\begin{array}{c}\text { Items rated } \\
\text { as a great } \\
\text { or } \\
\text { moderate } \\
\text { facilitator } \\
\text { n (\%) }\end{array}$ & $\begin{array}{l}\text { No } \\
\text { Opinion } \\
\mathrm{n}(\%)\end{array}$ \\
\hline 1 & $\begin{array}{l}\text { Availability of research that is } \\
\text { relevant to clinical needs }\end{array}$ & Research & $258(84 \%)$ & $15(5 \%)$ \\
\hline 2 & $\begin{array}{l}\text { Increased budget for continuing } \\
\text { education courses, workshops, or } \\
\text { presentations }\end{array}$ & Organization & 245 (80\%) & $22(7 \%)$ \\
\hline 3 & $\begin{array}{l}\text { Conducting more clinically focused } \\
\text { and relevant research }\end{array}$ & Research & 239 (78\%) & $23(8 \%)$ \\
\hline 4 & $\begin{array}{l}\text { Improving the understandability of } \\
\text { research reports }\end{array}$ & Communication & $229(74 \%)$ & $26(8 \%)$ \\
\hline 5 & $\begin{array}{l}\text { Providing colleague support } \\
\text { network/mechanisms }\end{array}$ & Organization & $221(72 \%)$ & $29(10 \%)$ \\
\hline 6 & $\begin{array}{l}\text { Enhancing the dissemination of new } \\
\text { ideas about patient care to colleagues }\end{array}$ & Organization & $221(72 \%)$ & 39 (13\%) \\
\hline 7 & $\begin{array}{l}\text { Improving availability and } \\
\text { accessibility of research reports }\end{array}$ & Communication & $213(69 \%)$ & $31(10 \%)$ \\
\hline 8 & $\begin{array}{l}\text { Increasing the time available for } \\
\text { reviewing and implementing research } \\
\text { findings }\end{array}$ & Organization & 213 (69\%) & $30(10 \%)$ \\
\hline 9 & $\begin{array}{l}\text { Improving ability to critically analyze } \\
\text { evidence against set standards }\end{array}$ & Adopter & 209 (68\%) & $28(9 \%)$ \\
\hline 10 & $\begin{array}{l}\text { Advanced education to increase your } \\
\text { research knowledge base }\end{array}$ & Adopter & $203(66 \%)$ & $24(8 \%)$ \\
\hline
\end{tabular}


Table 7 (continued)

Frequency of Rating Facilitators to a Moderate to Great Extent $(N=313)$

\begin{tabular}{|c|c|c|c|c|}
\hline $\begin{array}{l}\text { Rank } \\
\text { order }\end{array}$ & Facilitators & Characteristic & $\begin{array}{l}\text { Items rated } \\
\text { as a great } \\
\text { or } \\
\text { moderate } \\
\text { facilitator } \\
\text { n (\%) } \\
\end{array}$ & $\begin{array}{c}\text { No } \\
\text { Opinion } \\
\mathrm{n}(\%) \\
\end{array}$ \\
\hline 11 & $\begin{array}{l}\text { Opportunity for research } \\
\text { collaboration with colleagues }\end{array}$ & Research & 195 (64\%) & $48(15 \%)$ \\
\hline 12 & $\begin{array}{l}\text { Improving awareness of major } \\
\text { information types and sources }\end{array}$ & Communication & $194(63 \%)$ & $37(12 \%)$ \\
\hline 13 & $\begin{array}{l}\text { Advanced education to better } \\
\text { improve understanding of the EBP } \\
\text { process }\end{array}$ & Adopter & $185(60 \%)$ & $38(12 \%)$ \\
\hline 14 & $\begin{array}{l}\text { Enhancing managerial/administrative } \\
\text { support and encouragement of } \\
\text { research implementation }\end{array}$ & Organization & $185(60 \%)$ & $42(14 \%)$ \\
\hline 15 & $\begin{array}{l}\text { Employing athletic trainers with } \\
\text { research skills to serve as role models }\end{array}$ & Organization & 135 (44\%) & $63(20 \%)$ \\
\hline 16 & $\begin{array}{l}\text { Advanced education to better convert } \\
\text { your information needs into a } \\
\text { research question }\end{array}$ & Adopter & $133(43 \%)$ & $60(19 \%)$ \\
\hline
\end{tabular}




\section{Appendix K. Frequency of Rating the Three Greatest Facilitators}

Table 8

Frequency of rating the three greatest facilitators $(N=281)$

\begin{tabular}{|c|c|c|c|}
\hline $\begin{array}{l}\text { Rank } \\
\text { order }\end{array}$ & Facilitator & Characteristic & $\begin{array}{c}\text { Item rated in } \\
\text { three greatest } \\
\text { facilitators } \\
\mathrm{n}(\%)\end{array}$ \\
\hline 1 & $\begin{array}{l}\text { Increased budget for continuing education courses, } \\
\text { workshops, or presentations }\end{array}$ & Organization & $121(43 \%)$ \\
\hline 2 & $\begin{array}{l}\text { Increasing time available for reviewing and } \\
\text { implementing research findings }\end{array}$ & Organization & $102(36 \%)$ \\
\hline 3 & $\begin{array}{l}\text { Conducting more clinically focused and relevant } \\
\text { research }\end{array}$ & Research & $93(33 \%)$ \\
\hline 4 & $\begin{array}{l}\text { Availability of research that is relevant to clinical } \\
\text { needs }\end{array}$ & Research & $70(25 \%)$ \\
\hline 5 & $\begin{array}{l}\text { Improving the understandability of research } \\
\text { reports }\end{array}$ & Communication & $63(22 \%)$ \\
\hline 6 & $\begin{array}{l}\text { Improving availability and accessibility of } \\
\text { research reports }\end{array}$ & Communication & $61(22 \%)$ \\
\hline 7 & $\begin{array}{l}\text { Advanced education to increase your research } \\
\text { knowledge base }\end{array}$ & Adopter & $44(16 \%)$ \\
\hline 8 & $\begin{array}{l}\text { Enhancing the dissemination of new ideas about } \\
\text { patient care to colleagues }\end{array}$ & Organization & $38(14 \%)$ \\
\hline 9 & $\begin{array}{l}\text { Improving ability to critically analyze evidence } \\
\text { against set standards }\end{array}$ & Adopter & $37(13 \%)$ \\
\hline 10 & Providing colleague support network/mechanisms & Organization & $35(12 \%)$ \\
\hline
\end{tabular}


Table 8 (continued)

Frequency of rating the three greatest facilitators $(N=281)$

\begin{tabular}{|c|c|c|c|}
\hline $\begin{array}{l}\text { Rank } \\
\text { order }\end{array}$ & Facilitator & Characteristic & $\begin{array}{c}\text { Item rated in } \\
\text { three greatest } \\
\text { facilitators } \\
\mathrm{n}(\%)\end{array}$ \\
\hline 11 & $\begin{array}{l}\text { Advanced education to better improve } \\
\text { understanding of the evidence-based practice } \\
\text { process }\end{array}$ & Adopter & $33(12 \%)$ \\
\hline 12 & $\begin{array}{l}\text { Opportunity for research collaboration with } \\
\text { colleagues }\end{array}$ & Research & $32(11 \%)$ \\
\hline 13 & $\begin{array}{l}\text { Employing ATs with research skills to serve as } \\
\text { role models }\end{array}$ & Organization & $31(11 \%)$ \\
\hline 14 & $\begin{array}{l}\text { Improving awareness of major information types } \\
\text { and sources }\end{array}$ & Communication & 30 (11\%) \\
\hline 15 & $\begin{array}{l}\text { Enhancing managerial/administrative support and } \\
\text { encouragement }\end{array}$ & Organization & $28(10 \%)$ \\
\hline 16 & $\begin{array}{l}\text { Advanced education to better convert your } \\
\text { information needs into a research question }\end{array}$ & Adopter & $12(4 \%)$ \\
\hline 17 & The response from 17 & & $5(2 \%)$ \\
\hline 18 & The response from 18 & & $4(1 \%)$ \\
\hline
\end{tabular}




\section{Appendix L. Open Responses of Facilitators}

Table 9

Open responses to other facilitators question and characteristic $(N=12)$

\begin{tabular}{lc}
\hline \multicolumn{1}{c}{ Response } & Characteristic \\
\hline Better research info at conferences & Adopter \\
Funding & Organization \\
Incentives & Organization \\
Time & Organization \\
Administrative support & Organization \\
A budget line to purchase research articles & Organization \\
$\begin{array}{l}\text { Facilities } \\
\text { There are some athletic trainers who are meant to be in research and some } \\
\text { meant to do the job, those two groups can work together to better patient } \\
\text { care }\end{array}$ & Organization \\
$\begin{array}{l}\text { Engagement in/with an academic environment } \\
\text { Free access to other professional journals }\end{array}$ & Research \\
EBM should not be just focused on reading research articles and writing \\
research articles, EBM would be less intimidating if it were presented in a \\
$\begin{array}{l}\text { different way. } \\
\text { Reimbursement for downloading articles }\end{array}$ & Communication \\
\hline
\end{tabular}




\section{Appendix M. Barriers to EBP Table}

Table 10

Barriers to $\operatorname{EBP}(N=313)$

\begin{tabular}{|c|c|c|c|c|}
\hline $\begin{array}{l}\text { Rank } \\
\text { order }\end{array}$ & Barrier & Characteristic & M & SD \\
\hline 1 & $\begin{array}{l}\text { The amount of research information is } \\
\text { overwhelming }\end{array}$ & Not Listed & 3.18 & 1.23 \\
\hline 2 & $\begin{array}{l}\text { The athletic trainer does not have time to read } \\
\text { research }\end{array}$ & Organization & 3.12 & 1.32 \\
\hline 3 & The facilities are inadequate for use & Organization & 3.12 & 1.20 \\
\hline 4 & Statistical analyses are not understandable & Communication & 3.10 & 1.22 \\
\hline 5 & Relevant literature is not compiled in one place & Communication & 3.08 & 1.16 \\
\hline 6 & $\begin{array}{l}\text { The athletic trainer feels results are not } \\
\text { generalizable to own setting }\end{array}$ & Organization & 2.96 & 1.17 \\
\hline 7 & The athletic trainer is unaware of the research & Adopter & 2.95 & 1.34 \\
\hline 8 & The literature reports conflicting results & Research & 2.92 & 1.09 \\
\hline 9 & $\begin{array}{l}\text { There is insufficient time on the job to use new } \\
\text { ideas }\end{array}$ & Organization & 2.89 & 1.34 \\
\hline 10 & The research has not been replicated & Research & 2.89 & 1.03 \\
\hline 11 & Implications for practice are not made clear & Communication & 2.85 & 1.12 \\
\hline 12 & The research has methodological inadequacies & Research & 2.76 & 0.92 \\
\hline 13 & $\begin{array}{l}\text { The athletic trainer does not feel capable of } \\
\text { evaluating the quality of the research }\end{array}$ & Adopter & 2.76 & 1.24 \\
\hline 14 & The research is not reported clearly and readably & Communication & 2.76 & 1.17 \\
\hline 15 & $\begin{array}{l}\text { The research is not relevant to the athletic trainer's } \\
\text { practice }\end{array}$ & Communication & 2.72 & 1.16 \\
\hline 16 & $\begin{array}{l}\text { The athletic trainer is uncertain whether to believe } \\
\text { the results of the research }\end{array}$ & Research & 2.70 & 1.17 \\
\hline 17 & $\begin{array}{l}\text { The athletic trainer feels the benefits of changing } \\
\text { practice will be minimal }\end{array}$ & Adopter & 2.66 & 1.18 \\
\hline 18 & $\begin{array}{l}\text { The athletic trainer is isolated from knowledgeable } \\
\text { colleagues with whom to discuss the research }\end{array}$ & Adopter & 2.61 & 1.41 \\
\hline 19 & Other staff are not supportive of implementation & Organization & 2.52 & 1.25 \\
\hline 20 & Research reports/articles are not readily available & Communication & 2.46 & 1.17 \\
\hline 21 & There is not a documented need to change practice & Adopter & 2.40 & 1.17 \\
\hline 22 & $\begin{array}{l}\text { The athletic trainer does not feel they have enough } \\
\text { authority to change patient care procedures }\end{array}$ & Organization & 2.39 & 1.30 \\
\hline
\end{tabular}


Table 10 (continued)

Barriers to EBP $(N=313)$

\begin{tabular}{|c|c|c|c|c|}
\hline $\begin{array}{l}\text { Rank } \\
\text { order }\end{array}$ & Barrier & Characteristic & M & SD \\
\hline 23 & Physicians will not cooperate with implementation & Organization & 2.33 & 1.12 \\
\hline 24 & $\begin{array}{l}\text { The conclusions drawn from the research are not } \\
\text { justified }\end{array}$ & Research & 2.32 & 0.99 \\
\hline 25 & Administration will not allow implementation & Organization & 2.32 & 1.19 \\
\hline 26 & $\begin{array}{l}\text { Research reports/articles are not published fast } \\
\text { enough }\end{array}$ & Research & 2.28 & 1.10 \\
\hline 27 & The athletic trainer sees little benefit for self & Adopter & 2.23 & 1.17 \\
\hline 28 & $\begin{array}{l}\text { The athletic trainer is unwilling to change/try new } \\
\text { ideas }\end{array}$ & Adopter & 2.21 & 1.29 \\
\hline 29 & $\begin{array}{l}\text { The athletic trainer does not see the value of } \\
\text { research for practice }\end{array}$ & Adopter & 1.93 & 1.14 \\
\hline
\end{tabular}




\section{Appendix N. Frequency of Rating Barriers to a Moderate to Great Extent Table}

Table 11

Frequency of Rating Barriers to a Moderate to Great Extent $(N=313)$

\begin{tabular}{|c|c|c|c|c|}
\hline $\begin{array}{l}\text { Rank } \\
\text { order }\end{array}$ & Barrier & Characteristic & $\begin{array}{c}\text { Items rated } \\
\text { as a great } \\
\text { or } \\
\text { moderate } \\
\text { barrier } \\
\text { n (\%) }\end{array}$ & $\begin{array}{l}\text { No } \\
\text { Opinion } \\
\mathrm{n}(\%)\end{array}$ \\
\hline 1 & $\begin{array}{l}\text { The amount of research information } \\
\text { is overwhelming }\end{array}$ & Not listed & $161(52 \%)$ & $33(11 \%)$ \\
\hline 2 & $\begin{array}{l}\text { Statistical analyses are not } \\
\text { understandable }\end{array}$ & Communication & $160(51 \%)$ & $21(7 \%)$ \\
\hline 3 & $\begin{array}{l}\text { The athletic trainer does not have } \\
\text { time to read research }\end{array}$ & Organization & $160(51 \%)$ & $15(5 \%)$ \\
\hline 4 & $\begin{array}{l}\text { The athletic trainers is unaware of the } \\
\text { research }\end{array}$ & Adopter & $146(47 \%)$ & $17(5 \%)$ \\
\hline 5 & $\begin{array}{l}\text { Relevant literature is not compiled in } \\
\text { one place }\end{array}$ & Communication & $141(45 \%)$ & $66(21 \%)$ \\
\hline 6 & The facilities are inadequate for use & Organization & $140(45 \%)$ & $66(21 \%)$ \\
\hline 7 & $\begin{array}{l}\text { The athletic trainer feels results are } \\
\text { not generalizable to own setting }\end{array}$ & Organization & 137 (44\%) & $35(11 \%)$ \\
\hline 8 & $\begin{array}{l}\text { There is insufficient time on the job } \\
\text { to use new ideas }\end{array}$ & Organization & $127(41 \%)$ & $31(10 \%)$ \\
\hline 9 & $\begin{array}{l}\text { Implications for practice are not } \\
\text { made clear }\end{array}$ & Communication & $125(40 \%)$ & $25(8 \%)$ \\
\hline 10 & $\begin{array}{l}\text { The athletic trainer does not feel } \\
\text { capable of evaluating the quality of } \\
\text { the research }\end{array}$ & Adopter & 119 (38\%) & $32(10 \%)$ \\
\hline 11 & $\begin{array}{l}\text { The athletic trainer is isolated from } \\
\text { knowledgeable colleagues with } \\
\text { whom to discuss the research }\end{array}$ & Adopter & $117(37 \%)$ & $20(6 \%)$ \\
\hline 12 & $\begin{array}{l}\text { The literature reports conflicting } \\
\text { results }\end{array}$ & Research & $113(36 \%)$ & $62(20 \%)$ \\
\hline 13 & $\begin{array}{l}\text { The research is not reported clearly } \\
\text { and readably }\end{array}$ & Communication & $110(35 \%)$ & $39(13 \%)$ \\
\hline 14 & $\begin{array}{l}\text { The research is not relevant to the } \\
\text { athletic trainer's practice }\end{array}$ & Communication & $104(33 \%)$ & 48 (15\%) \\
\hline
\end{tabular}


Table 11 (continued)

Frequency of Moderate to Great Extent Rating of Barriers $(N=313)$

\begin{tabular}{|c|c|c|c|c|}
\hline $\begin{array}{l}\text { Rank } \\
\text { order }\end{array}$ & Barrier & Characteristic & $\begin{array}{c}\text { Items rated } \\
\text { as a great } \\
\text { or } \\
\text { moderate } \\
\text { barrier } \\
\text { n (\%) } \\
\end{array}$ & $\begin{array}{l}\text { No } \\
\text { Opinion } \\
\mathrm{n}(\%)\end{array}$ \\
\hline 15 & $\begin{array}{l}\text { The athletic trainer is uncertain } \\
\text { whether to believe the results of the } \\
\text { research }\end{array}$ & Research & $98(31 \%)$ & $51(16 \%)$ \\
\hline 16 & $\begin{array}{l}\text { Research Reports/articles are not } \\
\text { readily available }\end{array}$ & Communication & $96(31 \%)$ & $16(5 \%)$ \\
\hline 17 & $\begin{array}{l}\text { The athletic trainer feels the benefits } \\
\text { of changing practice will be minimal }\end{array}$ & Adopter & $96(31 \%)$ & $47(15 \%)$ \\
\hline 18 & The research has not been replicated & Research & 95 (30\%) & $93(30 \%)$ \\
\hline 19 & $\begin{array}{l}\text { Other staff are not supportive of } \\
\text { implementation }\end{array}$ & Organization & $83(27 \%)$ & $62(20 \%)$ \\
\hline 20 & $\begin{array}{l}\text { The athletic trainer does not feel they } \\
\text { have enough authority to change } \\
\text { patient care procedures }\end{array}$ & Organization & $79(25 \%)$ & $34(11 \%)$ \\
\hline 21 & $\begin{array}{l}\text { There is not a documented need to } \\
\text { change practice }\end{array}$ & Adopter & $75(24 \%)$ & $44(14 \%)$ \\
\hline 22 & $\begin{array}{l}\text { The athletic trainer is unwilling to } \\
\text { change/try new ideas }\end{array}$ & Adopter & $72(23 \%)$ & $28(9 \%)$ \\
\hline 23 & $\begin{array}{l}\text { The research has methodological } \\
\text { inadequacies }\end{array}$ & Research & $66(21 \%)$ & $\begin{array}{c}122 \\
(39 \%)\end{array}$ \\
\hline 24 & $\begin{array}{l}\text { The athletic trainer sees little benefit } \\
\text { for self }\end{array}$ & Adopter & $62(20 \%)$ & $46(15 \%)$ \\
\hline 25 & $\begin{array}{l}\text { Administration will not allow } \\
\text { implementation }\end{array}$ & Organization & $61(20 \%)$ & $66(21 \%)$ \\
\hline 26 & $\begin{array}{l}\text { Physicians will not cooperate with } \\
\text { implantation }\end{array}$ & Organization & 57 (18\%) & 67 (21\%) \\
\hline 27 & $\begin{array}{l}\text { Research reports/articles are not } \\
\text { published fast enough }\end{array}$ & Research & 44 (14\%) & 85 (27\%) \\
\hline 28 & $\begin{array}{l}\text { The athletic trainer does not see value } \\
\text { of research for practice }\end{array}$ & Adopter & $44(14 \%)$ & 33 (11\%) \\
\hline 29 & $\begin{array}{l}\text { The conclusions drawn from the } \\
\text { research are not justified }\end{array}$ & Research & 36 (12\%) & 85 (27\%) \\
\hline
\end{tabular}




\section{Appendix O. Frequency of Rating the Three Greatest Barriers}

Table 12

Frequency of rating the three greatest barriers $(N=283)$

\begin{tabular}{|c|c|c|c|}
\hline $\begin{array}{l}\text { Rank } \\
\text { order }\end{array}$ & Barrier & Characteristic & $\begin{array}{c}\text { Item rated in } \\
\text { three } \\
\text { greatest } \\
\text { barriers } \\
\mathrm{n}(\%) \\
\end{array}$ \\
\hline 1 & $\begin{array}{l}\text { Athletic Trainer does not have time to read } \\
\text { research }\end{array}$ & Organization & $82(29 \%)$ \\
\hline 2 & Athletic Trainer is unaware of the research & Adopter & $68(24 \%)$ \\
\hline 3 & Facilities are inadequate for implementation & Organization & $52(18 \%)$ \\
\hline 4 & $\begin{array}{l}\text { The amount of research information is } \\
\text { overwhelming }\end{array}$ & Not Listed & $48(17 \%)$ \\
\hline 5 & Statistical analyses are not understandable & Communication & $43(15 \%)$ \\
\hline 6 & $\begin{array}{l}\text { There is insufficient time on the job to } \\
\text { implement new ideas }\end{array}$ & Organization & $43(15 \%)$ \\
\hline 7 & The literature reports conflicting results & Research & $39(14 \%)$ \\
\hline 8 & Implications for practice not made clear & Communication & $38(13 \%)$ \\
\hline 9 & $\begin{array}{l}\text { Relevant literature is not compiled in one } \\
\text { place }\end{array}$ & Communication & $36(13 \%)$ \\
\hline 10 & $\begin{array}{l}\text { Athletic Trainer feels results are not } \\
\text { generalizable to own setting }\end{array}$ & Organization & $36(13 \%)$ \\
\hline 11 & Research not readily available & Communication & $32(11 \%)$ \\
\hline 12 & $\begin{array}{l}\text { Athletic Trainer does not feel she/he has } \\
\text { enough authority to change patient care } \\
\text { procedures }\end{array}$ & Organization & $30(11 \%)$ \\
\hline 13 & $\begin{array}{l}\text { Athletic Trainer is isolated from } \\
\text { knowledgeable colleagues with who to } \\
\text { discuss research }\end{array}$ & Adopter & $28(10 \%)$ \\
\hline 14 & $\begin{array}{l}\text { Research not relevant to Athletic Trainer's } \\
\text { practice }\end{array}$ & Communication & $24(8 \%)$ \\
\hline 15 & $\begin{array}{l}\text { Athletic Trainer does not feel capable of } \\
\text { evaluating the quality of the research }\end{array}$ & Adopter & $24(8 \%)$ \\
\hline 16 & $\begin{array}{l}\text { Athletic Trainer is unwilling to change/try } \\
\text { new ideas }\end{array}$ & Adopter & $23(8 \%)$ \\
\hline 17 & Research has not been replicated & Research & $20(7 \%)$ \\
\hline
\end{tabular}


Table 12 (continued)

Frequency of rating the three greatest barriers $(N=283)$

\begin{tabular}{|c|c|c|c|}
\hline $\begin{array}{l}\text { Rank } \\
\text { order }\end{array}$ & Barrier & Characteristic & $\begin{array}{c}\text { Item rated in } \\
\text { three } \\
\text { greatest } \\
\text { barriers } \\
\mathrm{n}(\%) \\
\end{array}$ \\
\hline 18 & $\begin{array}{l}\text { Athletic Trainer is uncertain whether to } \\
\text { believe the results of the research }\end{array}$ & Research & $20(7 \%)$ \\
\hline 19 & Administration will not allow implementation & Organization & $20(7 \%)$ \\
\hline 20 & $\begin{array}{l}\text { The Athletic Trainer does not see the value of } \\
\text { research for practice }\end{array}$ & Adopter & $19(7 \%)$ \\
\hline 21 & $\begin{array}{l}\text { Other staff are not supportive of } \\
\text { implementation }\end{array}$ & Organization & $17(6 \%)$ \\
\hline 22 & $\begin{array}{l}\text { Athletic Trainer feels the benefits of changing } \\
\text { practice will be minimal }\end{array}$ & Adopter & $16(6 \%)$ \\
\hline 23 & $\begin{array}{l}\text { There is not a documented need to change } \\
\text { practice }\end{array}$ & Adopter & $14(5 \%)$ \\
\hline 24 & Athletic Trainer sees little benefit for self & Adopter & $13(5 \%)$ \\
\hline 25 & Research is not reported clearly and readably & Communication & $13(5 \%)$ \\
\hline 26 & $\begin{array}{l}\text { Physicians will not cooperate with } \\
\text { implementation }\end{array}$ & Organization & $12(4 \%)$ \\
\hline 27 & What the respondent answered for 30 & & $12(4 \%)$ \\
\hline 28 & The research has methodological inadequacies & Research & $7(2 \%)$ \\
\hline 29 & $\begin{array}{l}\text { Research reports/articles are not published } \\
\text { fast enough }\end{array}$ & Research & $7(2 \%)$ \\
\hline 30 & $\begin{array}{l}\text { Conclusions drawn from the research are not } \\
\text { justified }\end{array}$ & Research & 7 (2\%) \\
\hline 31 & What the respondent answered for 31 & & $6(2 \%)$ \\
\hline
\end{tabular}




\section{Appendix P. Open Responses of Barriers}

Table 13

Open responses to other barriers question and subcategories $(N=45)$

Responses

Further subcategory

Characteristics of the Adopter

The Athletic Trainer feels that learning from other athletic trainers is a much better approach than reading research articles to better patient care, such as

Skills learning from colleagues, attending conferences and lectures.

Current practitioners who did not study EBP in graduate school do not feel adequately prepared to read and implement the research

Skills

Limited opportunities to use research in setting to personally evaluate their benefit

Importance to me

No incentive

Not expected to use research in practice

Skills

Values

Values

Values

Access

Access to research data bases cost money that many clinics do not have.

Access

Access to free databases to seek out research is not available

Access

Cost of buying articles

Access

Lack of free research articles

Access

Lack of access to other professional journals

Access

Availability of resources

Access

Availability

Access

Secondary School Audience

Patients

Patients

Patients 
Table 13 (continued)

Open responses to other barriers question and subcategories $(N=45)$

\begin{tabular}{|c|c|}
\hline Responses & $\begin{array}{l}\text { Further } \\
\text { subcategory }\end{array}$ \\
\hline \multicolumn{2}{|l|}{ Characteristics of the Organization } \\
\hline Expense of implementation & Resources \\
\hline Lack of Equipment available for rehab & Resources \\
\hline Cost of equipment or additional training. & Resources \\
\hline Cost of implementation & Resources \\
\hline $\begin{array}{l}\text { Inadequate resources to perform the studies needed to } \\
\text { identify best practices. }\end{array}$ & Resources \\
\hline Cost is an issue if research suggests use of expensive equipment or training. & Resources \\
\hline I may not have equipment to follow new protocols & Resources \\
\hline Computer access & Resources \\
\hline Facilities available & Resources \\
\hline Money, departmental goals & Resources \\
\hline Time constraints treating athletes & Time \\
\hline Time available & Time \\
\hline Time management & Time \\
\hline Time, & Time \\
\hline Time management & Time \\
\hline $\begin{array}{l}\text { Often too much research to take the time to search through to } \\
\text { find one answer }\end{array}$ & Time \\
\hline Time to conduct and report the research & Time \\
\hline Head Athletic Trainer does not use new techniques. & Colleagues \\
\hline Coaches & Colleagues \\
\hline Coaches & Colleagues \\
\hline Stubborn AT & Colleagues \\
\hline
\end{tabular}


Table 13 (continued)

Open responses to other barriers question and subcategories $(N=45)$

\begin{tabular}{lc}
\multicolumn{1}{c}{ Responses } & $\begin{array}{c}\text { Further } \\
\text { subcategory }\end{array}$ \\
\hline Characteristics of the Research & Quality \\
& Quality \\
The poor quality of the research & Quality \\
$\begin{array}{l}\text { Research articles need to get to the point quicker, "what's the issue?" } \\
\text { and "How do we make it better?" }\end{array}$ & Quality \\
$\begin{array}{l}\text { The poor quality of the research } \\
\text { Lack of clear protocols. } \\
\text { Lack of clear guidelines for the definition of "what is an outcome". } \\
\text { Research is not always practical. It is good to know, but does not have } \\
\text { an application. }\end{array}$ & $\begin{array}{c}\text { Understanding } \\
\text { Understanding }\end{array}$ \\
\end{tabular}




\section{Appendix Q. MANOVA Mean Scores and Standard Deviation}

Table 14

Mean Scores and Standard Deviations for Measures of Barrier Characteristics Related to Career Setting

\begin{tabular}{|c|c|c|c|c|}
\hline $\begin{array}{c}\text { Barrier } \\
\text { Characteristic }\end{array}$ & Career setting & Mean & $\begin{array}{c}\text { Std. } \\
\text { Deviation }\end{array}$ & $\mathrm{n}$ \\
\hline \multirow[t]{8}{*}{ Communication } & $\begin{array}{l}\text { College/University - } \\
\text { Academic only }\end{array}$ & 2.77 & 0.57 & 25 \\
\hline & $\begin{array}{l}\text { College/University - } \\
\text { Athletic only }\end{array}$ & 2.92 & 0.61 & 77 \\
\hline & $\begin{array}{l}\text { College/University - } \\
\text { Mixed academic and } \\
\text { athletic }\end{array}$ & 2.86 & 0.74 & 46 \\
\hline & Clinic & 2.27 & 0.65 & 19 \\
\hline & $\begin{array}{l}\text { Clinic Outreach } \\
\text { (Secondary School) }\end{array}$ & 2.81 & 0.74 & 49 \\
\hline & Secondary School & 2.76 & 0.65 & 67 \\
\hline & Physician Extender & 2.21 & 0.42 & 4 \\
\hline & Other & 3.21 & 0.52 & 7 \\
\hline \multirow[t]{8}{*}{ Adopter } & $\begin{array}{l}\text { College/University - } \\
\text { Academic only }\end{array}$ & 2.73 & 0.85 & 25 \\
\hline & $\begin{array}{l}\text { College/University - } \\
\text { Athletic only }\end{array}$ & 2.44 & 0.72 & 77 \\
\hline & $\begin{array}{l}\text { College/University - } \\
\text { Mixed academic and } \\
\text { athletic }\end{array}$ & 2.43 & 0.95 & 46 \\
\hline & Clinic & 1.97 & 0.71 & 19 \\
\hline & $\begin{array}{l}\text { Clinic Outreach } \\
\text { (Secondary School) }\end{array}$ & 2.46 & 0.90 & 49 \\
\hline & Secondary School & 2.46 & 0.82 & 67 \\
\hline & Physician Extender & 2.28 & 0.89 & 4 \\
\hline & Other & 2.70 & 0.68 & 7 \\
\hline
\end{tabular}


Table 14 (continued)

Mean Scores and Standard Deviations for Measures of Barrier Characteristics Related to Career Setting

\begin{tabular}{|c|c|c|c|c|}
\hline $\begin{array}{c}\text { Barrier } \\
\text { Characteristic }\end{array}$ & Career setting & Mean & $\begin{array}{c}\text { Std. } \\
\text { Deviation }\end{array}$ & $\mathrm{n}$ \\
\hline \multirow[t]{8}{*}{ Organization } & $\begin{array}{l}\text { College/University - } \\
\text { Academic only }\end{array}$ & 2.57 & 0.64 & 25 \\
\hline & $\begin{array}{l}\text { College/University - } \\
\text { Athletic only }\end{array}$ & 2.60 & 0.68 & 77 \\
\hline & $\begin{array}{l}\text { College/University - } \\
\text { Mixed academic and } \\
\text { athletic }\end{array}$ & 2.73 & 0.78 & 46 \\
\hline & Clinic & 2.30 & 0.73 & 19 \\
\hline & $\begin{array}{l}\text { Clinic Outreach } \\
\text { (Secondary School) }\end{array}$ & 2.73 & 0.88 & 49 \\
\hline & Secondary School & 2.81 & 0.64 & 67 \\
\hline & Physician Extender & 2.97 & 1.19 & 4 \\
\hline & Other & 3.05 & 1.12 & 7 \\
\hline \multirow[t]{8}{*}{ Research } & $\begin{array}{l}\text { College/University - } \\
\text { Academic only }\end{array}$ & 2.65 & 0.65 & 25 \\
\hline & $\begin{array}{l}\text { College/University - } \\
\text { Athletic only }\end{array}$ & 2.72 & 0.63 & 77 \\
\hline & $\begin{array}{l}\text { College/University - } \\
\text { Mixed academic and } \\
\text { athletic }\end{array}$ & 2.70 & 0.72 & 46 \\
\hline & Clinic & 2.34 & 0.68 & 19 \\
\hline & $\begin{array}{l}\text { Clinic Outreach } \\
\text { (Secondary School) }\end{array}$ & 2.68 & 0.67 & 49 \\
\hline & Secondary School & 2.52 & 0.67 & 67 \\
\hline & Physician Extender & 2.33 & 0.49 & 4 \\
\hline & Other & 2.88 & 0.98 & 7 \\
\hline
\end{tabular}




\section{Appendix R. MANOVA Significant differences}

Table 15

Significant differences of barriers associated to the characteristics of the communication by career setting

\begin{tabular}{lccccccc}
\hline & 1 & 2 & 3 & 4 & 5 & 6 & 7 \\
\hline $\begin{array}{l}\text { 1. College/University - } \\
\text { Academic }\end{array}$ & & & & & & & \\
2. College/University - Athletic & 1.000 & & & & & & \\
3. College/University - Mixed & 1.000 & 1.000 & & & & & \\
4. Clinic & 0.299 & $0.002^{*}$ & $0.024^{*}$ & & & & \\
5. Clinic Outreach & 1.000 & 1.000 & 1.000 & 0.062 & & & \\
(Secondary Schools) & & & & & & & \\
6. Secondary School & 1.000 & 0.983 & 1.000 & 0.082 & 1.000 & & \\
7. Physician Extender & 0.909 & 0.301 & 0.578 & 1.000 & 0.731 & 0.801 & \\
8. Other & 0.947 & 0.998 & 0.988 & $0.027 *$ & 0.931 & 0.773 & 0.332 \\
\hline
\end{tabular}

$* p<.05$

Table 16

Significant differences of barriers associated to the characteristics of the adopter by career setting

\begin{tabular}{lccccccc}
\hline & 1 & 2 & 3 & 4 & 5 & 6 & 7 \\
\hline $\begin{array}{l}\text { 1. College/University - } \\
\text { Academic }\end{array}$ & & & & & & & \\
2. College/University - & 0.970 & & & & & & \\
Athletic & & & & & & & \\
3. College/University - Mixed & 0.986 & 1.000 & & & & & \\
4. Clinic & 0.081 & 0.441 & 0.669 & & & & \\
5. Clinic Outreach & 0.996 & 1.000 & 1.000 & 0.522 & & & \\
(Secondary Schools) & & & & & & & \\
6. Secondary School & 0.992 & 1.000 & 1.000 & 0.394 & 1.000 & & \\
7. Physician Extender & 1.000 & 1.000 & 1.000 & 1.000 & 1.000 & 1.000 & \\
8. Other & 1.000 & 1.000 & 1.000 & 0.698 & 1.000 & 1.000 & 1.000 \\
\hline
\end{tabular}

$$
* p<.05
$$


Table 17

Significant differences of barriers associated to the characteristics of the organization by career setting

\begin{tabular}{lllllll}
1 & 2 & 3 & 4 & 5 & 6 & 7 \\
\hline
\end{tabular}

1. College/University -

Academic

2. College/University - Athletic 1.000

3. College/University - Mixed $1.000 \quad 1.000$

4. Clinic $\quad 1.000 \quad 0.949 \quad 0.572$

$\begin{array}{lllll}\text { 5. Clinic Outreach } & 1.000 & 1.000 & 1.000 & 0.567\end{array}$

(Secondary Schools)

6. Secondary School $\quad \begin{array}{lllll}0.988 & 0.920 & 1.000 & 0.166 & 1.000\end{array}$

$\begin{array}{lllllll}\text { 7. Physician Extender } & 1.000 & 1.000 & 1.000 & 0.907 & 1.000 & 1.000\end{array}$

\begin{tabular}{llllllll} 
8. Other & 0.957 & 0.893 & 1.000 & 0.417 & 1.000 & 1.000 & 1.000 \\
\hline
\end{tabular}

$* p<.05$

Table 18

Significant differences of barriers associated to the characteristics of the research by career setting

\begin{tabular}{lccccccc}
\hline & 1 & 2 & 3 & 4 & 5 & 6 & 7 \\
\hline $\begin{array}{l}\text { 1. College/University - } \\
\text { Academic }\end{array}$ & & & & & & & \\
2. College/University - & 1.000 & & & & & & \\
Athletic & 1.000 & 1.000 & & & & & \\
3. College/University - Mixed & 0.983 & 0.452 & 0.757 & & & & \\
4. Clinic & & & & & & & \\
5. Clinic Outreach & 1.000 & 1.000 & 1.000 & 0.819 & & & \\
(Secondary Schools) & & & & & & & \\
6. Secondary School & 1.000 & 0.871 & 0.993 & 1.000 & 0.998 & & \\
7. Physician Extender & 1.000 & 0.996 & 0.999 & 1.000 & 1.000 & 1.000 & \\
8. Other & 1.000 & 1.000 & 1.000 & 0.836 & 1.000 & 0.977 & 0.997 \\
\hline
\end{tabular}

$* p<.05$ 


\section{Appendix S. ANOVA Summary Table}

Table 19

One-Way Repeated Analysis of Variance Summary Table for the Effects of Athletic Trainers' Career Setting on Rating of Barriers to EBP Utilization

\begin{tabular}{lcccccr}
\hline \multicolumn{1}{c}{ Source } & $d f$ & SS & MS & F & $p$ & $\eta^{2}$ \\
\hline Between-group & 2.90 & 19.54 & 6.74 & 24.50 & .000 & .08 \\
Within-group & 851.92 & 234.55 & 0.28 & & & \\
Total & 854.82 & 254.10 & & & & \\
\hline
\end{tabular}




\section{Appendix T. Comparison of Athletic Trainers and Nurses Top Ten Barriers}

Table 20

Comparison of Athletic Trainers and Nurses rating of top ten barriers to EBP

\begin{tabular}{|c|c|c|c|}
\hline Barrier Item & Subscale & $\begin{array}{c}\text { Athletic } \\
\text { Trainers } \\
\text { rating }\end{array}$ & $\begin{array}{c}\text { Number of } \\
\text { studies rating } \\
\text { item among top } \\
\text { ten by Nurses } \\
(N=53) \\
\end{array}$ \\
\hline $\begin{array}{l}\text { *The amount of research information is } \\
\text { overwhelming }\end{array}$ & Not listed & 1 & $13 *$ \\
\hline $\begin{array}{l}\text { The athletic trainer/nurse does not have } \\
\text { time to read research }\end{array}$ & Organization & 2 & 48 \\
\hline The facilities are inadequate for use & Organization & 3 & 36 \\
\hline Statistical analyses are not understandable & Communication & 4 & 40 \\
\hline $\begin{array}{l}\text { Relevant literature is not compiled in one } \\
\text { place }\end{array}$ & Communication & 5 & 37 \\
\hline $\begin{array}{l}\text { The athletic trainer/nurse feels results are } \\
\text { not generalizable to own setting }\end{array}$ & Organization & 6 & 24 \\
\hline $\begin{array}{l}\text { The athletic trainer/nurse is unaware of the } \\
\text { research }\end{array}$ & Adopter & 7 & 27 \\
\hline The literature reports conflicting results & Research & 8 & 5 \\
\hline $\begin{array}{l}\text { There is insufficient time on the job to use } \\
\text { new ideas }\end{array}$ & Organization & 9 & 49 \\
\hline The research has not been replicated & Research & 10 & 6 \\
\hline
\end{tabular}

*Item only included in 27 studies $(N=27)$ 


\section{Appendix U. Dissertation Concept Map}

Figure 3

\section{Dissertation concept map}

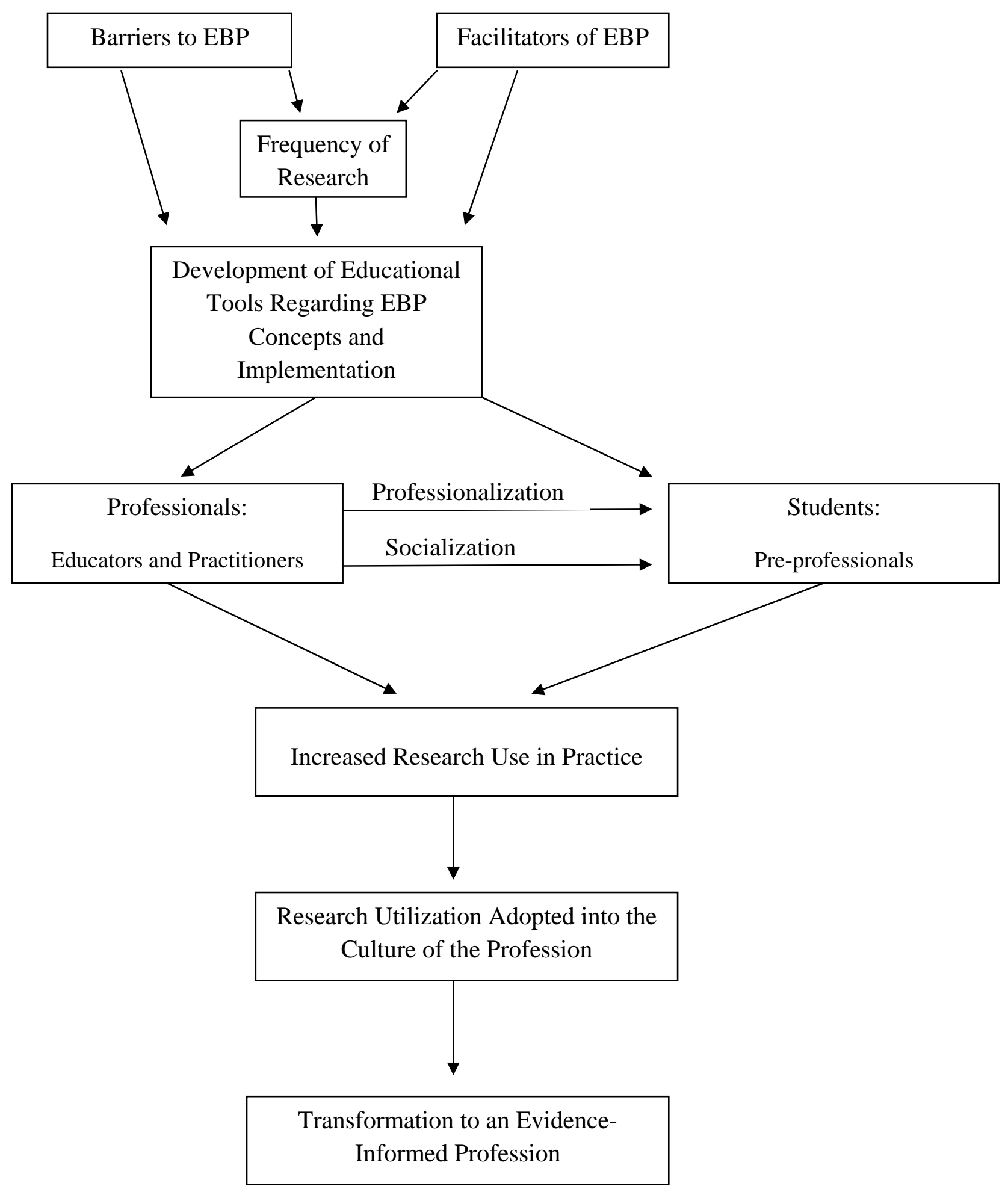




\section{Appendix V. Significant Findings for Frequency of Research Graphic}

Figure 4

Significant Findings for Frequency of Research

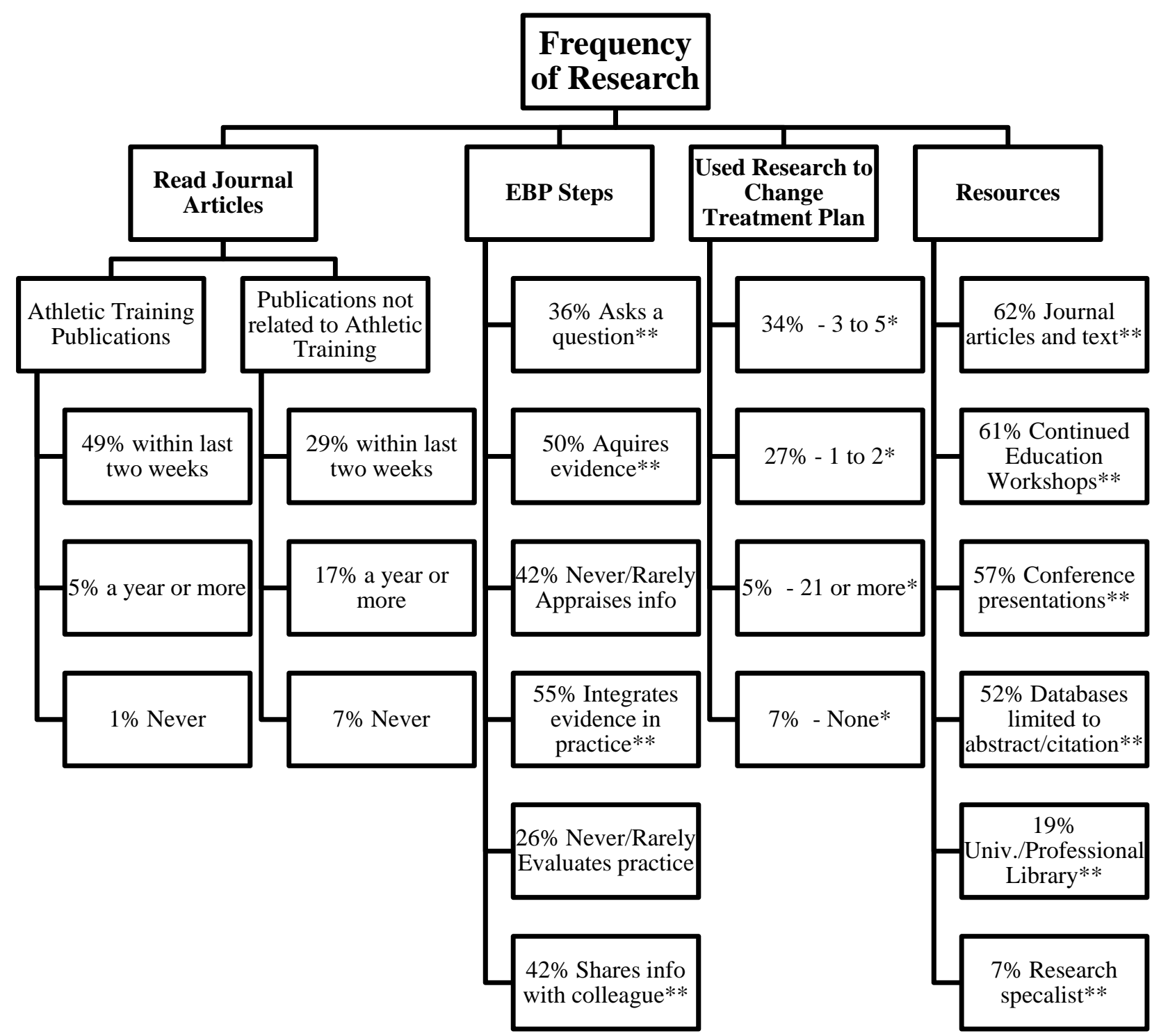

* Number of times research was used to alter a treatment plan in the past year

**Percent of 'Often' and 'Always' responses

Frequency of research as reported by Certified-Regular Members of the NATA 


\section{Appendix W. Significant Findings for Facilitators to EBP}

Figure 5

Significant Findings for Facilitators to EBP Utilization

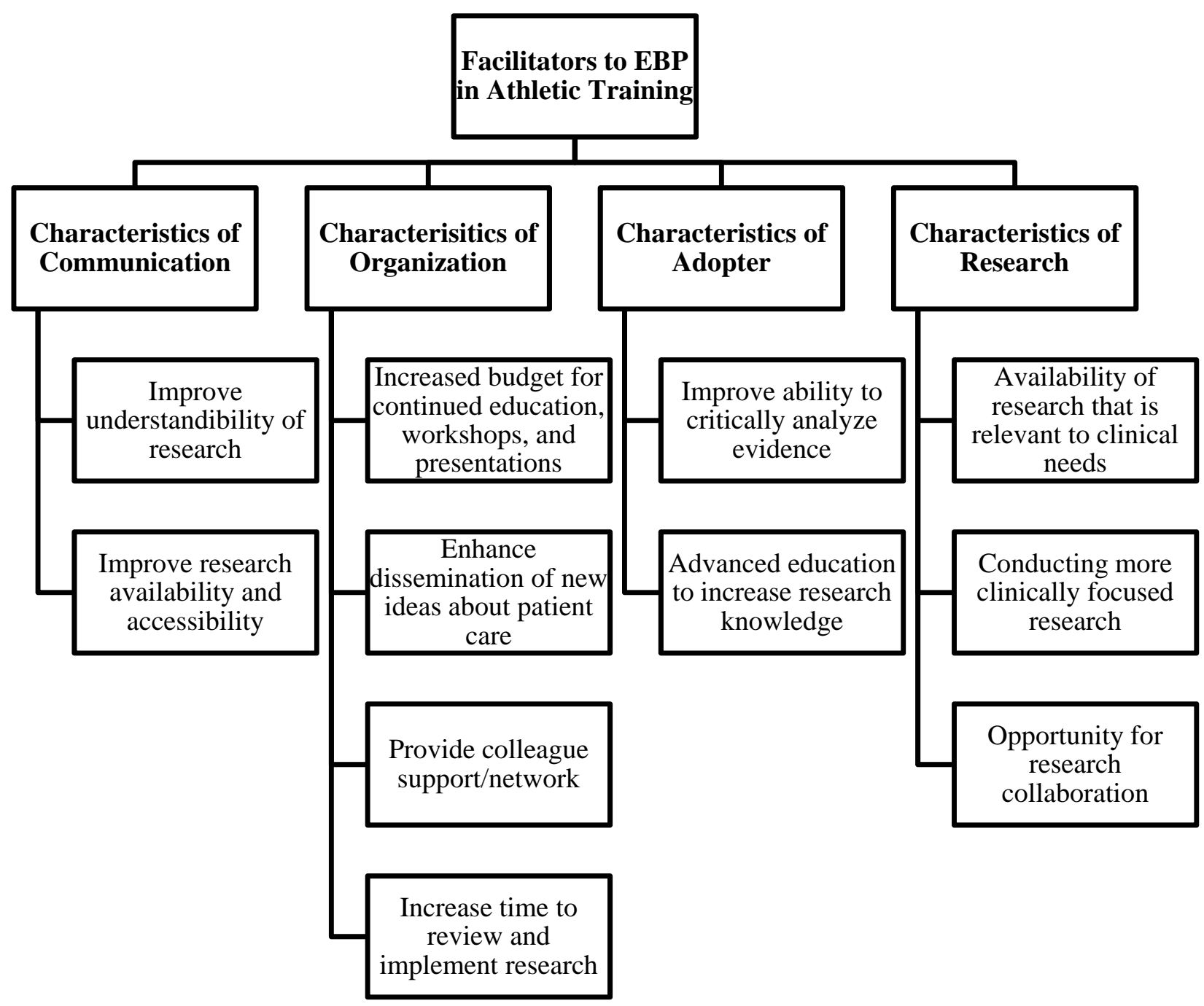

Items represented were consistently identified among top ten for ranking, rating, and frequency of being listed as the three greatest facilitators by Certified-Regular Members of the NATA.

$\mathrm{EBP}=$ Evidence-based practice

Characteristics associated with the BARRIERS Scale (Funk et al, 1991a) 


\section{Appendix X. Significant Findings for Barriers to EBP}

Figure 6

\section{Significant Findings for Barriers to EBP Utilization}

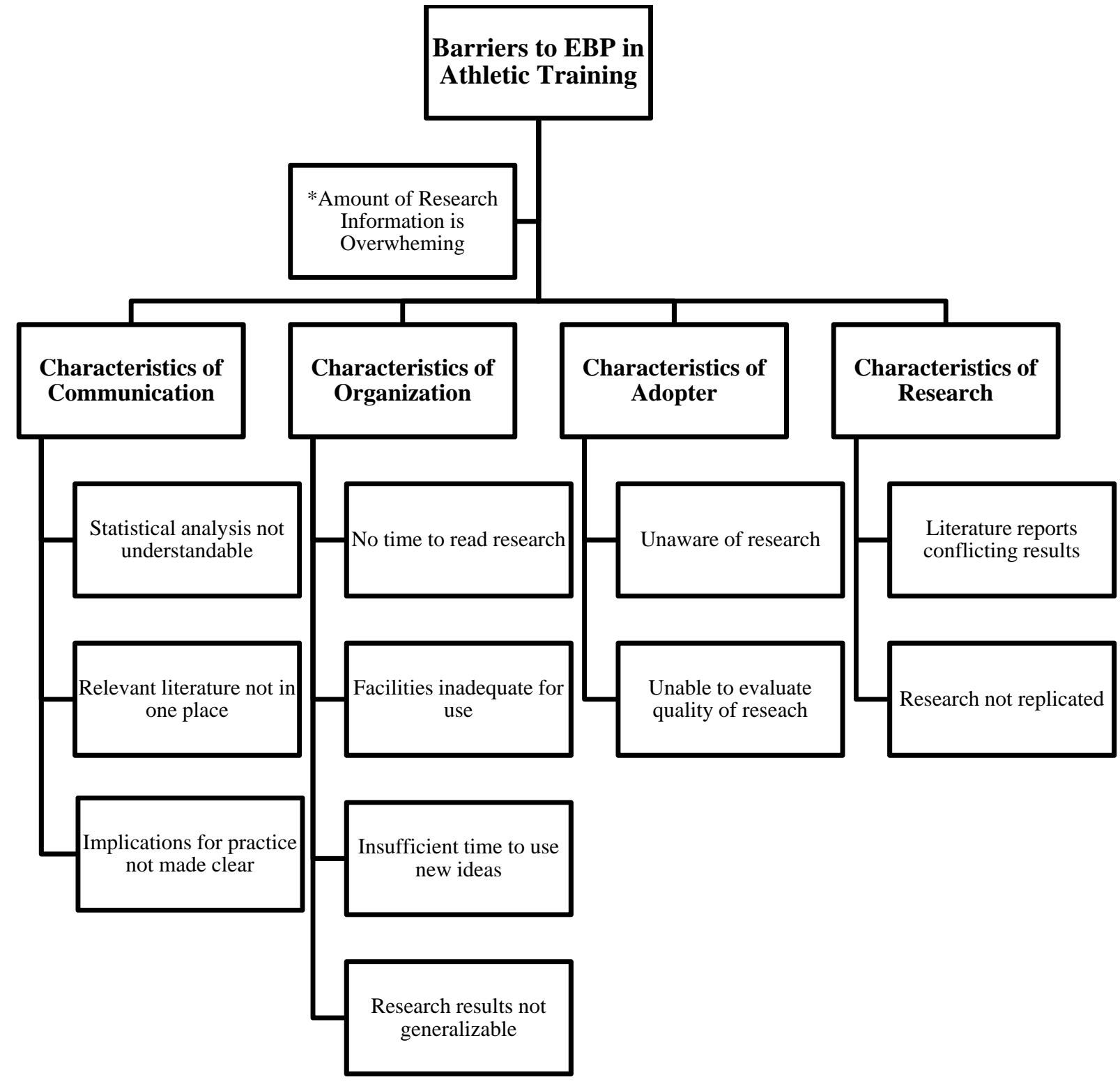

*'The amount of research information is overwhelming' was found to be amongst the greatest barriers but is not identified in a characteristic subcategory.

Items represented were consistently identified among top ten for ranking, rating, and frequency of being listed as the three greatest barriers by Certified-Regular Members of the NATA.

Characteristics associated with the BARRIERS Scale (Funk et al, 1991a) 